\title{
Estimating actual, potential, reference crop and pan evaporation using standard meteorological data: a pragmatic synthesis
}

\author{
T. A. McMahon ${ }^{1}$, M. C. Peel ${ }^{1}$, L. Lowe' ${ }^{2}$, R. Srikanthan ${ }^{3}$, and T. R. McVicar ${ }^{4}$ \\ ${ }^{1}$ Department of Infrastructure Engineering, The University of Melbourne, Parkville, Victoria, 3010, Australia \\ ${ }^{2}$ Sinclair Knight Merz, P.O. Box 312, Flinders Lane, Melbourne, 8009, Australia \\ ${ }^{3}$ Water Division, Bureau of Meteorology, GPO 1289, Melbourne, 3001, Australia \\ ${ }^{4}$ Land and Water Division, Commonwealth Scientific and Industrial Research Organisation, Clunies Ross Drive, \\ Acton, ACT 2602, Australia \\ Correspondence to: T. A. McMahon (thomasam@unimelb.edu.au)
}

Received: 19 September 2012 - Published in Hydrol. Earth Syst. Sci. Discuss.: 18 October 2012

Revised: 26 February 2013 - Accepted: 14 March 2013 - Published: 10 April 2013

\begin{abstract}
This guide to estimating daily and monthly actual, potential, reference crop and pan evaporation covers topics that are of interest to researchers, consulting hydrologists and practicing engineers. Topics include estimating actual evaporation from deep lakes and from farm dams and for catchment water balance studies, estimating potential evaporation as input to rainfall-runoff models, and reference crop evapotranspiration for small irrigation areas, and for irrigation within large irrigation districts. Inspiration for this guide arose in response to the authors' experiences in reviewing research papers and consulting reports where estimation of the actual evaporation component in catchment and water balance studies was often inadequately handled. Practical guides using consistent terminology that cover both theory and practice are not readily available. Here we provide such a guide, which is divided into three parts. The first part provides background theory and an outline of the conceptual models of potential evaporation of Penman, PenmanMonteith and Priestley-Taylor, as well as discussions of reference crop evapotranspiration and Class-A pan evaporation. The last two sub-sections in this first part include techniques to estimate actual evaporation from (i) open-surface water and (ii) landscapes and catchments (Morton and the advection-aridity models). The second part addresses topics confronting a practicing hydrologist, e.g. estimating actual evaporation for deep lakes, shallow lakes and farm dams, lakes covered with vegetation, catchments, irrigation areas and bare soil. The third part addresses six related issues: (i) automatic (hard wired) calculation of evaporation esti-
\end{abstract}

mates in commercial weather stations, (ii) evaporation estimates without wind data, (iii) at-site meteorological data, (iv) dealing with evaporation in a climate change environment, (v) $24 \mathrm{~h}$ versus day-light hour estimation of meteorological variables, and (vi) uncertainty in evaporation estimates.

This paper is supported by a Supplement that includes 21 sections enhancing the material in the text, worked examples of many procedures discussed in the paper, a program listing (Fortran 90) of Morton's WREVAP evaporation models along with tables of monthly Class-A pan coefficients for 68 locations across Australia and other information.

\section{Introduction}

Actual evaporation is a major component in the water balance of a catchment, reservoir or lake, irrigation region, and some groundwater systems. For example, across all continents evapotranspiration is $70 \%$ of precipitation, and varies from over $90 \%$ in Australia to approximately $60 \%$ in Europe (Baumgarter and Reichel, 1975, Table 12). For major reservoirs in Australia, actual evaporation losses represent $20 \%$ of reservoir yield (Hoy and Stephens, 1979, p. 1). Compared with precipitation and streamflow, the magnitude of actual evaporation over the long term is more difficult to estimate than either precipitation or streamflow.

This paper deals with estimating actual, potential, reference crop and pan evaporation at a daily and a monthly time step using standard meteorological data. A major discussion 
of the use of remotely sensed data to estimate actual evaporation is outside the scope of this paper but readers interested in the topic are referred to Kalma et al. (2008) and Glenn et al. (2010) for relevant material.

\subsection{Background}

The inspiration for the paper, which is a considered summary of techniques rather than a review, arose because over recent years the authors have reviewed many research papers and consulting reports in which the estimation of the actual evaporation component in catchment and water balance studies was inadequately handled. Our examination of the literature yielded few documents covering both theory and practice that are readily available to a researcher, consulting hydrologist or practicing engineer. Chapter 7 Evapotranspiration in Physical Hydrology by Dingman (1992), Chapter 4 Evaporation (Shuttleworth, 1992) in the Handbook of Hydrology (Maidment, 1992) and, for irrigated areas, FAO 56 Crop evapotranspiration: Guidelines for computing crop water requirements (Allen et al., 1998) are helpful references. We refer heavily to these texts in this paper which is aimed at improving the practice of estimating actual and potential evaporation, reference crop evapotranspiration and pan evaporation using standard daily or monthly meteorological data. This paper is not intended to be an introduction to evaporation processes. Dingman (1992) provides such an introduction. Readers, who wish to develop a strong theoretical background of evaporation processes, are referred to Evaporation into the Atmosphere by Brutsaert (1982), and to Shuttleworth (2007) for a historical perspective.

There are many practical situations where daily or monthly actual or potential evaporation estimates are required. For example, for deep lakes or post-mining voids, shallow lakes or farm dams, catchment water balance studies (in which actual evaporation may be land-cover specific or lumped depending on the style of analysis or modelling), rainfall-runoff modelling, or small irrigation areas or for irrigated crops within a large irrigation district. Each of these situations illustrates most of the practical issues that arise in estimating daily or monthly evaporation from meteorological data or from Class-A evaporation pan measurements. These cases are used throughout the paper as a basis to highlight common issues facing practitioners.

Following this introduction, Sect. 2 describes the background theory and models under five headings: (i) potential evaporation, (ii) reference crop evapotranspiration, (iii) pan evaporation, (iv) open-surface water evaporation and (v) actual evaporation from landscapes and catchments. Practical issues in estimating actual evaporation from deep lakes, reservoirs and voids, from shallow lakes and farm dams, for catchment water balance studies, in rainfall-runoff modelling, from irrigation areas, from lakes covered by vegetation, bare soil, and groundwater are considered in Sect. 3 . This section concludes with a guideline summary of pre- ferred methods to estimate evaporation. Section 4 deals with several outstanding issues of interest to practitioners and, in the final section (Sect. 5), a concluding summary is provided. Readers should note that there are 21 sections in the Supplement where more model details and worked examples are provided (sections, tables and figures in the Supplement are indicated by an $\mathrm{S}$ before the caption number).

\subsection{Definitions, time step, units and input data}

The definitions, time steps, units and input data associated with estimating evaporation and used throughout the literature vary and, in some cases, can introduce difficulties for practitioners who wish to compare various approaches. Throughout this paper, consistent definitions, time steps and units are adopted.

Evaporation is a collective term covering all processes in which liquid water is transferred as water vapour to the atmosphere. The term includes evaporation of water from lakes and reservoirs, from soil surfaces, as well as from water intercepted by vegetative surfaces. Transpiration is the evaporation from within the leaves of a plant via water vapour flux through leaf stomata (Dingman, 1992, Sect. 7.5.1). Evapotranspiration is defined as the sum of transpiration and evaporation from the soil surface (Allen et al., 1998, p. 1). Although the term "evapotranspiration" is used rather loosely in the literature, we have retained the term where we refer to literature in which it is used, for example, when discussing reference crop evapotranspiration. This paper does not deal with sublimation from snow or ice.

Two processes are involved in the exchange of water molecules between a water surface and air. Condensation is the process of capturing molecules that move from the air towards the surface and vaporisation is the movement of molecules away from the surface. The difference between the vaporisation rate, which is a function of temperature, and the condensation rate, which is a function of vapour pressure, is the evaporation rate (Shuttleworth, 1992, p. 4.3). The rate of evaporation from any wet surface is determined by three factors: (i) the physical state of the surrounding air, (ii) the net available heat, and (iii) the wetness of the evaporating surface. The state of the surrounding air is determined by its temperature, its vapour pressure and its velocity (Monteith, 1991, p. 12).

The amount of available heat energy for evaporation equals the net incoming radiation plus net input of water advected energy associated with inflows and outflows to a water body minus net output via conduction to the ground minus net output of sensible heat exchange with the atmosphere and minus the change in heat storage in the water body (Dingman, 1992, Eq. 7.14). The net incoming radiation equals the incoming shortwave solar radiation less the outgoing shortwave, which is a function of surface albedo, plus the incoming longwave less the outgoing longwave. In addition to the net incoming radiation, heat for plant evaporation 
can be supplied by turbulent transfer from the air, or by conduction from the soil (Dingman, 1992, Sect. 7.3.4). For evaporation from vegetation using the combination equations of Penman and Penman-Monteith (see later Sect. 2), water advection and heat storage can be neglected, and the equations are so arranged as to eliminate the need to estimate sensible heat exchange explicitly, leaving net incoming radiation as the major energy term to be assessed. Loss of heat to the ground via conduction is often neglected.

For evaporation to occur, in addition to energy needed for latent heat of vaporisation, there must be a process to remove the water vapour from the evaporating surface. Here, the atmospheric boundary layer is continually responding to largescale weather movements, which maintain a humidity deficit even over the oceans (Brutsaert and Strickler, 1979, p. 444), and provide a sink for the water vapour.

The two processes, radiant energy and turbulent transfer of water vapour, are utilised by several evaporation equations which will be described later. According to Penman (1948, p. 122) the main resistance to evaporation flux is a thin nonturbulent layer of air (about 1 to $3 \mathrm{~mm}$ thick) next to the surface. This resistance is known as aerodynamic or atmospheric resistance. Once through this impediment the escaping water molecules are entrained into the turbulent airflow passing over the surface. For leaves, another resistance to the evaporation process, known as surface resistance, depends on the degree of stomatal opening in the leaves, and in turn regulates transpiration (Monteith, 1991, p. 12).

According to Monteith (1965, p. 230), when air moves across a landscape, water vapour is transported at a rate equal to the product of the water vapour content and the wind speed. This transport is known as an advective flow and is present throughout the atmosphere. As shown in Fig. 1, when air moves from a dry region to a wetter area, the concentration of water vapour increases at the transition to a higher value downwind. On the other hand, at the transition the evaporation rate immediately increases to a much higher value compared to that over the dryland, and then decreases slowly to a value representative of the wetter area. The low evaporation over the dryland means the overpassing air will be hotter and drier, thus increasing the available heat energy to increase evaporation in the downwind wetter area (Morton, 1983a, p. 3). In this context, it should be noted that because a lake is defined as one so wide that the effects of an upwind transition (as in Fig. 1) are negligible, overall lake evaporation is independent of the wetness of the upwind environment (Morton, 1983a, p. 17).

Throughout the paper, unless otherwise stated, pan evaporation means a Class-A evaporation pan with a standard screen. A Class-A evaporation pan, which was developed in the United States and is used widely throughout the world, is a circular pan $(1.2 \mathrm{~m}$ in diameter and $0.25 \mathrm{~m}$ deep) constructed of galvanised iron and is supported on a wooden frame 30 to $50 \mathrm{~mm}$ above the ground (WMO, 2006, Sect. 10.3.1). In Australia, a standard wire screen covers the

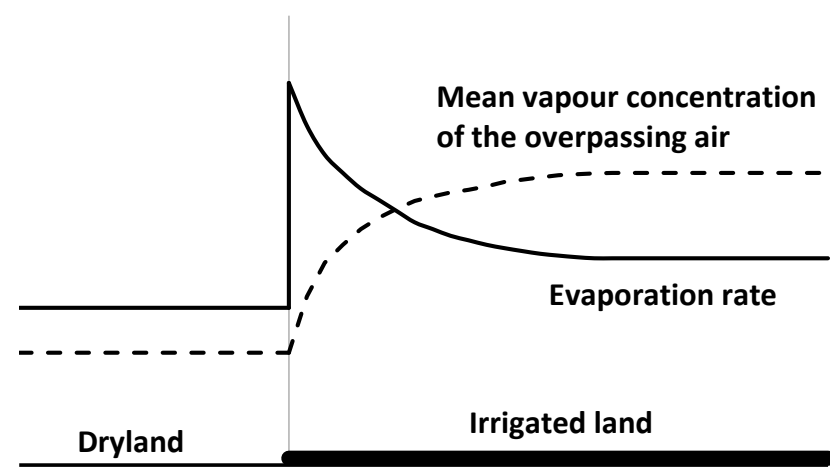

Fig. 1. Conceptual representation of the effect of advected air passing from dryland over an irrigated area.

water surface to prevent water consumption by animals and birds (Jovanovic et al., 2008, Sect. 2).

In this paper, the term "lake" includes lakes, reservoirs and voids (as a result of surface mining) and is defined, following Morton (1983b, p. 84), as a body of water so wide that the advection of air with low water vapour concentration from the adjacent terrestrial environment has negligible effect on the evaporation rate beyond the immediate shoreline or transition zone. Furthermore, Morton distinguishes between shallow and deep lakes, the former being one in which seasonal heat storage changes are insignificant. Deep lakes may also be considered shallow if one is interested only in annual or mean annual evaporation because at those time steps seasonal heat storage changes are considered unimportant (Morton, 1983b, Sect. 3). However, for other procedures there is no clear distinction between shallow and deep lakes (see Table S5) and, therefore, we have identified them as shallow or deep in terms of the description in the relevant reference.

Because of the scope of evaporation topics across analyses and measurements, we deliberately restrict the content of the paper to techniques that can be applied at a daily and/or monthly time step. Under each method we set out the time step that is appropriate. Dealing with shorter time steps, say one hour, is mainly a research issue and is beyond the scope of this paper.

In the literature, there is little consistency in the units for the input data, constants and variables. Here, except for several special cases, we use a consistent set of units and have adjusted the empirical constants accordingly. The adopted units are: evaporation in mm per unit time, pressure in $\mathrm{kPa}$, wind speed in $\mathrm{ms}^{-1}$ averaged over the unit time, and radiation in $\mathrm{MJ} \mathrm{m}^{-2}$ per unit time. Furthermore, we distinguish between measurements that are cumulated or averaged over $24 \mathrm{~h}$, denoted as "daily" values, and those that are cumulated or measured during day-light hours, designated as "day-time" values (Van Niel et al., 2011).

Evaporation can be expressed as depth per unit time, e.g. $\mathrm{mm} \mathrm{day}^{-1}$, or expressed as energy during a day and, noting that the latent heat of water is $2.45 \mathrm{MJ} \mathrm{kg}^{-1}$ (at $20^{\circ} \mathrm{C}$ ) it 
follows that $1 \mathrm{~mm} \mathrm{day}^{-1}$ of evaporation equals $2.45 \mathrm{MJ} \mathrm{m}^{-2}$ day $^{-1}$. Furthermore, many evaporation equations described herein express evaporation in units of $\mathrm{mm} \mathrm{day}^{-1}$ rather than the correct unit of $\mathrm{kg} \mathrm{m}^{-2} \mathrm{day}^{-1}$. In these cases, the unit conversion is $1000 \mathrm{~mm} \mathrm{~m}^{-1} /\left(\rho_{\mathrm{w}}=\sim 1000 \mathrm{~kg} \mathrm{~m}^{-3}\right)$, which equals one and, therefore, the conversion factor from $\mathrm{kg} \mathrm{m}^{-2}$ to $\mathrm{mm}$ is not included in the equation. We remind readers of this equivalence where the equations are defined in the text.

The evaporation models discussed in this paper, including Penman, Penman-Monteith, Priestley-Taylor, reference crop evapotranspiration, PenPan, Morton and advection-aridity models, require a range of meteorological and other data as input. The data required are highlighted in Table 1 along with the time step for analysis and the sections in the paper where the models are discussed. Availability of input data is discussed in Sect. S1. Sections S2 and S3 list the equations for calculating the meteorological variables like saturation vapour pressure, and net radiation. Values of specific constants like the latent heat of vaporization, aerodynamic and surface resistances, and albedo values are listed in Tables S1, $\mathrm{S} 2$, and S3, respectively.

\section{Background theory and models}

The evaporation process over a vegetated landscape is linked by two fundamental equations - a water balance equation and an energy balance equation as follows.

Water balance:

$\bar{P}=\bar{E}_{\mathrm{Act}}+\bar{Q}+\Delta S$,

$\bar{P}=\left(\bar{E}_{\text {Soil }}+\bar{E}_{\text {Trans }}+\bar{E}_{\text {Inter }}\right)+\bar{Q}+\Delta S$.

Energy balance:

$\bar{R}=\bar{H}+\lambda \bar{E}_{\mathrm{Act}}+\bar{G}$

where, during a specified time period, e.g. one month, and over a given area, $\bar{P}$ is the mean rainfall $\left(\mathrm{mm} \mathrm{day}^{-1}\right), \bar{E}_{\text {Act }}$, $\bar{E}_{\text {Soil }}, \bar{E}_{\text {Trans }}$, and $\bar{E}_{\text {Inter }}$ are respectively the mean actual evaporation $\left(\mathrm{mm} \mathrm{day}^{-1}\right)$, the mean evaporation from the soil $\left(\mathrm{mm} \mathrm{day}{ }^{-1}\right)$, the mean transpiration $\left(\mathrm{mm} \mathrm{day}^{-1}\right)$ and mean evaporation of intercepted precipitation $\left(\mathrm{mm} \mathrm{day}^{-1}\right), \bar{Q}$ is the mean runoff $\left(\mathrm{mm} \mathrm{day}^{-1}\right), \Delta S$ is the change in soil moisture storage $\left(\mathrm{mm} \mathrm{day}^{-1}\right)$ and deep seepage is assumed negligible, $\bar{R}$ is the mean net radiation received at the soil/plant surfaces $\left(\mathrm{MJ} \mathrm{m}^{-2} \mathrm{day}^{-1}\right), \bar{H}$ is the mean sensible heat flux $\left(\mathrm{MJ} \mathrm{m}^{-2} \mathrm{day}^{-1}\right), \lambda \bar{E}_{\text {Act }}$ is the outgoing energy $\left(\mathrm{MJ} \mathrm{m}^{-2}\right.$ day $^{-1}$ ) as mean actual evaporation, $\bar{G}$ is the mean heat conduction into the soil $\left(\mathrm{MJ} \mathrm{m}^{-2} \mathrm{day}^{-1}\right)$, and $\lambda$ is the latent heat of vaporisation $\left(\mathrm{MJ} \mathrm{m}^{-2}\right)$. Models used to estimate evaporation are based on these two fundamental equations.

This section covers five types of models. Section 2.1 (Potential evaporation) discusses the conceptual basis for estimating potential evaporation, which is followed by Sect. 2.2
(FAO-56 reference crop evapotranspiration) where estimating evapotranspiration for reference crop conditions is considered. Section 2.3 (Pan evaporation) deals with the measurement and modelling of evaporation by a Class-A evaporation pan. Section 2.4 (Open-surface water evaporation) discusses actual evaporation from open-surface water of shallow lakes, deep lakes (reservoirs) and large voids. Finally, in Sect. 2.5 (Actual evaporation (from catchments)) actual evaporation from landscapes and catchments is discussed.

\subsection{Potential evaporation}

In 1948, Thornthwaite (1948, p. 56) coined the term "potential evapotranspiration", the same year that Penman (1948) published his approach for modelling evaporation for a short green crop completely shading the ground. Penman (1956, p. 20) called this "potential transpiration" and since then there have been many definitions and redefinitions of the term potential evaporation or evapotranspiration.

In a detailed review, Granger (1989a, Table 1) (see also Granger, 1989b) examined the concept of potential evaporation and identified five definitions, but considered only three to be useful, which he labelled EP2, EP3 and EP5. They are generally related as

$\mathrm{EP} 5 \geq \mathrm{EP} 3 \geq \mathrm{EP} 2 \geq E_{\text {Act }}$,

where $E_{\mathrm{Act}}$ is the actual evaporation rate. EP2, which is known as the "wet environment" or "equilibrium evaporation" rate (see Sect. 2.1.4), is defined as the evaporation rate that would occur from a saturated surface with a constant energy supply to the surface. This represents the lower limit of actual evaporation from a wet surface, noting that for a drier surface $E_{\mathrm{Act}}<\mathrm{EP} 2$. EP2 is effectively the energy flux term in the Penman equation (Eq. 4). EP3 is defined as the evaporation rate that would occur from a saturated surface with constant energy supply to, and constant atmospheric conditions over, the surface. This is equivalent to the Penman evaporation from a free-water surface and is dependent on available energy and atmospheric conditions. Granger (1989a, Table 1) denotes EP5 as "potential evaporation" that represents an upper limit of evaporation. It is defined as the evaporation rate that would occur from a saturated surface with constant atmospheric conditions and constant surface temperature.

In this paper we have adopted Dingman's (1992, Sect. 7.7.1) definition of potential evapotranspiration, namely that it "... is the rate at which evapotranspiration would occur from a large area completely and uniformly covered with growing vegetation which has access to an unlimited supply of soil water, and without advection or heating effects." The assumptions of no advection and no heating effects refer to water-advected energy (for example, by inflow to a lake) and to heat storage effects, which will be valid for water bodies but may not be so for vegetation surfaces (Dingman, 1992, p. 299). Two other terms need to be defined - reference crop evapotranspiration and actual evaporation. 
Table 1. Data required to compute evaporation using key models described in the paper.

\begin{tabular}{|c|c|c|c|c|c|c|c|c|c|}
\hline Models & Penman & $\begin{array}{l}\text { Penman- } \\
\text { Monteith }\end{array}$ & $\begin{array}{c}\text { Priestley- } \\
\text { Taylor }\end{array}$ & $\begin{array}{l}\text { FAO } 56 \\
\text { Ref. crop }\end{array}$ & PenPan & $\begin{array}{l}\text { Morton } \\
\text { CRAE }\end{array}$ & $\begin{array}{l}\text { Morton } \\
\text { CRWE }\end{array}$ & $\begin{array}{l}\text { Morton } \\
\text { CRLE }\end{array}$ & $\begin{array}{c}\text { Advection- } \\
\text { Aridity }\end{array}$ \\
\hline Sub-section discussed & 2.1 .1 & 2.1 .2 & 2.1 .3 & 2.2 & 2.3 .2 & 2.5 .2 & 2.5 .2 & 2.5 .2 & 2.5 .3 \\
\hline Time step ( $\mathrm{D}=$ daily, $\mathrm{M}=$ Monthly) & $\mathrm{D}$ or $\mathrm{M}$ & $\mathrm{D}$ & $\mathrm{D}$ or $\mathrm{M}$ & $\mathrm{D}$ & M & $\mathrm{M}($ or D) & $\mathrm{M}($ or $\mathrm{D})$ & M & $\mathrm{D}$ \\
\hline Sunshine hours or solar radiation & yes & yes & yes & yes & yes & yes & yes & yes & yes \\
\hline Maximum air temperature & yes & yes & yes & yes & yes & yes & yes & yes & yes \\
\hline Minimum air temperature & yes & yes & yes & yes & yes & yes & yes & yes & yes \\
\hline Relative humidity & yes & yes & no & yes & yes & yes & yes & yes & yes \\
\hline Wind speed & yes & yes & no & yes & yes & no & no & no & yes \\
\hline Latitude & no & no & no & no & no & yes & yes & yes & no \\
\hline Elevation & yes* & yes* & yes* & yes* & yes* & yes & yes & yes & yes* \\
\hline Mean annual rainfall & no & no & no & no & no & yes & yes & yes & no \\
\hline Salinity of lake & no & no & no & no & no & no & no & yes & no \\
\hline Average depth of lake & no & no & no & no & no & no & no & yes & no \\
\hline
\end{tabular}

* To estimate the psychrometric constant.

Reference crop evapotranspiration is the evapotranspiration from a crop with specific characteristics and which is not short of water (Allen et al, 1998, p. 7). Details are given in Sect. 2.2. The second term is actual evaporation, which is defined as the quantity of water that is transferred as water vapour to the atmosphere from an evaporating surface (Wiesner, 1970, p. 5). Readers are referred to an interesting discussion by Katerji and Rana (2011), who discuss further the definitions of potential evaporation, reference crop evapotranspiration and evaporative demand.

\subsubsection{Penman}

In 1948, Penman was the first to combine an aerodynamic approach for estimating potential evaporation with an energy equation based on net incoming radiation. These components of the evaporative process are discussed in Sect. 1.2. This approach eliminates the surface temperature variable, which is not a standard meteorological measurement, resulting in the following equation, known as the Penman or Penman combination equation, to estimate potential evaporation (Penman, 1948, Eq. 16; see also Shuttleworth, 1992, Sect. 4.2.6; Dingman, 1992, Sect. 7.3.5):

$E_{\text {Pen }}=\frac{\Delta}{\Delta+\gamma} \frac{R_{\mathrm{n}}}{\lambda}+\frac{\gamma}{\Delta+\gamma} E_{\mathrm{a}}$,

where $E_{\mathrm{Pen}}$ is the daily potential evaporation $\left(\mathrm{mm} \mathrm{day}^{-1} \equiv\right.$ $\mathrm{kg} \mathrm{m}^{-2}$ day $^{-1}$ ) from a saturated surface, $R_{\mathrm{n}}$ is net daily radiation to the evaporating surface ( $\mathrm{MJ} \mathrm{m}{ }^{-2}$ day $^{-1}$ ) where $R_{\mathrm{n}}$ is dependent on the surface albedo (Sect. S3), $E_{\mathrm{a}}(\mathrm{mm}$ day $\left.^{-1}\right)$ is a function of the average daily wind speed $\left(\mathrm{m} \mathrm{s}^{-1}\right)$, saturation vapour pressure $(\mathrm{kPa})$ and average vapour pressure $(\mathrm{kPa}), \Delta$ is the slope of the vapour pressure curve $\left(\mathrm{kPa}^{\circ} \mathrm{C}^{-1}\right)$ at air temperature, $\gamma$ is the psychrometric constant $\left(\mathrm{kPa}^{\circ} \mathrm{C}^{-1}\right)$, and $\lambda$ is the latent heat of vaporization $\left(\mathrm{MJ} \mathrm{kg}{ }^{-1}\right) . E_{\mathrm{a}}$ is the aerodynamic component in the Pen- man equation and is discussed in Sect. 2.4.1 and in more detail in Sect. S4. The Penman equation assumes no heat exchange with the ground, no change in heat storage, and no water-advected energy (as inflow in the case of a lake) (Dingman, 1992, Sect. 7.3.5). Penman (1956, p. 18) and Monteith (1981, p. 4 and 5) provide helpful discussions of the dependence of latent heat flux on surface temperature. Application of the Penman equation is discussed in Sect. 2.4.1 with further details provided in Sect. S4.

The Penman approach has spawned many other procedures (e.g. Priestley and Taylor, 1972; see Sect. 2.1.3) including the incorporation of resistance factors that extend the general method to vegetated surfaces. The Penman-Monteith formulation described in the following section is an example of the latter.

\subsubsection{Penman-Monteith}

The Penman-Monteith model, defined as Eq. (5), is usually adopted to estimate potential evaporation from a vegetated surface. The fundamental Penman-Monteith formulation depends on the unknown temperature of the evaporating surface (Raupach, 2001, p. 1154). Raupach provides a detailed discussion of the approaches to eliminate the surface temperature from the surface energy balance equations. The simplest solution results in the following well known PenmanMonteith equation (Allen et al., 1998, Eq. 3):

$\mathrm{ET}_{\mathrm{PM}}=\frac{1}{\lambda} \frac{\Delta\left(R_{\mathrm{n}}-G\right)+\rho_{\mathrm{a}} c_{\mathrm{a}} \frac{\left(v_{\mathrm{a}}^{*}-v_{\mathrm{a}}\right)}{r_{\mathrm{a}}}}{\Delta+\gamma\left(1+\frac{r_{\mathrm{s}}}{r_{\mathrm{a}}}\right)}$,

where $\mathrm{ET}_{\mathrm{PM}}$ is the Penman-Monteith potential evaporation ( $\mathrm{mm}$ day $^{-1} \equiv \mathrm{kg} \mathrm{m}^{-2}$ day $^{-1}$ ), $R_{\mathrm{n}}$ is the net daily radiation at the vegetated surface $\left(\mathrm{MJ} \mathrm{m}^{-2}\right.$ day $\left.^{-1}\right), G$ is the soil heat flux $\left(\mathrm{MJ} \mathrm{m}^{-2} \mathrm{day}^{-1}\right), \rho_{\mathrm{a}}$ is the mean air density at constant pressure $\left(\mathrm{kg} \mathrm{m}^{-3}\right), c_{\mathrm{a}}$ is the specific heat of the air 
$\left(\mathrm{MJ} \mathrm{kg}-1{ }^{\circ} \mathrm{C}^{-1}\right), r_{\mathrm{a}}$ is an "aerodynamic or atmospheric resistance" to water vapour transport $\left(\mathrm{s} \mathrm{m}^{-1}\right)$ for neutral conditions of stability (Allen et al., 1998, p. 20), $r_{\mathrm{s}}$ is a "surface resistance" term $\left(\mathrm{s} \mathrm{m}^{-1}\right),\left(v_{\mathrm{a}}^{*}-v_{\mathrm{a}}\right)$ is the vapour pressure deficit $(\mathrm{kPa}), \lambda$ is the latent heat of vaporization (MJ $\left.\mathrm{kg}^{-1}\right), \Delta$ is the slope of the saturation vapour pressure curve $\left(\mathrm{kPa}^{\circ} \mathrm{C}^{-1}\right)$ at air temperature, and $\gamma$ is the psychrometric constant $\left(\mathrm{kPa}^{\circ} \mathrm{C}^{-1}\right)$. Values of $r_{\mathrm{a}}$ and $r_{\mathrm{s}}$ are discussed in Sect. S5. The major difference between the PenmanMonteith and the Penman equations is the incorporation of the two resistance (atmospheric and surface, as described in Sect. 1.2) terms in Penman-Monteith rather than using a wind function. Although the original Penman equation (Penman, 1948, Eq. 16) does not include a soil heat flux term, Penman noted that for his test chamber the heat conducted through the walls of the container was negligible.

\subsubsection{Priestley-Taylor}

The Priestley-Taylor equation (Priestley and Taylor, 1972, Eq. 14) allows potential evaporation to be computed in terms of energy fluxes without an aerodynamic component as follows

$E_{\mathrm{PT}}=\alpha_{\mathrm{PT}}\left[\frac{\Delta}{\Delta+\gamma} \frac{R_{\mathrm{n}}}{\lambda}-\frac{G}{\lambda}\right]$,

where $\mathrm{E}_{\mathrm{PT}}$ is the Priestley-Taylor potential evaporation ( $\mathrm{mm}$ day $^{-1} \equiv \mathrm{kg} \mathrm{m}^{-2}$ day $\left.^{-1}\right), R_{\mathrm{n}}$ is the net daily radiation at the evaporating surface $\left(\mathrm{MJ} \mathrm{m}^{-2} \mathrm{day}^{-1}\right), G$ is the soil flux into the ground $\left(\mathrm{MJ} \mathrm{m}^{-2}\right.$ day $\left.^{-1}\right), \Delta$ is the slope of the vapour pressure curve $\left(\mathrm{kPa}^{\circ} \mathrm{C}^{-1}\right)$ at air temperature, $\gamma$ is the psychrometric constant $\left(\mathrm{kPa}^{\circ} \mathrm{C}^{-1}\right)$, and $\lambda$ is the latent heat of vaporization $\left(\mathrm{MJ} \mathrm{kg}^{-1}\right) . \alpha_{\mathrm{PT}}$ is the Priestley-Taylor constant.

Based on non-water-limited field data, Priestley and Taylor (1972, Sect. 6) adopted $\alpha_{\mathrm{PT}}=1.26$ for "advection-free" saturated surfaces. Eichinger et al. (1996, p. 163) developed an analytical expression for $\alpha_{\mathrm{PT}}$ and found that 1.26 was an appropriate value for an irrigated bare soil. Lhomme (1997) developed a theoretical basis for the Priestley-Taylor coefficient of 1.26 for non-advective conditions. Based on field data in northern Spain, Castellvi et al. (2001) found that $\alpha_{\mathrm{PT}}$ exhibited large seasonal (up to $27 \%)$ and spatial ( $\alpha_{\mathrm{PT}}=1.35$ to 1.67) variations. Improved performance was achieved by including adjustments for vapour pressure deficit and available energy. Pereira (2004), noting the analysis by Monteith (1965, p. 220) and Perrier (1975), considered the hypothesis $\alpha_{\mathrm{PT}}=\Omega^{-1}$ where $\Omega$ is a decoupling coefficient and is a function of the aerodynamic and surface resistances, implying $\alpha_{\mathrm{PT}}$ is not a constant. The decoupling coefficient is discussed in Sect. S5. Values of $\alpha_{\mathrm{PT}}$ for a range of surfaces are listed in Table S8 and it is noted that $\alpha_{\mathrm{PT}}$ values are dependent on the observation period, daily $(24 \mathrm{~h})$ or day-time. Priestley and Taylor (1972, Sect. 1) adopted a daily time step for their analysis.

\subsubsection{Equilibrium evaporation}

Slatyer and McIlroy (1961) developed the concept of equilibrium evaporation $\left(E_{\mathrm{EQ}}\right)$ in which air passing over a saturated surface will gradually become saturated until an equilibrium rate of evaporation is attained. Edinger et al. (1968) defined equilibrium temperature as the surface temperature of the evaporating surface at which the net rate of heat exchange (by shortwave and longwave radiation, conduction and evaporation) is zero. But because of the daily cycles in the meteorological conditions, equilibrium temperature is never achieved (Sweers, 1976, p. 377).

Stewart and Rouse (1976, Eq. 4) interpreted the Slatyer and McIlroy (1961) concept in terms of the Priestley and Taylor (1972) equation as

$E_{\mathrm{EQ}}=\frac{1}{\alpha_{\mathrm{PT}}} E_{\mathrm{PT}}$,

where $E_{\mathrm{PT}}$ and $\alpha_{\mathrm{PT}}$ are defined in the previous section. McNaughton (1976) proposed a similar argument. However, based on lysimeter data Eichinger et al. (1996) question this concept of equilibrium evaporation and suggest that the Priestley-Taylor equation with $\alpha_{\mathrm{PT}}=1.26$ is more representative of equilibrium evaporation under wet surface conditions. In 2001, Raupach (2001) carried out a historical review and theoretical analysis of the concept of equilibrium evaporation. He concluded that for any closed evaporating system (that is, a system in which there is no mass exchange with the external environment theoretically approximated by a large area with an inversion, provided entrainment is small) with steady energy supply, the system moves towards a quasisteady state in which the Bowen ratio $(\beta)$ takes the equilibrium value of $1 / \varepsilon$, where $\varepsilon$ is the ratio of latent to sensible heat contents of saturated air in a closed system. Raupach (2001) also concluded that open systems cannot reach equilibrium.

\subsubsection{Other methods for estimating potential evaporation}

There are many other potential evaporation equations proposed and evaluated during the past 100 or so years that could have been included in this paper. Some of these, e.g. Thornthwaite (Thornthwaite, 1948) and Makkink models (Keijman, 1981, p. 22; de Bruin, 1987, footnote p. 19), are discussed in Sect. S9.

\subsection{FAO-56 reference crop evapotranspiration}

Adopting the characteristics of a hypothetical reference crop (height $=0.12 \mathrm{~m}$, surface resistance $=70 \mathrm{~s} \mathrm{~m}^{-1}$, and albedo $=0.23$ (ASCE (American Society of Civil Engineers) Standardization of Reference Evapotranspiration Task Committee, 2000; Allen et al., 1998, p. 15)), the Penman-Monteith equation (Eq. 5) becomes Eq. (8), which is known as the 
(Food and Agriculture Organization) FAO-56 reference crop or the standardized reference evapotranspiration equation, short (ASCE, 2005, Table 1), and is defined as follows

$\mathrm{ET}_{\mathrm{RC}}=\frac{0.408 \Delta\left(R_{\mathrm{n}}-G\right)+\gamma \frac{900}{T_{\mathrm{a}}+273} u_{2}\left(v_{\mathrm{a}}^{*}-v_{\mathrm{a}}\right)}{\Delta+\gamma\left(1+0.34 u_{2}\right)}$,

where $\mathrm{ET}_{\mathrm{RC}}$ is the daily reference crop evapotranspiration $\left(\mathrm{mm} \mathrm{day}{ }^{-1} \equiv \mathrm{kg} \mathrm{m}^{-2}\right.$ day $\left.^{-1}\right), T_{\mathrm{a}}$ is the mean daily air temperature $\left({ }^{\circ} \mathrm{C}\right)$ at $2 \mathrm{~m}$, and $u_{2}$ is the average daily wind speed $\left(\mathrm{m} \mathrm{s}^{-1}\right)$ at $2 \mathrm{~m}$. Other symbols are as defined previously. Allen et al. (1998) provide a detailed explanation of the development of Eq. (8) from Eq. (5) including an explanation of the units of $0.408\left(\mathrm{~kg} \mathrm{MJ}^{-1}\right), 900\left(\mathrm{~kg} \mathrm{~m}^{-3} \mathrm{~s} \mathrm{day}^{-1}\right)$ and 0.34 $\left(\mathrm{s} \mathrm{m}^{-1}\right)$. A detailed explanation of the theory of reference crop evapotranspiration is presented by McVicar et al. (2005, Sect. 2). It should be noted that a second reference crop evapotranspiration equation has been developed for a $0.5 \mathrm{~m}$ tall crop (ASCE, 2005, Table 1). Further details are included in Sect. S5.

The time step recommended by Allen et al. (1998, Chapter 4 ) for analysis using Eq. (8) is one day ( $24 \mathrm{~h})$. Equations for other time steps may be found in the same reference.

A detailed discussion of the variables is given in Sect. S5. $G$ is a function of successive daily temperatures and, therefore, $\mathrm{ET}_{\mathrm{PM}}$ and $\mathrm{ET}_{\mathrm{RC}}$ are sensitive to $G$ when there is a large difference between successive daily temperatures. An algorithm for estimating $G$ is presented in Sect. S5. It should be noted that the Penman-Monteith equation assumes that the actual evaporation does not affect the overpassing air (Wang et al., 2001).

There are other equations for estimating reference crop evapotranspiration, e.g. FAO-24 Blaney and Criddle (Allen and Pruitt, 1986), Turc (1961), Hargreaves-Samani (Hargreaves and Samani, 1985), and the modified Hargreaves approach (Droogers and Allen, 2002). These are included in Sect. S9.

\subsection{Pan evaporation}

\subsubsection{Class-A evaporation pan}

Evaporation data from a Class-A pan, when combined with an appropriate pan coefficient or with an adjustment for the energy exchange through the sides and bottom of the tank, can be considered to be open-water evaporation (Dingman, 1992, p. 289). Pan data can be used to estimate actual evaporation for situations that require free-water evaporation as follows

$E_{\mathrm{fw}, j}=K_{j} E_{\mathrm{Pan}, j}$,

where $E_{\mathrm{fw}, j}$ is an estimate of monthly (or daily) opensurface water evaporation (mm/unit time), $j$ is the specific month (or day), $K_{j}$ is the average monthly (or daily) ClassA pan coefficient, and $E_{\mathrm{Pan}, j}$ is the monthly (or daily) ob- served Class-A pan value (mm/unit time). Usually, pan coefficients are estimated by comparing observed pan evaporations with estimated or measured open-surface water estimates, although Kohler et al. (1955) and Allen et al. (1998, p. 86) proposed empirically derived relationships. These are described in Sect. S16. Published pan coefficients are available for a range of regions and countries. Some of these are reported also in Sect. S16 and associated tables. In addition, monthly Class-A pan coefficients are provided for 68 locations across Australia (Sect. S16 and Table S6). In China, micro-pans ( $200 \mathrm{~mm}$ diameter, $100 \mathrm{~mm}$ high that are filled to 20 or $30 \mathrm{~mm}$ ) are used to measure pan evaporation. Based on an analytical analysis of the pan energetics (McVicar et al., 2007b, p. 209), the pan coefficients for a Chinese micro-pan are lower than Class-A pan coefficients but with a seasonal range being similar to those of a Class-A pan.

Masoner et al. (2008) compared the evaporation rate from a floating evaporation pan (which estimated open-surface water evaporation - see Keijman and Koopmans, 1973; Ham and DeSutter, 1999) with the rate from a land-based ClassA pan. They concluded that the floating pan to land pan ratios were similar to Class-A pan coefficients used in the United States.

The disaggregation of an annual actual or potential evaporation estimate into monthly or especially daily values is not straightforward, assuming there is no concurrent at-site climate data which could be used to gain insight into how the annual value should be partitioned. One approach is to use monthly pan coefficients if available, as noted above. Another approach, that is available to Australian analysts, is to adopt average monthly values of point potential evapotranspiration for the given location (maps for each month are provided in Wang et al., 2001) and pro rata the values to sum to the annual values of $E_{\mathrm{fw}}$. This suggestion is based on the recent analysis by Kirono et al. (2009, Fig. 3) who found that, for 28 locations around Australia, Morton's potential evapotranspiration $\mathrm{ET}_{\text {Pot }}$ (see Sect. 2.5.2) correlated satisfactorily $\left(R^{2}=0.81\right)$ with monthly Class-A pan evaporation values, although the Morton values overestimated the pan values by approximately $11 \%$. Further discussion is provided in Sect. 3.1.3.

\subsubsection{The PenPan model}

There have been several variations of the Penman equation (Eq. 4) to model the evaporation from a Class-A evaporation pan. Linacre (1994) developed a physical model which he called the Penpan formula or equation. Rotstayn et al. (2006) coupled the radiative component of Linacre (1994) and the aerodynamic component of Thom et al. (1981) to develop the PenPan model (note the two capital Ps to differentiate it from Linacre's (1994) contribution). Based on the PenPan model, Roderick et al. (2007, Fig. 1) and Johnson and Sharma (2010, Fig. 1) demonstrate separately that the model 
can successfully estimate monthly and annual Class-A pan evaporation at sites across Australia.

Following Rotstayn et al. (2006, Eq. 2) the PenPan equation is defined as

$E_{\text {PenPan }}=\frac{\Delta}{\Delta+a_{\mathrm{p}} \gamma} \frac{R_{\mathrm{NPan}}}{\lambda}+\frac{a_{\mathrm{p}} \gamma}{\Delta+a_{\mathrm{p}} \gamma} f_{\mathrm{Pan}}(u)\left(v_{\mathrm{a}}^{*}-v_{\mathrm{a}}\right)$

where $E_{\text {PenPan }}$ is the modelled Class-A (unscreened) pan evaporation $\left(\mathrm{mm}\right.$ day $^{-1} \equiv \mathrm{kg} \mathrm{m}^{-2}$ day $\left.^{-1}\right), R_{\mathrm{NPan}}$ is the net daily radiation at the pan $\left(\mathrm{MJ} \mathrm{m}^{-2}\right.$ day $\left.^{-1}\right), \Delta$ is the slope of the vapour pressure curve $\left(\mathrm{kPa}^{\circ} \mathrm{C}^{-1}\right)$ at air temperature, $\gamma$ is psychrometric constant $\left(\mathrm{kPa}^{\circ} \mathrm{C}^{-1}\right)$, and $\lambda$ is the latent heat of vaporization $\left(\mathrm{MJ} \mathrm{kg}^{-1}\right), a_{\mathrm{p}}$ is a constant adopted as 2.4 (Rotstayn et al., 2006, p. 2), $v_{\mathrm{a}}^{*}-v_{\mathrm{a}}$ is vapour pressure deficit $(\mathrm{kPa})$, and $f_{\mathrm{Pan}}(u)$ is defined as (Thom et al., 1981, Eq. 34)

$f_{\mathrm{Pan}}(u)=1.202+1.621 u_{2}$,

where $u_{2}$ is the average daily wind speed at $2 \mathrm{~m}$ height ( $\mathrm{m} \mathrm{s}^{-1}$ ). Details to estimate $R_{\mathrm{NPan}}$ and results of the application of the model to 68 Australian sites are given in Sect. S6.

\subsection{Open-surface water evaporation}

In this paper the terms open-water evaporation and free-water evaporation are used interchangeably and assume that water available for evaporation is unlimited. We discuss two approaches to estimate open-water evaporation: Penman's combination equation and an aerodynamic approach.

\subsubsection{Penman equation}

The Penman equation (Penman, 1948, Eq. 16) is widely and successfully used for estimating open-water evaporation as

$E_{\text {PenOw }}=\frac{\Delta}{\Delta+\gamma} \frac{R_{\mathrm{nw}}}{\lambda}+\frac{\gamma}{\Delta+\gamma} E_{\mathrm{a}}$,

where $E_{\text {PenOw }}$ is the daily open-surface water evaporation $\left(\mathrm{mm}\right.$ day $^{-1} \equiv \mathrm{kg} \mathrm{m}^{-2}$ day $\left.^{-1}\right), R_{\mathrm{nw}}$ is the net daily radiation at the water surface ( $\mathrm{MJ} \mathrm{m}^{-2} \mathrm{day}^{-1}$ ), and other terms have been previously defined. In estimating the net radiation at the water surface, the albedo value for water should be used (Table S3). Details of the Penman calculations are presented in Sect. S4. Section S3 lists the equations required to compute net radiation with or without incoming solar radiation measurements. We note that of the 20 methods reviewed by Irmak et al. (2011) the method described in Sect. S3 (based on Allen et al. (1998, p. 41 to 55$)$ ) to estimate $R_{\text {nw }}$ was one of the better performing procedures.

The first term in Eq. (12) is the radiative component and the second term is the aerodynamic component. To estimate $R_{\mathrm{nw}}$, the incoming solar radiation $\left(R_{\mathrm{S}}\right)$, measured at automatic weather stations or estimated from extraterrestrial radiation, is reduced by estimates of shortwave reflection, using the albedo for water, and net outgoing longwave radiation. $E_{\mathrm{a}}$ is known as the aerodynamic equation (Kohler and Parmele, 1967, p. 998) and represents the evaporative component due to turbulent transport of water vapour by an eddy diffusion process (Penman, 1948, Eq. 1) and is defined as

$E_{\mathrm{a}}=f(u)\left(v_{\mathrm{a}}^{*}-v_{\mathrm{a}}\right)$,

where $f(u)$ is a wind function typically of the form $f(u)=$ $a+b u$, and $\left(v_{\mathrm{a}}^{*}-v_{\mathrm{a}}\right)$ is the vapour pressure deficit $(\mathrm{kPa})$.

There have been many studies dealing with Penman's wind function including Penman's (1948, 1956) analyses (see Penman (1956, Eq. 8a and b) for a comparison of the two equations), Stigter (1980, p. 322, 323), Fleming et al. (1989, Sect. 8.4), Linacre (1993, Appendix 1), Cohen et al. (2002, Sect. 4) and Valiantzas (2006). Based on Valiantzas' (2006, page 695) summary of these studies, we recommend that the Penman (1956, Eq. 8b) wind function be adopted as the standard for evaporation from open water with $a=1.313$ and $b=1.381$ (wind speed is a daily average value in $\mathrm{ms}^{-1}$ and the vapour deficit in $\mathrm{kPa}$ ). Typically, the wind function assumes wind speed is measured at $2 \mathrm{~m}$ above the ground surface but if not it should be adjusted using Eq. (S4.4). More details about alternative wind functions are provided in Sect. S4. It is noted here that because the wind function coefficients were empirically derived, the Penman equation for a specific application is an empirical one.

According to Dingman (1992, p. 286), in the Penman equation it is assumed there is no change in heat storage, no heat exchange with the ground, and no advected energy. Data required to use the equation include solar radiation, sunshine hours or cloudiness, wind speed, air temperature, and relative humidity (or dew point temperature). Although Penman (1948) carried out his computations of evaporation based on 6-day and monthly time steps, most analysts have adopted a monthly time step (e.g. Weeks, 1982; Fleming et al., 1989, Sect. 8.4; Chiew et al., 1995; Cohen et al., 2002; Harmsen et al., 2003) and several have used a daily or shorter time step (e.g. Chiew et al., 1995; Sumner and Jacobs, 2005).

van Bavel (1966) amended the original Penman (1948) equation to take into account boundary layer resistance. The modified equation is considered in Sect. S4.

Linacre (1993, p. 239) discusses potential errors in the Penman equation and the accuracy of the estimates, and reports that lake evaporation estimates are much more sensitive to errors in net radiation and humidity than to errors in air temperature and wind.

\subsubsection{Aerodynamic formula}

The aerodynamic method is based on the Dalton-type approach (Dingman, 1992, Sect. 7.3.2), in which evaporation is the product of a wind function and the vapour pressure deficit between the evaporating surface and the overlying atmosphere. Following a review of 19 studies, McJannet et al. (2012, Eq. 11) proposed the following empirical 
relationship to estimate open surface water evaporation.

$E_{\text {Larea }}=\left(2.36+1.67 u_{2}\right) A^{-0.05}\left(v_{\mathrm{a}}^{*}-v_{\mathrm{a}}\right)$,

where $E_{\text {Larea }}$ is an estimate of open-surface water evaporation $\left(\mathrm{mm} \mathrm{day}^{-1}\right)$ as a function of evaporating area, $A,\left(\mathrm{~m}^{2}\right)$, $u_{2}$ is the wind speed $\left(\mathrm{m} \mathrm{s}^{-1}\right)$ over land at $2 \mathrm{~m}$ height, $v_{w}^{*}$ is the saturated vapour pressure $(\mathrm{kPa})$ at the water surface, and $v_{\mathrm{a}}$ is the vapour pressure $(\mathrm{kPa})$ at air temperature.

\subsection{Actual evaporation (from catchments)}

\subsubsection{The complementary relationship}

In 1963, Bouchet hypothesised that, for large homogeneous areas where there is little advective heat and moisture (discussed in Sect. 1.2), potential and actual evapotranspiration depend on each other in a complementary way via feedbacks between the land and the atmosphere. This led Bouchet (1963) to propose the complementary relationship (CR) illustrated in Fig. 2 and defined as

$\mathrm{ET}_{\mathrm{Act}}=2 \mathrm{ET}_{\mathrm{Wet}}-\mathrm{ET}_{\mathrm{Pot}}$.

$\mathrm{ET}_{\mathrm{Act}}$ is the actual areal or regional evapotranspiration ( $\mathrm{mm}$ per unit time) from an area large enough that the heat and vapour fluxes are controlled by the evaporating power of the lower atmosphere and unaffected by upwind transitions (In the context of the complementary relationship, and techniques using the relationship, $\mathrm{ET}_{\mathrm{Act}}$ includes transpiration and evaporation from water bodies, soil and interception storage). $\mathrm{ET}_{\text {Wet }}$ is the potential (or wet-environment) evapotranspiration (mm per unit time) that would occur under steady state meteorological conditions in which the soil/plant surfaces are saturated and there is an abundant water supply. According to Morton (1983a, p. 16), ET Wet is equivalent to the conventional definition of potential evapotranspiration. $\mathrm{ET}_{\mathrm{Pot}}$ is the (point) potential evapotranspiration ( $\mathrm{mm}$ per unit time) for an area so small that the heat and water vapour fluxes have no effect on the overpassing air, in other words, evaporation that would occur under the prevailing atmospheric conditions if only the available energy were the limiting factor.

Consider an infinitesimal point in an arid landscape with no soil moisture (origin of Fig. 2a). We observe from the $\mathrm{CR}$ (Eq. 15) that actual areal evapotranspiration $\mathrm{ET}_{\mathrm{Act}}=0$ and, therefore, $\mathrm{ET}_{\mathrm{Pot}}=2 \mathrm{ET}_{\mathrm{Wet}}$. For the same location and the same evaporative energy, when the soil becomes wet after rainfall actual evapotranspiration can take place. Consider point $\mathrm{C}$ in Fig. 2. The actual areal evapotranspiration has increased to D with a corresponding decrease in point potential evapotranspiration as modelled by the CR (Eq. 15). However, when the landscape becomes saturated (point $\mathrm{F}$ in Fig. 2a), that is, the water supply to the plants is not limiting, $\mathrm{ET}_{\text {Act }}=\mathrm{ET}_{\text {Pot }}=\mathrm{ET}_{\text {Wet }}$.

The complementary relationship is the basis for estimating actual and potential evapotranspiration by the three
Morton (1983a) models (known as Complementary Relationship Areal Evapotranspiration (CRAE), Complementary Relationship Wet-surface Evaporation (CRWE) and Complementary Relationship Lake Evaporation (CRLE)) and by the Advection-Aridity (AA) model of Brutsaert and Strickler (1979) with modifications by Hobbins et al. (2001a, b).

In his 1983a paper, Morton argues that the CR cannot be verified directly, but based on a water balance study of four rivers in Malawi and another in Puerto Rico, he argued that the concept is plausible (Morton, 1983a, Figs. 7-9). Based on independent evidence of regional $\mathrm{ET}_{\mathrm{Act}}$ and on pan evaporation data from 192 observations in 25 catchments in the US, Hobbins and Ramírez (2004) and Ramírez et al. (2005) argue that the complementary relationship is beyond conjecture. The shape of the CR relationship for the observed pan data, assuming a pan represents an infinitesimal point as required in the CR relationship, is similar to the shape in Fig. 2a. Using a mesoscale model over an irrigation area in south-eastern Turkey, Ozdogan et al. (2006) concluded that their results lend credibility to the CR hypothesis. However, research is underway into understanding whether the constant of proportionality ("2" in Eq. 15) varies and, if so, what is the nature of the asymmetry in the relationship (Ramírez et al., 2005; Szilagyi, 2007; Szilagyi and Jozsa, 2008). Some other references of relevance include Hobbins et al. (2001a); Yang et al. (2006); Kahler and Brutsaert (2006); Lhomme and Guilioni (2006); Yu et al. (2009) and Han et al. (2011).

\subsubsection{Morton's models}

F. I. Morton was at the forefront of evaporation analyses from about 1965 culminating in the mid-80s with the publication of the program WREVAP (Morton et al., 1985). WREVAP, which is summarised in Table 2, combines three models namely CRAE (Morton, 1983a), CRWE (Morton, 1983b) and CRLE (Morton, 1986), typically at a monthly time step. The CRAE model computes actual evapotranspiration for land environments, the CRWE model computes evaporation for shallow lakes and the CRLE model computes evaporation for deep lakes. Details of the models are discussed briefly in this section, in Sects. 3.1.2 and 3.2, and in detail in Sect. S7.

Nash (1989, Abstract) concluded that Morton's analysis based mainly on the complementary relationship provides a valuable extension to Penman in that it allows one to estimate actual evapotranspiration under a limiting water supply. As air passes from a land environment to a lake environment it is modified and the complementary relationship takes this into account. This is illustrated in Fig. 2 where the potential evaporation in the land environment operates as shown in Fig. 2a, whereas the lake evaporation is constant and equal to the wet environment evaporation estimated for a water body as shown in Fig. $2 b$. 
Table 2. Morton's models ( $\alpha$ is albedo, $\varepsilon_{\mathrm{S}}$ is surface emissivity, and $b_{0}, b_{1}, b_{2}$ and $f_{\mathrm{Z}}$ are defined in Sect. S7).

\begin{tabular}{|c|c|c|c|c|}
\hline Program & \multicolumn{4}{|c|}{ WREVAP (Morton 1983a, b, 1986) } \\
\hline Environment & \multicolumn{2}{|l|}{ Land environment } & Shallow lake & Deep lake \\
\hline $\begin{array}{l}\text { Radiation input } \\
\text { (if not using Morton, } \\
\text { 1983a method) }\end{array}$ & \multicolumn{2}{|l|}{$\begin{array}{l}\alpha=0.10-0.30 \\
\text { depending on vegetation } \\
\varepsilon_{\mathrm{S}}=0.92\end{array}$} & $\begin{array}{l}\alpha=0.05 \\
\varepsilon_{\mathrm{S}}=0.97\end{array}$ & $\begin{array}{l}\alpha=0.05 \\
\varepsilon_{\mathrm{S}}=0.97\end{array}$ \\
\hline Models & \multicolumn{2}{|l|}{ CRAE } & CRWE & CRLE \\
\hline Data & \multicolumn{2}{|c|}{$\begin{array}{l}\text { Latitude, elevation, mean annual precipitation, } \\
\text { and daily temperature, humidity } \\
\text { and sunshine hours }\end{array}$} & $\begin{array}{l}\text { As for CRAE plus lake salinity } \\
\text { (Morton, 1986, Sect. 4, item 2) }\end{array}$ & $\begin{array}{l}\text { As for CRAE plus lake salinity and } \\
\text { average depth (Morton, 1986, Sect. 4) }\end{array}$ \\
\hline \multirow[t]{4}{*}{$\begin{array}{l}\text { Component models } \\
\text { and variable values }\end{array}$} & \multicolumn{2}{|c|}{$\begin{array}{l}\mathrm{ET}_{\text {Pot }}^{\mathrm{MO}} \\
\text { Potential evapotranspiration }\end{array}$} & \multirow{2}{*}{$\begin{array}{l}E_{\mathrm{Pot}} * \\
\text { Potential evaporation } \\
\text { (in the land environment) } \\
\text { or pan-size wet surface } \\
\text { evaporation Morton (1983a, p. } 26) \\
b_{0}=1.12 f_{\mathrm{Z}}=25 \mathrm{~W} \mathrm{~m}^{-2} \text { mbar }^{-1}\end{array}$} & \\
\hline & $\begin{array}{l}\text { Morton (1983a) } \\
b_{0}=1.0(\mathrm{p} .64) \\
f_{\mathrm{Z}}=28 \mathrm{~W} \mathrm{~m}^{-2} \\
\operatorname{mbar}^{-1}(\mathrm{p} .25)\end{array}$ & $\begin{array}{l}\text { For Australia } \\
\text { (Chiew and Leahy, 2003, } \\
\text { Sect. 2.3) } b_{0}=1.0 \\
f_{\mathrm{Z}}=29.2 \mathrm{~W} \mathrm{~m}^{-2} \mathrm{mbar}^{-1}\end{array}$ & & \\
\hline & \multicolumn{2}{|c|}{$\begin{array}{l}\mathrm{ET}_{\text {Wet }}^{\mathrm{MO}} \\
\text { Wet environment areal evapotranspiration }\end{array}$} & $\begin{array}{l}\mathrm{ET}_{\text {Wet }}^{\mathrm{MO}} \\
\text { Shallow lake evaporation }\end{array}$ & $\begin{array}{l}\mathrm{ET}_{\text {Wet }}^{\mathrm{MO}} \\
\text { Deep lake evaporation }\end{array}$ \\
\hline & $\begin{array}{l}\text { Morton (1983a, p. 25) } \\
b_{1}=14 \mathrm{~W} \mathrm{~m}^{-2} \\
b_{2}=1.2\end{array}$ & $\begin{array}{l}\text { For Australia } \\
\text { (Chiew and Leahy, 2003, Sect. 2.3) } \\
b_{1}=13.4 \mathrm{~W} \mathrm{~m}^{-2} \\
b_{2}=1.13\end{array}$ & $\begin{array}{l}\text { Morton }(1983 \mathrm{a}, \mathrm{p} .26) \\
b_{1}=13 \mathrm{~W} \mathrm{~m}^{-2} \\
b_{2}=1.12 \\
R_{\text {ne }}\left(\text { net radiation at } T_{\mathrm{e}}{ }^{\circ} \mathrm{C}\right)\end{array}$ & $\begin{array}{l}b_{1}=13 \mathrm{~W} \mathrm{~m}^{-2} b_{2}=1.12 \\
R_{\mathrm{ne}} \text { (net radiation at } T_{\mathrm{e}}^{\circ} \mathrm{C} \text { ) } \\
\text { with seasonal adjustment of solar } \\
\text { and water borne inputs }\end{array}$ \\
\hline Outcome & \multicolumn{2}{|c|}{$\begin{array}{l}\text { Actual areal evapotranspiration } \\
\mathrm{ET}_{\mathrm{Act}}^{\mathrm{MO}}=2 \mathrm{ET}_{\mathrm{Wet}}^{\mathrm{MO}}-\mathrm{ET}_{\mathrm{Pot}}^{\mathrm{MO}}\end{array}$} & $\begin{array}{l}E_{\mathrm{SL}} \\
\text { Shallow lake evaporation }\end{array}$ & $\begin{array}{l}E_{\mathrm{DL}} \\
\text { Deep lake evaporation }\end{array}$ \\
\hline
\end{tabular}

* According to Morton (1986, p. 379, item 4) in the context of estimating lake evaporation, E Eot has no “... real world meaning..." because the estimates are sensitive to both the lake energy environment and the land temperature and humidity environment which are significantly out of phase. This is not so with lake evaporation as the model accounts for the impact of overpassing air.

\section{CRAE model}

The CRAE model estimates the three components: potential evapotranspiration, wet-environment areal evapotranspiration and actual areal evapotranspiration.

\section{Estimating potential evapotranspiration (ET Pot in Fig. 2).}

Because Morton's (1983a, p. 15) model does not require wind data, it has been used extensively in Australia (where historical wind data were unavailable until recently; see McVicar et al., 2008) to compute time series estimates of historical potential evaporation. Morton's approach is to solve the following energy-balance and vapour transfer equations respectively for potential evaporation at the equilibrium temperature, which is the temperature of the evaporating surface:

$\mathrm{ET}_{\mathrm{Pot}}^{\mathrm{MO}}=\frac{1}{\lambda}\left\{R_{\mathrm{n}}-\left[\gamma p f_{\mathrm{v}}+4 \epsilon_{\mathrm{s}} \sigma\left(T_{\mathrm{e}}+273\right)^{3}\right]\left(T_{\mathrm{e}}-T_{\mathrm{a}}\right)\right\}$

$\mathrm{ET}_{\mathrm{Pot}}^{\mathrm{MO}}=\frac{1}{\lambda}\left\{f_{\mathrm{v}}\left(v_{\mathrm{e}}^{*}-v_{\mathrm{D}}^{*}\right)\right\}$,

where $\mathrm{ET}_{\mathrm{Pot}}^{\mathrm{MO}}$ is Morton's estimate of potential evapotranspiration $\left(\mathrm{mm}\right.$ day $^{-1} \equiv \mathrm{kg} \mathrm{m}^{-2}$ day $^{-1}$ ), $R_{\mathrm{n}}$ is net radiation for soil/plant surfaces at air temperature $\left(\mathrm{W} \mathrm{m}^{-2}\right), f_{\mathrm{v}}$ is the vapour transfer coefficient $\left(\mathrm{W} \mathrm{m}^{-2} \mathrm{mbar}^{-1}\right)$ and is a function of atmospheric stability (details are provided in Sect. S7 or Morton (1983a, p. 24-25)), $\varepsilon_{\mathrm{S}}$ is the surface emissivity, $\sigma$ is the Stefan-Boltzmann constant $\left(\mathrm{W} \mathrm{m}^{-2} \mathrm{~K}^{-4}\right), T_{\mathrm{e}}$ and $T_{\mathrm{a}}$ are the equilibrium temperature $\left({ }^{\circ} \mathrm{C}\right)$ and air temperature $\left({ }^{\circ} \mathrm{C}\right)$ respectively, $v_{\mathrm{e}}^{*}$ is saturation vapour pressure (mbar) at $T_{\mathrm{e}}, v_{\mathrm{D}}^{*}$ is the saturation vapour pressure (mbar) at dew point temperature, $\lambda$ is the latent heat of vaporisation $\left(\mathrm{W}\right.$ day $\left.\mathrm{kg}^{-1}\right)$ and $\gamma p$ is a constant $\left(\mathrm{mbar}{ }^{\circ} \mathrm{C}^{-1}\right)$. Solving for $\mathrm{ET}_{\mathrm{Pot}}$ and $T_{\mathrm{e}}$ is an iterative process and guidelines are given in Sect. S7. A worked example is provided in Sect. S21.

\section{Estimating wet-environment areal evapotranspiration (ET Wet $_{\text {in Fig. 2). }}$}

Morton (1983b, p. 79) notes that the wet-environment areal evapotranspiration is the same as the conventional definition of potential evapotranspiration. To estimate the wet-environment areal evapotranspiration, Morton (1983a, Eq. 14) added a term $\left(b_{1}\right)$ to the Priestley-Taylor equation (see Sect. 2.1.3 for a discussion of Priestley-Taylor) to account for atmospheric advection as follows

$\mathrm{ET}_{\mathrm{Wet}}^{\mathrm{MO}}=\frac{1}{\lambda}\left\{b_{1}+b_{2} \frac{R_{\mathrm{ne}}}{\left(1+\frac{\gamma p}{\Delta_{\mathrm{e}}}\right)}\right\}$,

where $\mathrm{ET}_{\mathrm{Wet}}^{\mathrm{MO}}$ is the wet-environment areal evapotranspiration $\left(\mathrm{mm} \mathrm{day}^{-1}\right), R_{\mathrm{ne}}$ is the net radiation $\left(\mathrm{W} \mathrm{m}^{-2}\right)$ for the 


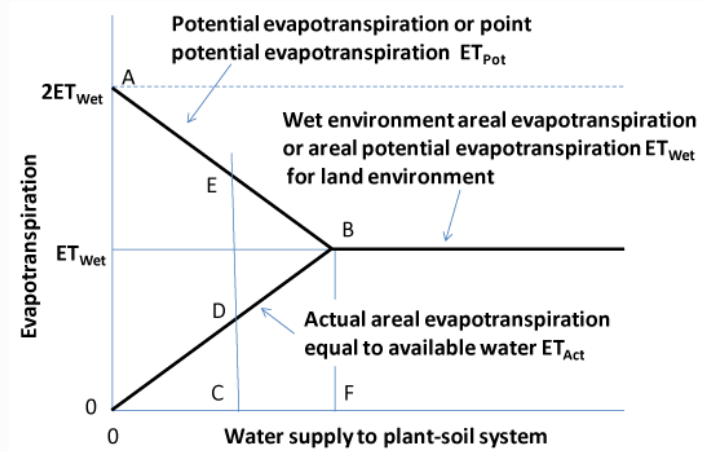

(a)

(b)

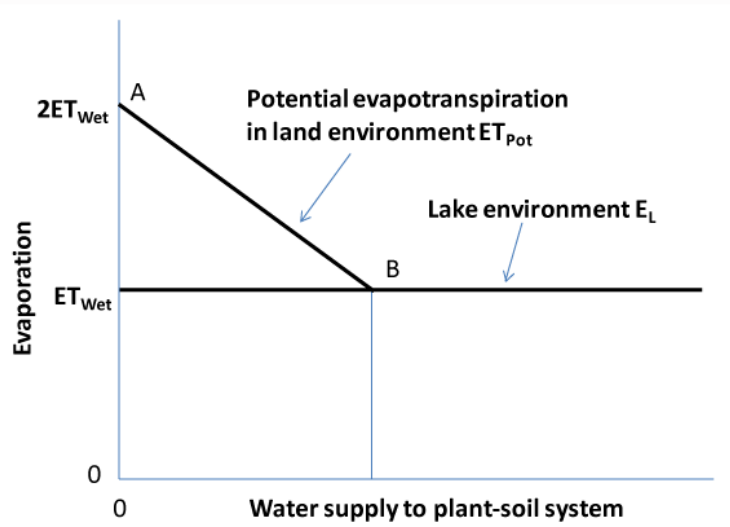

Fig. 2. Theoretical form of the complementary relationship for: (a) land environment and (b) lake environment (adapted from Morton, 1983a, Figs. 5 and 6). In Fig. 2a, at point B and beyond where there is adequate water supply (saturated soil moisture), actual evapotranspiration equals areal potential evapotranspiration. As the water supply reduces below B, evaporative energy not used in actual evapotranspiration remains as potential evapotranspiration as required by the complementary relationship (i.e. $\mathrm{ET}_{\mathrm{Act}}=2 \mathrm{ET}_{\mathrm{Wet}^{-}}$ ET Pot).

soil/plant surface at the equilibrium temperature $T_{\mathrm{e}}\left({ }^{\circ} \mathrm{C}\right), \gamma$ is the psychrometric constant $\left(\operatorname{mbar}{ }^{\circ} \mathrm{C}^{-1}\right), p$ is atmospheric pressure (mbar), $\Delta_{\mathrm{e}}$ is slope of the saturation vapour pressure curve $\left(\mathrm{mbar}{ }^{\circ} \mathrm{C}^{-1}\right)$ at $T_{\mathrm{e}}, b_{1}\left(\mathrm{~W} \mathrm{~m}^{-2}\right)$ and $b_{2}$ are the empirical coefficients, and the other symbols are as defined previously. Details to estimate $R_{\text {ne }}$ are given in Sect. S7.

\section{Estimating (actual) areal evapotranspiration (ET Act $_{\text {in Fig. 2). }}$}

Morton (1983a) formulated the CRAE model to estimate actual areal evapotranspiration $\left(\mathrm{ET}_{\mathrm{Act}}^{\mathrm{MO}}\right)\left(\mathrm{mm} \mathrm{day}^{-1}\right)$ from the complementary relationship (Eq. 15) as follows

$\mathrm{ET}_{\mathrm{Act}}^{\mathrm{MO}}=2 \mathrm{ET}_{\mathrm{Wet}}^{\mathrm{MO}}-\mathrm{ET}_{\text {Pot }}^{\mathrm{MO}}$,

$\mathrm{ET}_{\mathrm{Pot}}^{\mathrm{MO}}$ and $\mathrm{ET}_{\mathrm{Wet}}^{\mathrm{MO}}$ are estimated from Eqs. (16) and (17), and Eq. (18) respectively.
In the Morton (1983a) paper (Fig. 13), Morton compared estimates of actual areal evapotranspiration with waterbudget estimates for 143 river basins worldwide and found the monthly estimates to be realistic. Others have assessed various parts of the CRAE model. Based on a study of 120 minimally impacted basins in the US, Hobbins et al. (2001a, p. 1378) found that the CRAE model overestimated annual evapotranspiration by only $2.5 \%$ of the mean annual precipitation with $90 \%$ of values being within $5 \%$ of the water balance closure estimate of actual evapotranspiration. Szilagyi (2001), inter alia, checked how well WREVAP (incorporating the CRAE program) estimated values of incident global radiation at 210 sites and estimates of pan evaporation at 19 stations with measured values. The respective correlations were 0.79 (Fig. 3 of Szilagyi, 2001) and 0.87 (Fig. 4 of Szilagyi, 2001).

For application of the CRAE model accurate estimates of air temperature and relative humidity are required from a representative land-based location (Morton, 1986, p. 378). For CRAE, Morton (1983a, p. 28) suggested a 5-day limit as the minimum time step for analysis.

\section{CRWE model}

In Morton's (1983a) paper, he formulated and documented the CRAE model for land surfaces. In a second paper, Morton (1983b) converts CRAE to a complementary relationship lake evaporation which he designated as CRLE. However, in 1986 Morton (1986) introduced the complementary relationship wet-surface evaporation known as the CRWE model to estimate "lake-size wet surface evaporation" (Morton, 1986, p. 371), in other words, evaporation from shallow lakes. The evaporation from a shallow lake differs from the wet-environment areal evapotranspiration because the radiation absorption and vapour pressure characteristics between water and land surfaces are different (Morton, 1983b, p. 80) as documented in Table 2. It should also be noted that, for a lake, potential evaporation and actual evaporation will be equal but, for a land surface, actual evaporation will be less than potential evaporation, except when the surface is saturated (Morton, 1986, p. 81). Normally, land-based meteorological data would be used (Morton, 1983a, p. 70) but data measured over water has only a "relatively minor effect" on the estimate of lake evaporation (Morton, 1983b, p. 96).

In the 1983b paper, Morton (1983b, Eq. 11) introduced an equation (Eq. 23 herein) to deal with estimating evaporation from small lakes, farm dams and ponds.

\section{CRLE model}

In the CRLE (and the CRWE) model, a lake is defined as a water body so wide that the effect of upwind advection is negligible. In the Morton context, a deep lake is considered shallow if one is interested only in annual or mean annual 
evaporation (Morton, 1983b, p. 84) and the CRWE formulation would be used. Over an annual cycle there is no net change in the heat storage, although there is a phase shift in the seasonal evaporation, so that the sum of the seasonal lake evaporation approximately equals the annual estimate.

Morton's (1983b, Sect. 3) paper provides, inter alia, a routing technique which takes into account the effect of depth, salinity and seasonal heat changes on monthly lake evaporation. This is only approximate as seasonal heat changes in a lake should be based on the vertical temperature profiles which rarely will be available. In 1986, Morton changed the form of the routing algorithm outlined in Morton (1983b, Sect. 3) to a classical linear storage routing model (Morton, 1986, p. 376). This is the one we have adopted in the Fortran 90 listing of WREVAP (Sect. S20) and in the WREVAP worked example (Sect. S21).

Morton $(1979,1983 b)$ validated his approach for estimating lake evaporation against water budget estimates for ten major lakes in North America and East Africa. The average absolute percentage deviation between the model of lake evaporation and water budget estimates was $3.7 \%$ of the water budget estimates (Morton, 1979, p. 72).

Morton (1986, p. 378) notes that, because the complementary relationship takes into account the differences in surrounding, for the CRLE model it matters little where the meteorological measurements are made in relation to the lake; they can be land-based or from a floating raft.

Because routing of solar and water-borne energy is incorporated in the CRLE model, a monthly time step is adopted (Morton, 1983b, Sect. 9). Land-based meteorological data would normally be used (Morton, 1983b, p. 82) but as noted above data measured over water has only a minor effect on the estimate of lake evaporation (Morton, 1983b, p. 96; 1986, p. 378). Details of the application of Morton's procedures for estimating evaporation from a shallow lake, farm dam or deep lake are discussed in Sect. S7.

A worked example applying program WREVAP using a monthly time step is found in Sect. S21.

\subsubsection{Advection-aridity and like models}

Based on the complementary relationship (Eq. 15), Brutsaert and Strickler (1979, p. 445) proposed the original advection-aridity (AA) model in which they adopted the Penman equation (Eq. 4) for the potential evapotranspiration $\left(\mathrm{ET}_{\mathrm{Pot}}\right)$ and the Priestley-Taylor equation (Eq. 6) for the wetenvironment evapotranspiration $\left(\mathrm{ET}_{\mathrm{Wet}}\right)$ to estimate actual evaporation as follows

$E_{\mathrm{Act}}^{\mathrm{BS}}=\left(2 \alpha_{\mathrm{PT}}-1\right) \frac{\Delta}{\Delta+\gamma} \frac{R_{n}}{\lambda}-\frac{\gamma}{\Delta+\gamma} f\left(u_{2}\right)\left(v_{\mathrm{a}}^{*}-v_{\mathrm{a}}\right)$

where $E_{\text {Act }}^{\mathrm{BS}}$ is the actual evapotranspiration estimated by the Brutsaert and Strickler equation $\left(\mathrm{mm} \mathrm{day}^{-1} \equiv \mathrm{kg} \mathrm{m}^{-2}\right.$ day $\left.^{-1}\right), \alpha_{\mathrm{PT}}$ is the Priestley-Taylor coefficient, and the other symbols are as defined previously. In their analysis Brutsaert and Strickler (1979, Abstract) adopted a daily time step.

In a study of 120 minimally impacted basins in the United States, Hobbins et al. (2001a, Table 2) found that the Brutsaert and Strickler (1979) model underestimated actual annual evapotranspiration by $7.9 \%$ of mean annual precipitation, and for the same basins, Morton's (1983a) CRAE model overestimated actual annual evapotranspiration by only $2.4 \%$ of mean annual precipitation. Several modifications to the original AA model have been put forward. Hobbins et al. (2001b) reparameterized the wind function $f\left(u_{2}\right)$ on a monthly regional basis and recalibrated the PriestleyTaylor coefficient yielding small differences between computed evapotranspiration and water balance estimates. However, the regional nature of the wind function restricts the recalibrated model to the conterminous United States.

Alternatives to the advection-aridity model of Brutsaert and Strickler (1979) are the approach by Szilagyi (2007), amended by Szilagyi and Jozsa (2008); the Granger model (Granger, 1989b; Granger and Gray, 1989), which is not based on the complementary relationship; and the Han et al. (2011) modification of the Granger model. Details are presented in Sect. S8.

\section{Practical topics in estimating evaporation}

To address the practical issue of estimating evaporation one needs to keep in mind the setting of the evaporating surface along with the availability of meteorological data. The setting is characterised by several features: the meteorological conditions in which the evaporation is taking place, the water available for evaporation, the energy stored within the evaporating body, the advected energy due to water inputs and outputs from the evaporating water body, and the atmospheric advected energy.

In this paper, water availability refers to the water that is available at the evaporating surface. This will not be limiting for lakes, yet will likely be limiting under certain irrigation practices and, certainly at times, will be limiting for catchments in arid, seasonal tropical and temperate zones. For a global assessment of water-limited landscapes at annual, seasonal and monthly time steps see McVicar et al. (2012a; Fig. 1 and associated material). Stored energy in deep bodies of water, where thermal or salinity stratification can occur, may affect evaporation rates and needs to be addressed as does the energy in water inputs to and outputs from the water body. How atmospheric advected energy is dealt with in an analysis depends on the size of the evaporating body and the procedure adopted to estimate evaporation. In this context we need to heed the advice of McVicar et al. (2007b, p. 197) that a regional surface evaporating at its potential rate would modify the atmospheric conditions and, therefore, change the rate of local potential evaporation. For a large lake or a large irrigation area dry incoming wind will affect the 
upwind fringe of the area but the bulk of the area will experience a moisture-laden environment. On the other hand, for a small lake or farm dam, a small irrigation area or an irrigation canal in a dry region, the associated atmosphere will be minimally affected by the water body and the prevailing upwind atmosphere will be the driving influence on the evaporation rate.

In the following discussion, we assume that: (i) at-site daily meteorological data from an automatic weather station (AWS) are available; or (ii) meteorological data measured manually at the site and at an appropriate time interval are available; or (iii) at-site daily pan evaporation data are available. At some AWSs, hard-wired Penman or PenmanMonteith evaporation estimates are also available. Methods to estimate evaporation where meteorological data are not available are discussed in Sect. 4.3.

When incorporating estimates of lake evaporation into a water balance analysis of a reservoir and its related catchment, it is important to note that double counting will occur if the inflows to the reservoir are based on the catchment area including the inundated area and then an adjustment is made to the water balance by adding rainfall to and subtracting lake evaporation from the inundated area. The correct adjustment is the difference between evaporation prior to inundation and lake evaporation (see McMahon and Adeloye, 2005, p. 97 for a fuller explanation of this potential error).

\subsection{Deep lakes}

This paper does not address the measurement of evaporation from lakes but rather the estimation of lake evaporation by modelling. A helpful review article on the measurement and the calculation of lake evaporation is by Finch and Calver (2008).

In dealing with deep lakes (including constructed storages, reservoirs and large voids), three issues need to be addressed. First, the heat storage of the water body affects the surface energy flux and, because the depth of mixing varies in space and time and is rarely known, it is difficult to estimate changes at a short time step; typically, a monthly time step is adopted. Second, the effects of water advected energy needs to be considered. If the inflows to a lake are equivalent to a large depth of the lake area and their average temperatures are significantly different, advected energy needs to be taken into account (Morton, 1979, p. 75). Third, increased salinity reduces evaporation and, therefore, changes in lake salinity need to be addressed. Next, we explore three procedures for estimating evaporation from deep lakes.

\subsubsection{Penman model}

To estimate evaporation from a deep lake, the Penman estimate of evaporation, $E_{\mathrm{PenOW}}$, (Eq. 12) is a starting point. Water advected energy (precipitation, streamflow and groundwater flow into the lake) and heat storage in the lake are accounted for by the following equation recommended by Kohler and Parmele (1967, Eq. 12) and reported by Dingman (1992, Eqs. 7-37) as

$E_{\mathrm{DL}}=E_{\mathrm{PenOW}}+\alpha_{\mathrm{KP}}\left(A_{\mathrm{w}}-\frac{\Delta Q}{\Delta t}\right)$,

where $E_{\mathrm{DL}}$ is the evaporation from the deep lake (mm day $\left.^{-1}\right), E_{\text {PenOw }}$ is the Penman or open-surface water evaporation $\left(\mathrm{mm} \mathrm{day}^{-1}\right), \alpha_{\mathrm{KP}}$ is the proportion of the net addition of energy from water advection and storage used in evaporation during $\Delta t, A_{\mathrm{w}}$ is the net water advected energy during $\Delta t\left(\mathrm{~mm} \mathrm{day}^{-1}\right)$, and $\frac{\Delta Q}{\Delta t}$ is the change in stored energy expressed as a water depth equivalent $\left(\mathrm{mm} \mathrm{day}^{-1}\right)$. The latter three terms are complex and are set out in Sect. S10 along with details of the procedure.

Vardavas and Fountoulakis (1996, Fig. 4), using the Penman model, estimated the monthly lake evaporation for four reservoirs in Australia and found the predictions agreed satisfactorily with mean monthly evaporation measurements. Change in heat storage is based on the monthly surface water temperatures. Thus:

$E_{\mathrm{DL}}=\frac{\Delta}{\Delta+\gamma}\left(\frac{R_{\mathrm{n}}+\Delta H}{\lambda}\right)+\frac{\gamma}{\Delta+\gamma} E_{\mathrm{a}}$,

where $E_{\mathrm{DL}}$ is the evaporation from the deep lake (mm day $^{-1} \equiv \mathrm{kg} \mathrm{m}^{-2}$ day $\left.^{-1}\right), R_{\mathrm{n}}$ is the net radiation at the water surface $\left(\mathrm{MJ} \mathrm{m}^{-2}\right.$ day $\left.^{-1}\right), E_{\mathrm{a}}$ is the evaporation component $\left(\mathrm{mm} \mathrm{day}^{-1}\right)$ due to wind, $\Delta$ is the slope of the vapour pressure curve $\left(\mathrm{kPa}{ }^{\circ} \mathrm{C}^{-1}\right)$ at air temperature, $\gamma$ is the psychrometric constant $\left(\mathrm{kPa}^{\circ} \mathrm{C}^{-1}\right), \lambda$ is the latent heat of vaporization $\left(\mathrm{MJ} \mathrm{kg}^{-1}\right)$, and $\Delta H$ is the change in heat storage $\left(\mathrm{MJ} \mathrm{m}^{-2} \mathrm{day}^{-1}\right)$. We detail the Vardavas and Fountoulakis (1996) method in Sect. S10.

\subsubsection{Morton evaporation}

In Morton's WREVAP program, monthly evaporation from deep and shallow lakes can be estimated. As noted in Sect. 2.5.2, for annual evaporation estimates, there is no difference in magnitude between deep and shallow lake evaporation (see also Sacks et al., 1994, p. 331). In Morton's procedure, seasonal heat changes in deep lakes are incorporated through linear routing. Details are presented in Sect. S7. The data for Morton's WREVAP program are mean monthly air temperature, mean dew point temperature (or mean monthly relative humidity) and monthly sunshine hours as well as latitude, elevation and mean annual precipitation at the site. The broad computational steps are set out in Sect. S7 and details can be found in Appendix C of Morton (1983a). A Fortran 90 listing of a slightly modified version of the Morton WREVAP program is provided in Sect. S20 and a worked example is available in Sect. S21.

The complementary relationship lake evaporation model of Morton (1983b, 1986) and Morton et al. (1985) may be 
used to estimate lake evaporation directly. Comparing CRLE lake evaporation estimates with water budgets for 17 lakes worldwide, Morton (1986, p. 385) found the annual estimates to be within $7 \%$. In a lake study in Brazil, dos Reis and Dias (1998, Abstract) found the CRLE model estimated lake evaporation to within $8 \%$ of an estimate by the Bowen ratio energy budget method. Furthermore, Jones et al. (2001), using a water balance incorporating CRLE evaporation for three deep volcanic lakes in western Victoria, Australia, satisfactorily modelled water levels in the closed lakes system over a period exceeding $100 \mathrm{yr}$.

Some further comments on Morton's CRLE model are given in Sect. S7.

\subsubsection{Pan evaporation for deep lakes}

Dingman (1992, Sect. 7.3.6) implies that, through an application to Lake Hefner (US), Class-A pan evaporation data, appropriately adjusted for energy flux through the sides and the base of the pan, can be used to estimate daily evaporation from a deep lake. Based on the Lake Hefner study, Kohler notes that "annual lake evaporation can probably be estimated within 10 to $15 \%$ (on the average) by applying an annual coefficient to pan evaporation, provided lake depth and climatic regime are taken into account in selecting the coefficient" (Kohler, 1954).

In Australia, there was a detailed study of lake evaporation in the 1970s that resulted in two technical reports by Hoy and Stephens (1977, 1979). In these reports mean monthly pan coefficients were estimated for seven reservoirs across Australia and annual coefficients were provided for a further eight reservoirs. Values, which can vary between 0.47 and 2.19 seasonally and between 0.68 and 1.00 annually, are listed in the Tables S11 and S12.

Garrett and Hoy (1978, Table III) modelled annual pan coefficients based on a simple numerical lake model incorporating energy and vapour fluxes. The results show that for the seven reservoirs examined, the annual pan coefficients change little with lake depth.

\subsection{Shallow lakes, small lakes and farm dams}

For large shallow lakes, less than a meter or so in depth, where advected energy and changes in seasonal stored energy can be ignored, the Penman equation with the 1956 wind function or Morton's CRLE model (Morton, 1983a, b) may be used to estimate lake evaporation. The upwind transition from the land environment to the large lake is also ignored (Morton, 1983b).

Stewart and Rouse (1976) recommended the PriestleyTaylor model for estimating daily evaporation from shallow lakes. Based on summer evaporation of a small lake in Ontario, Canada, the monthly lake evaporation was estimated to within $\pm 10 \%$ (Stewart and Rouse, 1976, p. 628). GalleoElvira et al. (2010) found that incorporating a seasonal ad- vection component and heat storage into the Priestley-Taylor equation (Eq. 6) provided accurate estimates of monthly evaporation for a 0.24 ha water reservoir (maximum depth of $5 \mathrm{~m}$ ) in semi-arid southern Spain. Analytical details are given in Galleo-Elvira et al. (2010).

For shallow lakes, say less than $10 \mathrm{~m}$, in which heat energy should be considered, Finch (2001) adopted the Keijman (1974) and de Bruin (1982) equilibrium temperature approach which he applied to a small reservoir at Kempton Park, UK. The procedure adopted by Finch (2001) is described in detail in Sect. S11.

Finch and Gash (2002) provide a finite difference approach to estimating shallow lake evaporation. They argue the predicted evaporation is in excellent agreement with measurements (Kempton Park, UK) and closer than Finch's (2001) equilibrium temperature method.

Using a similar approach to Finch (2001) but based on Penman-Monteith rather than Penman, McJannet et al. (2008) estimated evaporation for a range of water bodies (irrigation channel, shallow and deep lakes) explicitly incorporating the equilibrium temperature. The method is described in detail in Sect. S11 and a worked example is available in Sect. S19.

McJannet et al. (2012) developed a generalised wind function that included lake area (Eq. 14) to be incorporated in the aerodynamic approach (Eq. 13). The equation is of limited use as the equilibrium (surface water) temperature needs to be estimated.

For small lakes and farm (and aesthetic) dams the increased evaporation at the upwind transition from a land environment may need to be addressed. Using an analogy of evaporation from a small dish moving from a dry fallow landscape downwind across an irrigated cotton field, Morton $(1983$, p. 78$)$ noted that the decreased evaporation from the transition into the irrigated area (analogous to a lake) was associated with decreased air temperature and increased humidity. Morton (1983b, Eq. 11) recommends the following equation be used to adjust lake evaporation for the upwind advection effects:

$E_{\mathrm{SLx}}=E_{\mathrm{L}}+\left(\mathrm{ET}_{\mathrm{p}}-E_{\mathrm{L}}\right) \frac{\ln \left(1+\frac{x}{C}\right)}{\frac{x}{C}}$,

where $E_{\mathrm{SLx}}$ is the average lake evaporation $\left(\mathrm{mm} \mathrm{day}^{-1}\right)$ for a crosswind width of $x \mathrm{~m}, E_{\mathrm{L}}$ is lake evaporation (mm day $^{-1}$ ) large enough to be unaffected by the upwind transition, i.e. well downwind of the transition, $\mathrm{ET}_{\mathrm{P}}$ is the potential evaporation $\left(\mathrm{mm} \mathrm{day}^{-1}\right)$ of the land environment, and $C$ is a constant equal to $13 \mathrm{~m}$.

Morton (1986, p. 379) recommends that $\mathrm{ET}_{\mathrm{P}}$ be estimated as the potential evaporation in the land environment as computed from CRWE and the lake evaporation $E_{\mathrm{L}}$ be computed from CRLE. ET $T_{P}$ could also be estimated using PenmanMonteith (Eq. 5) with appropriate parameters for the upwind landscape and the Penman open-water equation (Eq. 12) could be used to estimate $E_{\mathrm{L}}$. 


\subsection{Catchment water balance}

The traditional method to estimate annual actual evaporation for an unimpaired catchment is through a simple water balance:

$\overline{\mathrm{ET}}_{\mathrm{Act}}=\bar{P}-\bar{Q}-\bar{G}_{\mathrm{DS}}-\Delta S$,

where $\overline{\mathrm{ET}}_{\mathrm{Act}}$ is the mean annual actual catchment evaporation $\left(\mathrm{mm} \mathrm{yr}^{-1}\right), \bar{P}$ is the mean annual catchment precipitation $\left(\mathrm{mm} \mathrm{yr}^{-1}\right), \bar{Q}$ is the mean annual runoff $\left(\mathrm{mm} \mathrm{yr}^{-1}\right)$, $\bar{G}_{\mathrm{DS}}$ is the deep seepage $\left(\mathrm{mm} \mathrm{yr}^{-1}\right)$, and $\Delta S$ is the change in soil moisture storage over the analysis period $\left(\mathrm{mm} \mathrm{yr}^{-1}\right)$. At an annual time step, $\Delta S$ is assumed zero (see Wilson, 1990, p. 44). Often deep seepage is also assumed to be negligible. Based on an extensive review of the recharge literature in Australia, Petheram et al. (2002) developed several empirical relationships between recharge and precipitation. A more comprehensive and larger Australian data set was analysed by Crosbie et al. (2010) who developed relationships between average annual recharge and mean annual rainfall for combinations of soil and vegetation types. A considerably larger global study, but only for semi-arid and arid regions, was conducted by Scanlon et al. (2006) who also developed several generalised relationships relating recharge to mean annual precipitation. These generalised relationships could be used if deep seepage was considered important and relevant data were available.

An alternative and more direct method is to estimate actual monthly catchment evaporation either by Morton's CRAE model (Sect. 2.5.2) or one of the advection-aridity or likemodels (discussed in Sect. 2.5.3). An interesting comparison of monthly estimates of catchment evaporation by the Morton and Penman methods was carried out by Doyle (1990) for the Shannon catchment in Ireland. In the Penman approach when water was not freely available, actual evaporation was estimated using Thornthwaite's model of evaporation inhibition (Doyle, 1990, Fig. 1). The study examined the strengths and weaknesses of both approaches and concluded that the Morton approach is a valuable alternative to the empiricism introduced through using the Thornthwaite algorithm to convert potential evaporation to actual evaporation, but Doyle also noted the strong degree of empiricism in accounting for advection in the Morton approach.

A very different approach to estimating mean annual actual evaporation is based on the Budyko formulation (Budyko, 1974), which is a balance between the energy and the water availability in a catchment. Equations that fall into this category include: Schreiber (Schreiber, 1904), Ol'dekop (Ol'dekop, 1911), generalised Turc-Pike (Turc, 1954; Pike, 1964; Milly and Dunne, 2002), Budyko (Budyko, 1974), Fu (Fu, 1981; Zhang et al., 2004; Yang et al., 2008), Zhang 2parameter model (Zhang et al., 2001), and a linear model (Potter and Zhang, 2009), and have the following simple form:

$\bar{E}_{\text {act }}=\bar{P} f(\phi)$,

where $\bar{E}_{\text {act }}$ is mean annual actual catchment evaporation $\left(\mathrm{mm} \mathrm{yr}^{-1}\right), \bar{P}$ is mean annual catchment precipitation $(\mathrm{mm}$ $\mathrm{yr}^{-1}$ ) and $\varphi$ is the aridity index defined as $\bar{E}_{\text {pot }} / \bar{P}$ where $\bar{E}_{\text {pot }}$ is the mean annual catchment potential evapotranspiration $\left(\mathrm{mm} \mathrm{yr}^{-1}\right)$. The available functions $f(\varphi)$, based on the references above, are listed in Table 3. The Zhang function (Zhang et al., 2001, Eq. 8) allows long-term estimates of actual evaporation for grasslands and forests to be estimated. Donohue et al. (2007, 2010b, 2011) and Zhang and Chiew (2011) found that the accuracy of estimates of long-term actual evaporation can be improved by incorporating vegetation types and dynamics into the Budyko formulations. Within Budyko's steady-state hydroclimatological framework, current research using a variety of approaches aims to better account for sub-annual processes including: (i) rooting depth and soil store dynamics (Donohue et al., 2012; Feng et al., 2012; Szilagyi and Jozsa, 2009), and (ii) water storage, including groundwater, dynamics (Istanbulluoglu et al., 2012; Wang, 2012; Zhang et al., 2008).

\subsection{Daily and monthly rainfall-runoff modelling}

Most rainfall-runoff models at a daily or monthly time step (e.g. Sacramento (Burnash et al., 1973), Système Hydrologique Européen (SHE) (Abbott et al., 1986a, b), AWBM (Australian water balance model, Boughton, 2004), SIMHYD (Chiew et al., 2002)) require as input an estimate of potential evaporation in order to compute actual evaporation. In these models typically:

$\mathrm{ET}_{\mathrm{Act}}=f\left(\mathrm{SM}, \mathrm{ET}_{\mathrm{PET}}\right)$,

where $\mathrm{ET}_{\mathrm{Act}}$ is the estimated actual daily evaporation (mm day $^{-1}$ ), SM is a proxy soil moisture level for the given day $(\mathrm{mm})$, and $\mathrm{ET}_{\mathrm{PET}}$ is the daily potential evaporation $(\mathrm{mm}$ day $^{-1}$ ). In arid catchments and for much of the time in temperate catchments, actual evaporation will be limited by soil moisture availability with potential evaporation becoming more important in wet catchments where soil moisture is not limiting or "equitant" catchments that straddle the energylimited/water-limited divide for parts of the year (McVicar et al., 2012b). Generally, one of four approaches has been used to estimate potential evaporation in rainfall-runoff modelling: Penman-Monteith and variations (Beven, 1979; Watson et al., 1999), Priestley-Taylor and variations (Raupach et al., 2001; Zhang et al., 2001), Morton's procedure (Chiew et al., 1993; Siriwardena et al., 2006), and pan evaporation (Zhao, 1992; Lidén and Harlin, 2000; Abulohom et al., 2001; McVicar et al., 2007a; Welsh, 2008; Zhang et al., 2008). These approaches are discussed in detail in Sect. S13.

In detailed water balances, interception and, therefore, interception evaporation are key processes. Two important interception models are the Rutter (Rutter et al., 1971, 1975) 
Table 3. Functional relationships for the Budyko-like relationships ( $\varphi$ is the aridity index, $e$ is the Turc-Pike parameter, $f$ is the Fu parameter, $w$ is the plant available water coefficient, and $c$ is a parameter in the linear model).

\begin{tabular}{lll}
\hline Model & Model details & Reference \\
\hline Schreiber & $F(\varphi)=[1-\exp (-\varphi)]$ & Schreiber (1904) \\
Ol'dekop & $F(\varphi)=\varphi \tanh \left(\varphi^{-1}\right)$ & Ol'dekop (1911) \\
Generalised Turc-Pike & $F(\varphi)=\left(1+\varphi^{-e}\right)^{\frac{-1}{e}}$ For the Turc-Pike model, $e=2$ & Milly and Dunne (2002); Turc (1954); Pike (1964) \\
Budyko & $F(\varphi)=\left\{\varphi[1-\exp (-\varphi)] \tanh \left(\varphi^{-1}\right)\right\}^{0.5}$ & Budyko (1974) \\
Fu-Zhang & $F(\varphi)=1+\varphi-\left[1+(\varphi)^{f}\right]^{f^{-1}}$ & Fu (1981); Zhang et al. (2004) \\
Zhang 2-parameter model & $F(\varphi)=(1+w \varphi)\left(1+w \varphi+\varphi^{-1}\right)^{-1}$ & Zhang et al. (2001) \\
Linear model & $F(\varphi)=c \varphi$ & Potter and Zhang (2009) \\
\hline
\end{tabular}

and the Gash (Gash, 1979) models. The Rutter model incorporates the Penman (1956, Eq. 8b) equation to estimate potential evaporation while the Penman-Monteith equation is the evaporation model used in the Gash model. Details are provided in Sect. S14. Readers are referred to a recent and comprehensive review by Muzylo et al. (2009), who addressed the theoretical basis of 15 interception models including their evaporation components, identified inadequacies and research questions, and noted there were few comparative studies about uncertainty in field measurements and model parameters.

\subsection{Irrigation areas}

Internationally, the FAO-56 reference crop evapotranspiration equation (Eq. 8) which is the Penman-Monteith equation for specific reference conditions, is the accepted procedure to estimate reference crop evapotranspiration $\left(\mathrm{ET}_{\mathrm{RC}}\right)$. It is assumed that both water advected energy and heat storage effects can be ignored (Dingman, 1992, p. 299). Reference crop evapotranspiration is usually different to the actual evapotranspiration of a specific crop under normal growing conditions. To estimate crop evapotranspiration under standard conditions (disease-free, well-fertilised crop, grown in large fields, under optimum soil water conditions and achieving full yield) a crop coefficient $\left(K_{\mathrm{c}}\right)$ is applied to $\mathrm{ET}_{\mathrm{RC}}$. Values of $K_{\mathrm{c}}$ are a function of crop characteristics and soil moisture conditions. Because of the large number of crops and potential conditions, readers are referred to the details in Allen et al. (1998, Chapters 6 and 7).

The FAO-56 reference crop method (Allen et al., 1998, Chapter 4) (Sect. 2.2) for computing reference crop evapotranspiration is a two-step procedure and, according to Shuttleworth and Wallace (2009), humid conditions are a prerequisite for its applicability (Shuttleworth and Wallace, 2009, p. 1905). In irrigation regions like Australia that are arid and windy, Shuttleworth and Wallace (2009) recommend the FAO-56 method be replaced by a one-step method known as the Matt-Shuttleworth procedure in which the crop coef- ficients are replaced by their equivalent surface resistances. Some more details are set out in Sect. S5.

For small irrigation areas in dry regions, atmospheric advection may need to be taken into account. The significance of this situation, which is known as the "oasis effect", is illustrated in Fig. 3 (adapted from Allen et al., 1998, Fig. 46). In this example, some of the sensible heat generated from the adjacent dry land is advected into the irrigation area downwind. As observed in the figure, the effect can be important. For the climate and vegetation conditions examined by Allen et al. (1998) for a $100 \mathrm{~m}$ wide area of irrigation in dry surroundings, the crop coefficient of $K_{\mathrm{c}}$ would be increased by a little more than $30 \%$, and for a $300 \mathrm{~m}$ wide area, the increase is $20 \%$. However, as cautioned by Allen et al. (1998, p. 202) care needs to be exercised in adopting these sorts of adjustments.

Estimating actual crop evapotranspiration under nonoptimum soil-water conditions is not straightforward. Details are set out in Allen et al. (1998, Chapter 8). Sumner and Jacobs (2005, Sect. 7) found that Penman-Monteith and Priestley-Taylor models could reproduce actual evapotranspiration from a non-irrigated crop but both models required local calibration.

\subsection{Evaporation from lakes covered by vegetation}

There is an extensive body of literature addressing the question of evaporation from lakes covered by vegetation. Abtew and Obeysekera (1995, Table 1) summarise 19 experiments which, overall, show that the transpiration of macrophytes is greater than open-surface water evaporation. However, most experiments were not in situ experiments. On the other hand, Mohamed et al. (2008, Table 2) list the results of 11 in situ studies (mainly eddy correlation or Bowen ratio procedures) in which wetland evaporation is, overall, less than opensurface water. These issues are discussed in Sect. S12 and a comparison is provided (Table S7) of equations to estimate evaporation from lakes covered by vegetation. 


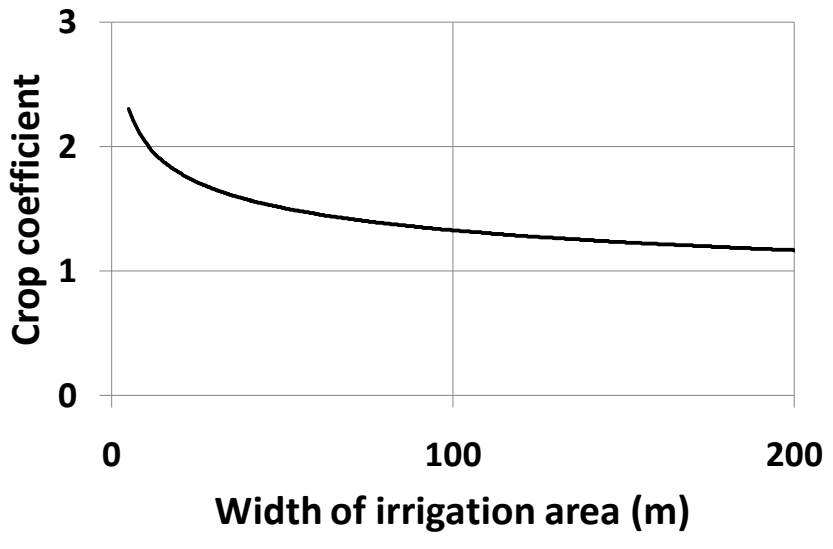

Fig. 3. Effect of an "oasis" environment on irrigation water requirement (adapted from Allen et al., 1998). In this example, the irrigation area is surrounded by dry land and the decreasing crop coefficient indicates the reduction in evaporation as one moves away from the edge of the irrigation area.

\subsection{Bare soil evaporation}

Numerous writers (e.g. Ritchie, 1972; Boesten and Stroosnijder, 1986; Katul and Parlange, 1992; Kondo and Saigusa, 1992; Yunusa et al., 1994; Daaman and Simmonds, 1996; Qiu et al., 1998; Snyder et al., 2000; Mutziger et al., 2005; Konukcu, 2007) have discussed bare soil evaporation. Most methods require field data in addition to the meteorological data to estimate evaporation from an initially wet surface. Ritchie (1972, p. 1205) proposed a two-stage model, following Philip (1957), for estimating bare soil evaporation: Stage1 evaporation, which is atmosphere-controlled (that is, the soil has adequate moisture so that the moisture can move to the surface at a rate that does not impede evaporation), and Stage-2 evaporation, which is soil-moisture controlled. It is noted that McVicar et al. (2012a, p. 183) observed that Stage1 evaporation is more appropriately described as energylimited evaporation and Stage-2 as water-limited evaporation. Salvucci (1997) developed this approach further. Details are provided in Sect. S15.

\subsection{Groundwater evaporation}

Luo et al. (2009) noted that a significant amount of groundwater evaporates from irrigated crops and phreatophytes as a result of shallow groundwater tables. After reviewing the literature, they field-tested four widely used groundwater relationships (linear, linear segment, power and exponential) that relate evapotranspiration to the depth to the groundwater table and the maximum evapotranspiration. The authors concluded that so long as appropriate parameters are chosen, the four functions can be used to describe the relationship between evapotranspiration from groundwater and water table depth. Readers are referred to Luo et al. (2009) for details.

\subsection{Guidelines in estimating monthly evaporation}

This section provides a brief justification of Table 4, which is a succinct summary of the preferred options for estimating monthly evaporation for the set of practical topics discussed in Sect. 3. In the table we have adopted four levels of guidelines: (i) preferred; (ii) acceptable; (iii) not preferred or insufficient field testing; and (iv) not recommended. Each assessment in Table 4 is based on two major criteria: (i) whether the method is an empirical procedure and, therefore, of limited value, or one based on a theoretical analysis and, therefore, more widely applicable; and (ii) whether or not the procedure has been independently tested over the range of climates and conditions for which it was developed. Other aspects of relevance, but of less importance, include consideration of particular features, for example modelling heat storage, need for model calibration, potential to produce incorrect answers, and degree of adoption by the scientific community. Each assessment is informed by the information summarised in the paper and in the supplementary materials along with the authors' personal experiences in applying or reviewing evaporation estimation procedures. Analysts using the table as a basis for choosing a specific procedure should be aware of the inadequacies of the procedures which are discussed in the relevant sections and in the supplementary material. Some comments on several of the assessments follow.

For deep lakes, the Morton (1986) method is the preferred approach because it has a theoretical background and the evaporation estimates have been widely and independently tested. The Kohler and Parmele (1967) and the Vardavas and Fountoulakis (1996) approaches for estimating deep lake evaporation are theoretically based and they both take into account heat storage effects. Although no independent testing was identified for either procedure, they are considered acceptable. Pan coefficients are required to apply evaporation pan data to estimating deep lake evaporation. These are available for selected reservoirs (Hoy and Stephens, 1977, 1979), but there appears to be little consistency in their monthly values. For this reason in Table 4 we adopt the "not preferred" guideline for pan coefficients.

For shallow lakes, less than $2 \mathrm{~m}$ depth, Penman (1956) is the preferred approach whereas for deeper lakes Morton's (1983a) CRWE model is preferred. Both models are based on theoretical analysis and have been subject to extensive field tests. Based on theoretical analysis, equilibrium temperature methods of Finch (2001) and McJannet et al. (2008) are acceptable along with the finite difference procedure of Finch and Gash (2002). As well as we can assess, none of these procedures have been independently tested. We acknowledge that pan evaporation data are widely used to estimate shallow lake evaporation, but we have adopted the "not preferred" guideline on the basis that reliable local pan coefficients are often not available. 
Table 4. Practical application in estimating monthly evaporation (This summary is based on models described in the paper and Supplement except those techniques that are discussed in Sect. S9). $\checkmark \checkmark \checkmark$ preferred; $\checkmark \checkmark$ acceptable; $\checkmark$ not preferred or insufficient field testing; X not recommended.

\begin{tabular}{|c|c|c|c|c|c|c|c|}
\hline & Application, & $\left.\mathrm{ET}_{\text {type }}\right)$, Sect. & & & & & \\
\hline Model, (Reference), Sect. & $\begin{array}{l}\text { Deep lakes } \\
\left(\mathrm{ET}_{\mathrm{act}}\right), 3.1\end{array}$ & $\begin{array}{l}\text { Shallow lakes } \\
\left(\mathrm{ET}_{\mathrm{act}}\right), 3.2\end{array}$ & $\begin{array}{c}\text { Catchment } \\
\text { water balance } \\
\left(\mathrm{ET}_{\mathrm{act}}\right), 3.3\end{array}$ & $\begin{array}{l}\text { Estimating crop } \\
\text { requirements } \\
\left(\mathrm{ET}_{\mathrm{act}}\right), 3.5\end{array}$ & $\begin{array}{l}\text { Lakes with } \\
\text { vegetation } \\
\left(\mathrm{ET}_{\mathrm{act}}\right), 3.6\end{array}$ & $\begin{array}{c}\text { Bare soil } \\
\text { evaporation } \\
\left(\mathrm{ET}_{\mathrm{act}}\right), 3.7\end{array}$ & $\begin{array}{c}\text { Rainfall-runoff } \\
\text { modelling } \\
\left(\mathrm{ET}_{\text {pot }}\right), 3.4\end{array}$ \\
\hline $\begin{array}{l}\text { Penman 1956, (Penman, 1956), } \\
\text { 2.4.1 }\end{array}$ & $\mathrm{X}$ & $\checkmark \checkmark \checkmark<2 \mathrm{~m}^{*}$ & $\mathrm{X}$ & $\mathrm{X}$ & $\mathrm{X}$ & $\mathrm{X}$ & $\checkmark \checkmark$ \\
\hline $\begin{array}{l}\text { Penman plus Kohler and } \\
\text { Parmele, (Kohler and Parmele, } \\
\text { 1967), 3.1.1 }\end{array}$ & $\checkmark \checkmark$ & $\mathrm{X}$ & $\mathrm{X}$ & $\mathrm{X}$ & $\mathrm{X}$ & $\mathrm{X}$ & $\mathrm{X}$ \\
\hline $\begin{array}{l}\text { Penman plus Vardavas- } \\
\text { Fountoulakis, (Vardavas and } \\
\text { Fountoulakis, 1996), 3.1.1 }\end{array}$ & $\checkmark \checkmark$ & $\mathrm{X}$ & $\mathrm{X}$ & $\mathrm{X}$ & $\mathrm{X}$ & $\mathrm{X}$ & $\mathrm{X}$ \\
\hline $\begin{array}{l}\text { Penman based on equilibrium } \\
\text { temperature, (Finch, 2001), } 3.2\end{array}$ & $\mathrm{X}$ & $\checkmark \checkmark$ & $\mathrm{X}$ & $\mathrm{X}$ & $\mathrm{X}$ & $\mathrm{X}$ & $\mathrm{X}$ \\
\hline $\begin{array}{l}\text { Penman-Monteith, (Monteith, } \\
\text { 1965), 2.1.2 }\end{array}$ & $\mathrm{X}$ & $\mathrm{X}$ & $\mathrm{X}$ & $\checkmark$ & $\mathrm{X}$ & $\mathrm{X}$ & $\checkmark \checkmark$ \\
\hline $\begin{array}{l}\text { FAO-56 Ref. crop, (Allen et al., } \\
\text { 1998), } 2.2\end{array}$ & $\mathrm{X}$ & $\mathrm{X}$ & $\mathrm{X}$ & $\checkmark \checkmark \checkmark$ (humid) & $\mathrm{X}$ & $\mathrm{X}$ & $\mathrm{X}$ \\
\hline $\begin{array}{l}\text { Matt-Shuttleworth, (Shuttle- } \\
\text { worth and Wallace, 2009), } \\
3.5\end{array}$ & $\mathrm{X}$ & $\mathrm{X}$ & $\mathrm{X}$ & $\checkmark \checkmark($ windy, semi-arid) & $\mathrm{X}$ & $\mathrm{X}$ & $\mathrm{X}$ \\
\hline $\begin{array}{l}\text { Weighted Penman-Monteith, } \\
\text { (Wessel and Rouse, 1994), } 3.6\end{array}$ & $\mathrm{X}$ & $\mathrm{X}$ & $\mathrm{X}$ & $\mathrm{X}$ & $\checkmark$ & $\mathrm{X}$ & $\mathrm{X}$ \\
\hline $\begin{array}{l}\text { Penman-Monteith based on equi- } \\
\text { librium temperature, (McJannet } \\
\text { et al., 2008), } 3.2\end{array}$ & $\checkmark \checkmark$ & $\checkmark \checkmark$ & $\mathrm{X}$ & $\mathrm{X}$ & $\mathrm{X}$ & $\mathrm{X}$ & $\mathrm{X}$ \\
\hline $\begin{array}{l}\text { Priestley-Taylor, (Priestley and } \\
\text { Taylor, 1972), 2.1.3 }\end{array}$ & $\mathrm{X}$ & $\mathrm{X}$ & $\mathrm{X}$ & $\mathrm{X}$ & $\mathrm{X}$ & $\mathrm{X}$ & $\checkmark \checkmark$ \\
\hline $\begin{array}{l}\text { Morton, (Morton, 1983a, 1986), } \\
\text { 2.5.2 }\end{array}$ & $\checkmark \checkmark \checkmark$ & $\checkmark \checkmark \checkmark$ & $\checkmark \checkmark$ & $\mathrm{X}$ & $\mathrm{X}$ & $\mathrm{X}$ & $\checkmark \checkmark$ \\
\hline $\begin{array}{l}\text { Advection-aridity, (Brutsaert and } \\
\text { Strickler, 1979), 2.5.3 }\end{array}$ & $\mathrm{X}$ & $\mathrm{X}$ & $\checkmark$ & $\mathrm{X}$ & $\mathrm{X}$ & $\mathrm{X}$ & $\mathrm{X}$ \\
\hline $\begin{array}{l}\text { Szilagyi-Jozsa, (Szilagyi and } \\
\text { Jozsa, 2008), 2.5.3 }\end{array}$ & $\mathrm{X}$ & $\mathrm{X}$ & $\checkmark$ & $\mathrm{X}$ & $\mathrm{X}$ & $\mathrm{X}$ & $\mathrm{X}$ \\
\hline $\begin{array}{l}\text { Granger-Gray, (Granger, 1989b; } \\
\text { Granger and Gray, 1989), 2.5.3 }\end{array}$ & $\mathrm{X}$ & $\mathrm{X}$ & $\checkmark$ & $\mathrm{X}$ & $\mathrm{X}$ & $\mathrm{X}$ & $\mathrm{X}$ \\
\hline $\begin{array}{l}\text { Budyko-like models, (Budyko, } \\
\text { 1974; Potter and Zhang, 2009), } \\
3.3\end{array}$ & $\mathrm{X}$ & $\mathrm{X}$ & $\checkmark \checkmark($ annual $)$ & $\mathrm{X}$ & $\mathrm{X}$ & $\mathrm{X}$ & $\mathrm{X}$ \\
\hline $\begin{array}{l}\text { Lake finite-difference model, } \\
\text { (Finch and Gash, 2002), } 3.2\end{array}$ & $\checkmark$ & $\checkmark \checkmark$ & $\mathrm{X}$ & $\mathrm{X}$ & $\mathrm{X}$ & $\mathrm{X}$ & $\mathrm{X}$ \\
\hline $\begin{array}{l}\text { Salvucci for bare soil, (Salvucci, } \\
\text { 1997), } 3.7\end{array}$ & $\mathrm{X}$ & $\mathrm{X}$ & $\mathrm{X}$ & $\mathrm{X}$ & $\mathrm{X}$ & $\checkmark$ & $\mathrm{X}$ \\
\hline $\begin{array}{l}\text { Class-A pan evaporation or Pen- } \\
\text { Pan, (Rotstayn et al., 2006), } 2.3\end{array}$ & $\checkmark$ & $\checkmark$ & $\mathrm{X}$ & $\checkmark$ & $\mathrm{X}$ & $\mathrm{X}$ & $\checkmark \checkmark$ \\
\hline
\end{tabular}

* Based on Monteith (1981, p. 9) and others (see Sect. S11), we suggest that Penman (1956) be not used for lakes greater than $2 \mathrm{~m}$ in depth. 
To estimate the actual monthly evaporation component for catchment water balance studies, Morton's (1983a) CRAE model is acceptable. It is not a preferred method because the parameters $f_{\mathrm{Z}}, b_{1}$ and $b_{2}$ were required to be calibrated for the Australian landscape (see Sect. S7). Both the Brutsaert and Strickler (1979) and Szilagyi and Jozsa (2008) models have theoretical backgrounds and have been tested mainly against Morton (1983a). Both procedures can generate negative values of actual evaporation and are not preferred.

To estimate crop water requirements in humid regions, FAO-56 reference crop (Allen et al., 1998) is widely adopted and preferred. However, for windy semi-arid regions, the Matt-Shuttleworth model (Shuttleworth and Wallace, 2009) is acceptable, noting that it has not undergone extensive independent testing. Again, we do not advise the evaporation pan approach because reliable local pan coefficients are not always readily available.

There are no preferred procedures for lakes with vegetation and bare soil evaporation. The major issue here is that there is little evidence in the literature of adequate testing of the methodologies.

Rainfall-runoff modelling requires potential evaporation as input and the selection of an adequate potential evaporation model is more important in energy-limited catchments, where soil moisture is readily available, than in waterlimited catchments. From a literature review, we regard several models as acceptable for this application - PenmanMonteith (Monteith, 1965), Priestley-Taylor (Priestley and Taylor, 1972), Morton (Morton, 1983a), and evaporation pan. Each has been applied on several occasions. These models are acceptable provided they are used as input during calibration of the rainfall-runoff model. To this list we add Penman (Penman, 1948, 1956), although its use in rainfallrunoff modelling has been generally restricted to estimating interception evaporation.

In practice, analysts must take several issues into consideration in the selection of the most appropriate option to estimate monthly actual or potential evaporation. The guidelines presented in Table 4 are predominantly based on the strength of the theoretical basis of the method and the results of testing. These are important characteristics that should influence the selection of an appropriate method. However, amongst other things, analysts must also consider the availability of the input data and the effort required to generate the monthly evaporation estimates. A summary of the data required by each method is given in Table 1 and Sect. 4.3 discusses approaches to estimate evaporation without at-site data. To our knowledge, there are no studies that have compared the relative accuracy of these methods when the data inputs are based on spatial interpolation or modelling. The effort required to generate monthly evaporation estimates varies between the methods available and, in some situations, it may be appropriate for an analyst to adopt a simpler, but less preferred method.

\section{Outstanding issues}

Within the context of this paper we have identified six issues that require discussion: (i) hard-wired potential evaporation estimates at AWSs; (ii) estimating evaporation without wind data; (iii) estimating evaporation without at-site data; (iv) dealing with a climate change environment: increasing annual air temperature but decreasing pan evaporation rates; (v) daily meteorological data average over $24 \mathrm{~h}$ or day-light hours only; and (vi) finally, uncertainty in evaporation estimates.

\subsection{Hard-wired evaporation estimates}

Some commercially available AWSs, in addition to providing values of the standard climate variables, output an estimate of Penman evaporation or Penman-Monteith evaporation. For practitioners, this will probably be the data of choice rather than recomputing Penman or Penman-Monteith evaporation estimates from basic principles. However, users need to understand the methodology adopted and check the values of the parameters and functions (e.g. albedo, wind function, $r_{\mathrm{a}}$ and $r_{\mathrm{s}}$ ) used in the AWS evaporation computation.

\subsection{Estimating potential evaporation without wind data}

Many countries do not have access to historical wind data to compute potential evaporation. In rainfall-runoff modelling in which potential evaporation estimates are required, several researchers (Jayasuria et al., 1988, 1989; Chiew and McMahon, 1990) overcame this situation by using Morton's algorithms (Morton, 1983a, b) (Sect. 2.5.2), which do not require wind information. (The basis of Morton's approach is discussed in Sect. S7.) In developing a water balance model for three volcanic crater lakes in western Victoria, Jones et al. (1993) successfully tested Morton's CRLE model (Morton et al., 1985) using independent lake level data to estimate actual lake evaporation using air and dew point temperatures and sunshine hours or global radiation. Valiantzas (2006) developed two empirical equations to provide approximate estimates of Penman's open-surface water evaporation and reference crop evaporation without wind data. Details are set out in Sects. S4 and S5. Another approach to estimating potential evaporation without wind data is the modified Hargreaves procedure described in Sect. S9.

\subsection{Estimating potential evaporation without at-site data}

Where at-site meteorological or pan evaporation data are unavailable, it is recommended that evaporation estimates be based on data from a nearby weather station that is considered to have similar climate and surrounding vegetation conditions to the site in question. This would mean that both stations would have similar elevation and would be exposed to similar climatic features. 
In many parts of the world an alternative approach is to use outputs from spatial interpolation and from spatial modelling (Sheffield et al., 2006; McVicar et al., 2007b; VicenteSerrano et al., 2007; Thomas, 2008; Donohue et al., 2010a; Weedon et al, 2011). However, sometimes this cannot be achieved as proximally located meteorological stations do not exist. If seeking an estimate of evaporation for a large area (e.g. a catchment or an administrative region) then using gridded output is required. Details for Australia are provided in Sect. S1.

Errors in lake evaporation estimates introduced by transposed data were studied using an energy budget by Rosenberry et al. (1993) for a lake in Minnesota, United States, from 1982 to 1986 . Their key conclusions are:

1. Replacing raft-based air temperature or humidity data with those from a land-based near-shore site affected computed estimates of annual evaporation between $+3.7 \%$ and $-3.6 \%$ (averaged $-1.2 \%$ ).

2. Neglecting heat transfer from the bottom sediments to the water resulted in an increase in lake evaporation of $+7 \%$.

3. For this local climate, lake shortwave solar radiation, air temperature and atmospheric vapour pressure with values from a site $110 \mathrm{~km}$ away resulted in errors of $+6 \%$ to $+8 \%$.

\subsection{Dealing with a climate change environment: increasing annual temperature but decreasing pan evaporation}

Based on analysis of regions, across seven countries, with more than 10 pan evaporation stations, Roderick et al. (2009a, Table 1) reported negative trends in pan evaporation measures over the last 30 to $50 \mathrm{yr}$. Recently, McVicar et al. (2012a, Table 5) showed that declining evaporative demand, as measured by pan evaporation rates, was globally widespread. In their review of 55 studies reporting pan evaporation trends, the average trend was $-3.19 \mathrm{~mm} \mathrm{yr}^{-2}$. Reductions over the past $40 \mathrm{yr}$ have also been observed in Australia (Roderick and Farquhar, 2004; Kirono and Jones, 2007; Jovanovic et al., 2008) and in China (Liu et al., 2004; Cong et al., 2009).

These reductions imply that there has been a decline in atmospheric evaporative demand as measured by pan evaporation (Petersen et al., 1995), which is in contrast to the increased air temperatures that have been observed during the same period (Hansen et al., 2010). Roderick et al. (2009b, Sect. 2.3) suggest that the decline in evaporative demand is due to increased cloudiness and reduced wind speeds and, for the Indian region, Chattopadhyay and Hulme (1997) suggested that relative humidity was also a factor. After an extensive literature review, Fu et al. (2009) concluded that more investigations are required to understand fully global evaporation trends. McVicar et al. (2012a, Table 7) demonstrated that broad generalisations pointing to one variable controlling evaporation trends is not possible, though observed declines in wind speed were often the major cause of observed atmospheric evaporative demand declines in a majority of studies. All variables influencing the evaporative process (i.e. wind speed, atmospheric humidity, radiation environment and air temperature) need to be taken into account. Further understanding of the area-average evaporation and pan evaporation is offered by Shuttleworth et al. (2009), who concluded from their study, that there are two influences on pan evaporation operating at different spatial scales and in opposite directions. The study confirmed that changes in pan evaporation are associated with: (i) large-scale changes in wind speed, with surface radiation having a secondary impact, and (ii) the landscape coupling between surface and the atmospheric boundary layer through surface radiation, wind speed and vapour pressure deficit (Shuttleworth et al., 2009, p. 1244). However, the above explanations are further complicated by analyses of Brutsaert and Parlange (1998), Kahler and Brutsaert (2006) and Pettijohn and Salvucci (2009) and summarised by Roderick et al. (2009b). Roderick et al. (2009b) examined a generalised complementary relationship incorporating pan evaporation and suggested that in water-limited environments declines in pan evaporation may be interpreted as evidence of increasing terrestrial evaporation if rainfall increases while in energy-limited environments terrestrial evaporation is decreasing.

As pointed out by Roderick et al. (2009b), to apply the reductions in pan evaporation to the terrestrial environment is not straightforward because of the importance of supply and demand of water through rainfall and evaporation (see also the comment by Brutsaert and Parlange, 1998). Roderick et al. (2009b, Sect. 4) described the issue as follows, "In energy-limited conditions, declining pan evaporation generally implies declining actual evapotranspiration. If precipitation were constant then one would also expect increasing runoff and/or soil moisture. In water-limited conditions, the interpretation is not so straightforward because actual evapotranspiration is then controlled by the supply and not demand. In such circumstances, one has to inspect how the supply (i.e. precipitation) has changed before coming to a conclusion about how actual evapotranspiration and other components of the terrestrial water balance have changed." Recently, McVicar et al. (2012a, Fig. 1) in a global review of terrestrial wind speed trends mapped the areas that are climatologically water-limited and energy-limited.

It is interesting to note that Jung et al. (2010, p. 951) argue that global annual actual evapotranspiration increased, on average, by $7.1 \mathrm{~mm} \mathrm{yr}^{-1}$ decade $^{-1}$ from 1982 to 1997 , after which the increase ceased. They suggested that the switch is due mainly to lower soil moisture in the Southern Hemisphere during the past decade.

For rainfall-runoff modelling, several researchers (Oudin et al., 2005; Kay and Davies, 2008) have observed in predominately water-limited environments that a calibrated 
记 芦

ช้

厌

言苍苛

竞

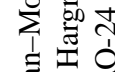

沗

㱐过

홍

要

可

定识

吕矛.

o

b掊

苍节

ㄷํำ

एँ

․ㅠㄹ

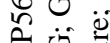

t。

过䜦范

。ํํำ

卷它

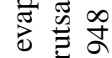

再

苛

요

5े

栗

吾

पे

造过

苛焉

论

部

를월

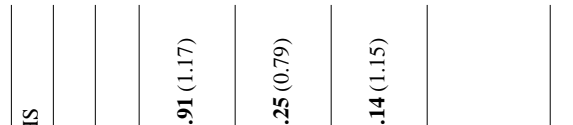

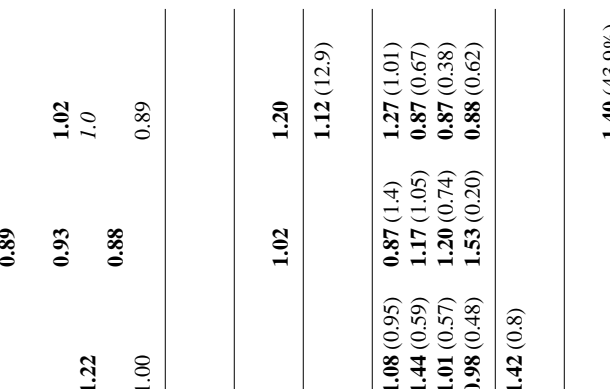

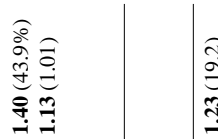

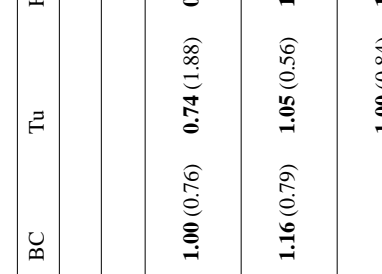

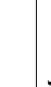

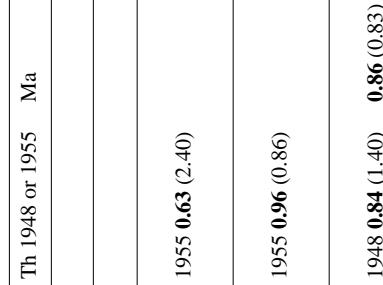

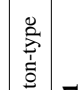

产

퐁

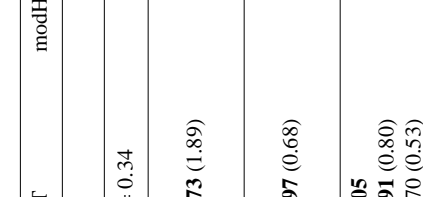

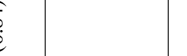

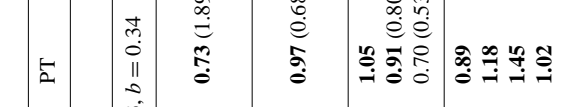

$\fallingdotseq$

ำ

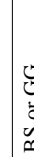

0
0
$\vdots$
$\vdots$
0
$m$
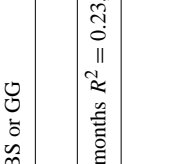

$\Xi$ 吾

永药

表会药

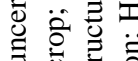

एँ

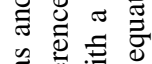

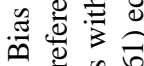

in

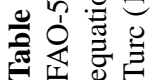

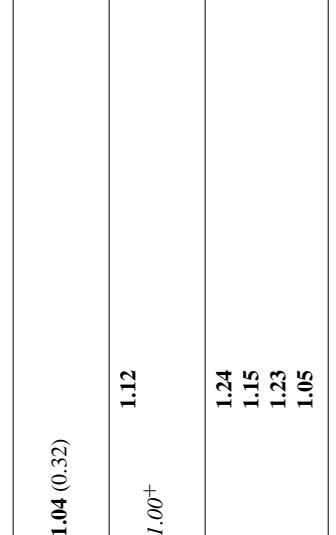

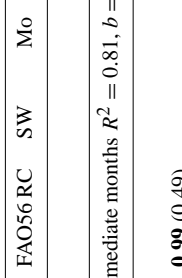

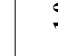

$\stackrel{8}{-}$

$\stackrel{8}{-}$

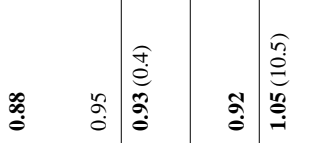

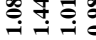

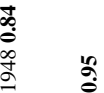

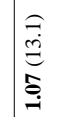

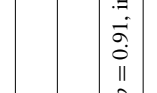

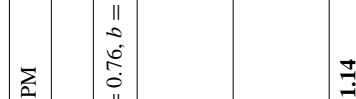

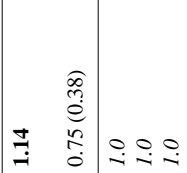

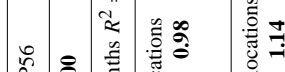

-

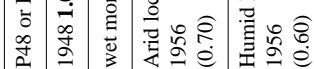
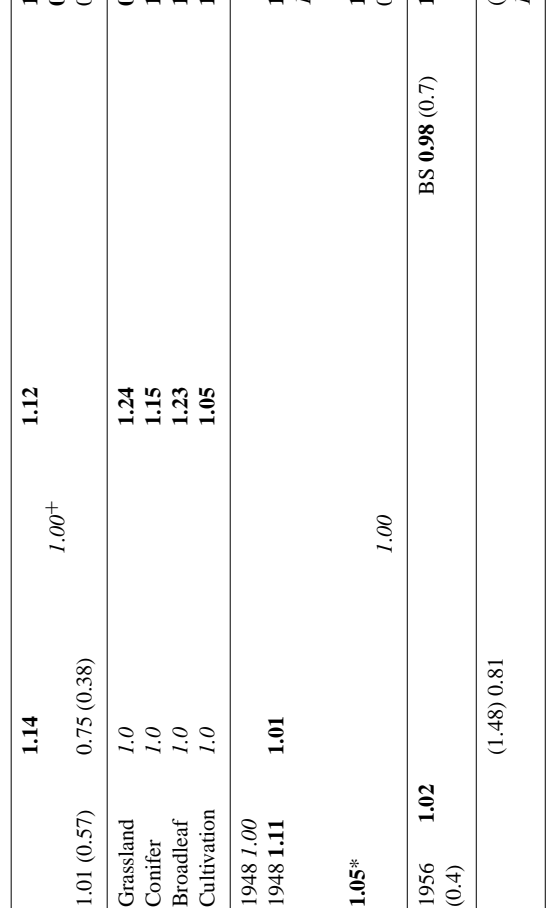

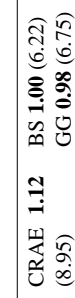

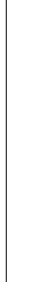

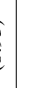




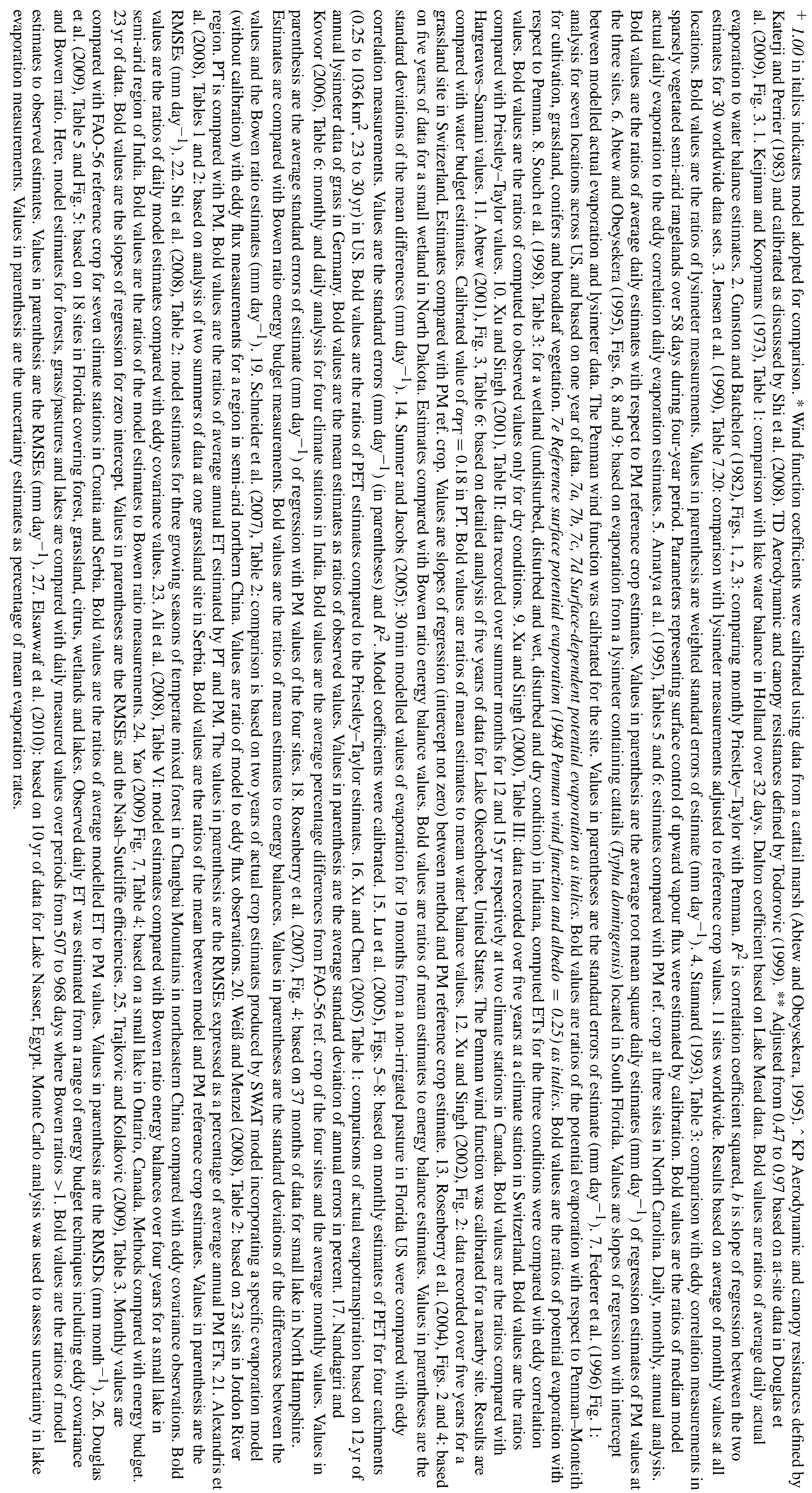


model performs at least as well with potential evaporation inputs based on air temperature as a model with inputs from the more data intensive Penman-Monteith model. However, when considering climatic changes, the recent evidence is compelling (Roderick et al., 2009a; McVicar et al., 2012a) that in a climate-changing environment all relevant and interacting climate variables should be taken into account wherever possible (McVicar et al., 2007b). Using air temperature as the only forcing variable for estimating potential evaporation will lead potentially to an incorrect outcome particularly in energy-limited environments which are important headwaters for many major river systems across the globe (see McVicar et al. (2012a) for discussion). In this context it is worth noting that by not considering one of the key variables (radiation, air temperature, relative humidity or wind) in an evaporation equation, it is implicitly assumed that variable is non-trending. This can be a very poor assumption as highlighted in the global wind review by McVicar et al. (2012a), following the original wind "stilling" paper by Roderick et al. (2007).

Finally, in the context of a changing climate, Donohue et al. (2010a) compare potential evaporation computed by Penman (Sect. 2.1.1), Priestley-Taylor (2.1.3), Morton point (Sect. 2.5.2), Morton areal (Sect. 2.5.2), and Thornthwaite (1948). Donohue et al. (2010a) concluded that the Penman model produced the most reasonable estimation of the dynamics of potential evaporation (Donohue et al., 2010a, p. 196). Their finding echoed several previous papers (e.g. Chen et al., 2005; Garcia et al., 2004; McKenney and Rosenberg, 1993; Shenbin et al., 2006) and is confirmed by an extensive review paper by McVicar et al. (2012a). In this context it is noted that estimates of the Morton point potential evapotranspiration by Donohue et al. (2010a) were very high. R. Donohue (personal communication, 2012) advised that "the reason Morton point potential values were so high in Donohue et al. (2010b) was because, in their modelling of net radiation, they explicitly accounted for actual land-cover dynamics. This procedure differs from Morton's (1983) methodology, developed over $25 \mathrm{yr}$ ago, when remotely sensed data were not routinely available, and thus Donohue et al. (2010b) calculations of Morton's potential evaporation contradicts Morton's (1983) methodology."

\subsection{Daily (24 h) or daytime (day-light hour)}

An issue that arose during this project relates to whether or not daily meteorological data used in evaporation equations should be averaged over a $24 \mathrm{~h}$ daily period or averaged during daylight hours when evaporation is mainly, but not only, taking place (Dawson et al., 2007). Most authors are silent about this as they are using standard meteorological daily data provided by the relevant agency. Furthermore, most procedures incorporate empirically derived coefficients that were estimated using the standard meteorological data. In view of this, except where we specifically have noted in the text and in the Supplement that the input climate data are averaged over day-light hours, in all analyses standard meteorological data should be used. Although the definitions may vary slightly from jurisdiction to jurisdiction, the issue is far too large to be further considered here. This is an important question that needs addressing. Stigter (1980, p. 328) and Van Niel et al. (2011) provide a starting point for such a discussion.

\subsection{Uncertainty in evaporation estimates and model performance}

In the previous sections we describe several models for estimating actual and potential evaporation. These models vary in complexity and in data requirements. In selecting an appropriate model, analysts should consider the uncertainty in alternative methods.

Winter (1981) provides a useful starting point. He examined the uncertainties in the components of the water balance of lakes. Regarding evaporation, he concluded that closing the surface energy balance was considered the most accurate method - annual estimates $< \pm 10 \%$. Errors of 15 to $20 \%$ in Dalton-type equations were assessed in terms of the mass transfer coefficient. Errors in monthly Class-A pan data were reported to be up to $30 \%$. In addition, several studies reported large variations in pan to lake coefficients (for error analyses see Hounam, 1973; Ficke, 1972; Ficke et al., 1977).

Nichols et al. (2004) also provide a detailed error analysis based on a semi-arid region in New Mexico, US, using a standard error propagation method. The conditions adopted in the uncertainty analysis using a daily time step included: air temperature $\pm 0.1 \%$, relative humidity $\pm 3 \%$, vapour deficit, $\pm 4 \%$, wind speed $\pm 5 \%$, net radiation $\pm 15 \%$, $\gamma \pm 0.1 \%$, and $\Delta \pm 0.5 \%$ from which the following uncertainties were computed: Penman (1948 equation) $\pm 13 \%$, Priestley-Taylor $\pm 18 \%$, and Penman-Monteith $\pm 10 \%$. McJannet et al. (2008, Table 6.1), in a review of open-surface water evaporation estimates in the Murray-Darling Basin, Australia, assessed through sensitivity analysis errors in actual evaporation due to meteorological and other inputs as follows: temperature (input $\pm 1.5^{\circ} \mathrm{C}$ ) $\pm 3 \%$, solar radiation (input $\pm 10 \%$ ) $\pm 6 \%$, vapour pressure (input $\pm 0.15 \mathrm{kPa}$ ) $\pm 3 \%$, wind speed (input $\pm 50 \%$ ) $\pm 7 \%$, elevation (input $\pm 50 \%$ ) $\pm 1 \%$, latitude (input $\pm 2^{\circ}$ ) $\pm 1 \%$, water depth (input $\pm 1 \mathrm{~m}) \pm 1 \%$, and water area $( \pm 20 \%) \pm 20 \%$.

Fisher et al. (2011) compared three models - Thornthwaite, Priestley-Taylor and Penman-Monteith - at 10 sites in the Americas and one in South Africa. The potential evapotranspiration estimates (here evapotranspiration includes transpiration, soil evaporation and open-water evaporation) varied by more than $25 \%$ across the sites, the PM model generally gave the highest PET estimates and Thornthwaite $20-30 \%$ lower than PT or PM. At the global and continental scales, the three models gave similar averaged PET estimates. 
Table 6. Consolidated list of biases expressed as ratios of model estimations of actual and/or potential evaporation to field measurements, lysimeter observations or comparison with evaporation equations (P48: Penman, 1948; P56: Penman 1956; PM: Penman-Monteith; FAO56 RCE: FAO-56 reference crop evapotranspiration; SW: Shuttleworth-Wallace; BS, GG: Brutsaert-Strickler or Granger-Gray respectively; PT: Priestley-Taylor; Dalton: Dalton-type model; Th: Thornthwaite; Ma: Makkink; BC: Blaney-Criddle; Tu: Turc; HS: Hargreaves-Samani).

\begin{tabular}{|c|c|c|c|c|c|c|c|c|c|c|c|c|c|c|c|}
\hline Ref\# & Surface & Location/climate & $\mathrm{P} 48$ & P56 & PM & FAO56 RCE & SW & BS, GG & PT & Dalton & Th & Ma & $\mathrm{BC}$ & $\mathrm{Tu}$ & HS \\
\hline & Comparisons with $\mathrm{y}$ & ater balance, eddy correlatic & or $\mathrm{Bo}$ & ven rati & & & & & & & & & & & \\
\hline 1 & Lake & Holland/temperate & 1.00 & & & & & & & 1.51 & & & & & \\
\hline 11 & Lake & Florida/sub-tropical & & $1.05^{*}$ & & & & & 1.03 & & & & & 0.88 & \\
\hline 18 & Lake & North Dakota/cold & & 1.09 & & & & $1.09 \mathrm{BS}$ & 1.09 & & & 0.98 & 1.42 & & \\
\hline 23 & Lake & India/semi-arid & & & & & & & 1.00 & 1.06 & & & & & \\
\hline 24 & Lake & Canada/cold & 1.06 & & & & & & 1.10 & & & 0.92 & & & \\
\hline \multirow[t]{4}{*}{$26 \mathrm{c}$} & Lake & Florida/sub-tropical & & & 0.99 & & & & 0.94 & & & & & 0.80 & \\
\hline & & Count & 2 & 2 & & & & & 5 & 2 & & 2 & & 2 & \\
\hline & & Average & 1.03 & 1.07 & & & & & 1.03 & 1.29 & & 0.95 & & 0.84 & \\
\hline & Comparisons with e & Idy correlation or Bowen ra & & & & & & & & & & & & & \\
\hline 8 & Dry wetland & Indiana/cold & 1.11 & & 1.01 & & & & 1.10 & & & & & & \\
\hline 13 & Wetland & North Dakota/cold & & 1.02 & & & & $0.98 \mathrm{BS}$ & 1.02 & & & 0.93 & & & \\
\hline 22 & Forest & NE China/cold & & & $1.15 \$$ & & & & 1.12 & & & & & & \\
\hline $26 \mathrm{a}$ & Forest & Florida/sub-tropical & & & 0.97 & & & & 1.37 & & & & & 1.37 & \\
\hline 4 & Rangeland & Colorado/semi-arid & & & 1.14 & & 1.12 & & 1.05 & & & & & & \\
\hline 19 & Rangeland & China/semi-arid & & & & 0.83 & & & 0.85 & & & 0.95 & & & \\
\hline \multirow[t]{4}{*}{$26 \mathrm{~b}$} & Grassland & Florida/sub-tropical & & & 0.72 & & & & 1.29 & & & & & 1.42 & \\
\hline & & Count & & & 5 & & & & 7 & & & 2 & & 2 & \\
\hline & & Average & & & 1.00 & & & & 1.11 & & & 0.94 & & 1.40 & \\
\hline & Comparisons with 1 . & simeter measurements & & & & & & & & & & & & & \\
\hline $3 \mathrm{a}$ & Grass & Worldwide/arid & & 0.98 & & 0.99 & & & 0.73 & & 0.63 & & 1.00 & 0.74 & 0.91 \\
\hline $3 b$ & Grass & Worldwide/humid & & 1.14 & & 1.04 & & & 0.97 & & 0.96 & & 1.16 & 1.05 & 1.25 \\
\hline 6 & Wetland & South Florida/humid & & 1.01 & & 0.75 & & & 0.70 & & & & & & \\
\hline \multirow[t]{4}{*}{16} & Grass & Germany/temperate/cold & & & & & & $1.00 \mathrm{BS} 0.98 \mathrm{GG}$ & 1.01 & & 1.07 & 1.05 & & & 1.12 \\
\hline & & Count & & 3 & & 3 & & & 4 & & 3 & & 2 & 2 & 3 \\
\hline & & Average & & 1.04 & & 0.93 & & & 0.85 & & 0.89 & & 1.08 & 0.90 & 1.09 \\
\hline & Comparisons with $\mathrm{P}$ & enman-Monteith (average v & ues as & atio of & M value & $=1.00)$ & & & & & & & & & \\
\hline 5 & Ref. crop & North Carolina/temperate & & & & 1.00 & & & 0.91 & & 0.84 & 0.86 & & 1.00 & 1.14 \\
\hline 21 & Grassland & Serbia/temperate/cold & & & & 1.00 & & & 1.05 & & & 0.79 & & 0.95 & 1.13 \\
\hline $7 \mathrm{a}$ & Grassland & USA/cold to semi-arid & & & 1.00 & & 1.24 & & 0.89 & & & & & & \\
\hline $7 b$ & Conifer & USA/cold to semi-arid & & & 1.00 & & 1.15 & & 1.18 & & & & & & \\
\hline $7 \mathrm{c}$ & Broadleaf & USA/cold to semi-arid & & & 1.00 & & 1.23 & & 1.45 & & & & & & \\
\hline $7 \mathrm{~d}$ & Cultivation & USA/cold to semi-arid & & & 1.00 & & 1.05 & & 1.02 & & & & & & \\
\hline $17 \mathrm{a}$ & Climate stn. & India/arid & & & & 1.00 & & & 1.02 & & & & 1.08 & 0.87 & 1.27 \\
\hline $17 \mathrm{~b}$ & Climate stn. & India/semi-arid & & & & 1.00 & & & 1.09 & & & & 1.44 & 1.17 & 0.87 \\
\hline $17 \mathrm{c}$ & Climate stn. & India/semi-humid & & & & 1.00 & & & 1.11 & & & & 1.01 & 1.2 & 0.87 \\
\hline $17 \mathrm{~d}$ & Climate stn. & India/humid & & & & 1.00 & & & 0.89 & & & & 0.98 & 1.53 & 0.88 \\
\hline 20 & Irrigation to desert & Jordon /arid & & & & 1.00 & & & 1.17 & & & & & & 1.40 \\
\hline \multirow[t]{4}{*}{25} & Climate stn. & Croatia, Serbia/humid & & & & 1.00 & & & 1.01 & 0.89 & & & & 0.95 & 1.23 \\
\hline & & Count & & & & & 4 & & 12 & & 2 & 2 & 4 & 7 & 7 \\
\hline & & Average & & & & 1.00 & 1.17 & & 1.07 & & 0.87 & 0.83 & 1.13 & 1.10 & 1.06 \\
\hline & Comparisons with $\mathrm{P}$ & riestley-Taylor (average val & $\mathrm{s}$ as $\mathrm{r}$ & io of $\mathrm{PT}$ & values $=$ & $1.00)$ & & & & & & & & & \\
\hline 9 & Climate stn. & Switzerland/cold & & & & & & & 1.00 & & & 0.88 & & 0.93 & 1.02 \\
\hline \multirow[t]{4}{*}{15} & Forest & USA/humid & & & & & & & 1.00 & & 0.79 & 0.92 & & 1.02 & 1.20 \\
\hline & & Count & & & & & & & & & & 2 & & 2 & 2 \\
\hline & & Average & & & & & & & 1.00 & & & 0.90 & & 0.98 & 1.11 \\
\hline & Comparison with $\mathrm{H}$ & rgreaves-Samani (average v & lues a & ratio of & $\mathrm{H}-\mathrm{S}$ valu & $=1.00)$ & & & & & & & & & \\
\hline 10 & Climate stn. & Canada/cold & & & & & & & & & 0.95 & & 1.22 & & 1.00 \\
\hline
\end{tabular}

\# Numbers refer to references listed in Table 5. *Indicate which of the three models the results refer to. \$ Average of KP and TD values in item 22 of Table 6.

To provide a more detailed guide to relative differences in the estimates of evaporation based on the models discussed in this paper, we review and summarise 27 references in Table 5 where cross-comparisons are carried out. (A consolidated list of relative differences is presented in Table 6 and a consolidated list of uncertainty estimates is available in Table 7.) For each case in Table 5 we have provided, where possible, an estimate of the mean annual evaporation by the specific procedure as a ratio of one of three base methods: (i) estimates based on a water balance, eddy correlation or Bowen ratio study; (ii) estimates based on lysimeter measurements of evaporation; or (iii) estimates compared with another procedure; we have used Penman-Monteith, FAO56 reference crop evapotranspiration, Priestley-Taylor and 
Table 7. Consolidated list of uncertainty estimates as RMSE or SEE expressed as ratio of the equivalent values estimated for the Priestley-Taylor equation (P56: Penman 1956; PT: PriestleyTaylor; Ma: Makkink; PM: Penman-Monteith; BC: BlaneyCriddle; HS: Hargreaves-Samani; Tu: Turc; Th: Thornthwaite).

\begin{tabular}{|c|c|c|c|c|c|c|c|c|}
\hline Ref.* & P56 & $\mathrm{PT}$ & $\mathrm{Ma}$ & PM & $\mathrm{BC}$ & HS & $\mathrm{Tu}$ & Th \\
\hline \multicolumn{9}{|c|}{ RMSE (mm day ${ }^{-1}$ ) } \\
\hline$\# 5$ & & 1.00 & 1.04 & & & 1.44 & 1.05 & 1.75 \\
\hline \#21 & & 1.00 & 3.00 & & & 5.05 & 1.15 & \\
\hline$\# 25$ & & 1.00 & & & & 2.10 & 0.97 & 1.70 \\
\hline$\# 26 \mathrm{a}$ & & 1.00 & & 0.78 & & & 0.75 & \\
\hline$\# 26 \mathrm{~b}$ & & 1.00 & & 0.73 & & & 1.09 & \\
\hline$\# 26 \mathrm{c}$ & & 1.00 & & 0.84 & & & 1.14 & \\
\hline Median & & 1.00 & 2.02 & 0.78 & & 2.10 & 1.07 & 1.73 \\
\hline \multicolumn{9}{|c|}{$\operatorname{SEE}\left(\mathrm{mm} \mathrm{day}^{-1}\right)$} \\
\hline$\# 3 \mathrm{~A}$ & 0.37 & 1.00 & & 0.26 & 0.40 & 0.62 & 0.99 & 1.27 \\
\hline$\# 3 \mathrm{H}$ & 0.88 & 1.00 & & 0.47 & & 1.16 & 0.82 & 1.26 \\
\hline$\# 6$ & 1.08 & 1.00 & & 0.72 & & & & \\
\hline$\# 13$ & 1.33 & 1.00 & 1.33 & & & & & \\
\hline$\# 17 \mathrm{a}$ & & 1.00 & & & 1.00 & 1.06 & 1.47 & \\
\hline$\# 17 \mathrm{~b}$ & & 1.00 & & & 0.51 & 0.58 & 0.91 & \\
\hline$\# 17 \mathrm{c}$ & & 1.00 & & & 1.02 & 0.68 & 1.32 & \\
\hline$\# 17 d$ & & 1.00 & & & 0.75 & 0.97 & 0.31 & \\
\hline Median & 0.98 & 1.00 & 1.33 & 0.47 & 0.75 & 0.83 & 0.95 & 1.27 \\
\hline
\end{tabular}

* Numbers refer to references listed in Table 5 .

Hargreaves-Samani methods. An estimate of the uncertainty for each analysis is also summarised in Table 7. Although space precludes a detailed discussion of the errors here, Fig. 4 provides a summary of the relative differences between the procedures where the results from at least two studies were available for comparison. A detailed discussion of the results presented in Tables 5, 6 and 7 and Fig. 4 is provided in Sect. S17.

Rather than undertake a direct comparison of the potential evapotranspiration estimates, Oudin et al. (2005) compared the efficiency of rainfall-runoff models when 27 different potential evapotranspiration models were used. Four lumped rainfall-runoff models were examined for a sample of 308 catchments from Australia, France and the United States. These catchments were mainly water-limited where potential evapotranspiration is less important to model performance. The study found little improvement in the efficiency of the rainfall-runoff models when the more complex and data intensive models were used. The models based on air temperature and radiation provided the best results (Oudin et al., 2005).

The majority of the literature has focused on providing a relative accuracy through ranking of the various models. Lowe et al. (2009) adopted a different approach and present a framework to quantify the uncertainties associated with estimates of reservoir evaporation generated using the pan coefficient method. The uncertainty in each model input was

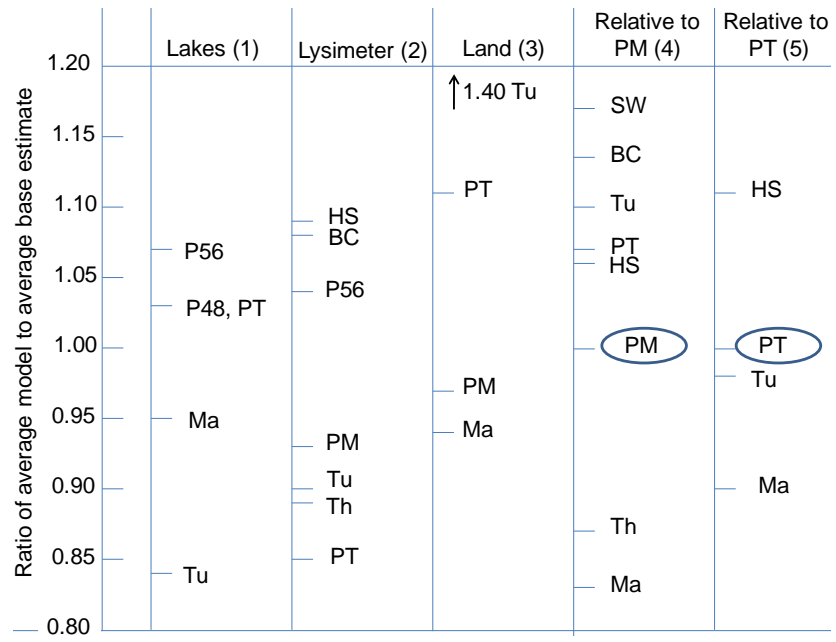

Fig. 4. Pictorial comparison of published evaporation estimates from Table 6. Values are average ratios of the nominated procedures to base evaporation. For the lakes, the base evaporation estimation was by water balance, eddy correlation or Bowen ratio, and for lysimeter results the base was estimated for lysimeters containing grass. Land estimates were based on eddy correlation or Bowen ratio. For the two columns to the right, the values were compared directly with Penman-Monteith or Priestley-Taylor, both set arbitrarily to a ratio of 1.00 , which are denoted by the ellipse. Symbols are defined in the caption of Table 6.

assessed (including rainfall and Class-A evaporation measurements, bird guard adjustment factor, pan coefficients and spatial transposition) and combined using Monte Carlo simulations. They applied the framework to three reservoirs in south-east Australia. The largest contributor to the overall uncertainty was the estimation of Class-A evaporation at locations without monitoring, followed by uncertainty in annual pan coefficients. The overall uncertainty in reservoir evaporation was found to be as large as $\pm 40 \%$ at three study sites (Lowe et al., 2009, p. 272). Factors affecting measurement errors in evaporation are discussed in detail in Allen et al. (2011). These can be combined with a methodology like that presented in Lowe et al. (2009) to assess uncertainty in evaporation estimates.

\section{Concluding summary}

This is not a review paper, but rather a considered summary of techniques that are readily available to the researcher, consulting hydrologist and practicing engineer to estimate both actual and potential evaporation, reference crop evapotranspiration and pan evaporation. There are three key procedures that are used to estimate potential evaporation: Penman, Penman-Monteith and Priestley-Taylor. To estimate reference crop evapotranspiration, FAO-56 reference crop equation, which is a Penman-Monteith equation for a $0.12 \mathrm{~m}$ high hypothetical crop in which the surface resistance is 
$70 \mathrm{~s} \mathrm{~m}^{-1}$, is used worldwide. It is applicable to humid conditions. If reliable pan coefficients are available, Class-A evaporation pans provide useful data for a range of studies and the PenPan model, which models very satisfactorily Class-A pan evaporation, is a useful tool to the hydrologist. The Penman equation estimates actual evaporation from large shallow open-surface water in which there is no change in heat storage, no heat exchange with the ground, and no advected energy. There are two wind functions (Penman, 1948, 1956, Eq. 8a and b) which have been widely used that form part of the aerodynamic term in the Penman equation. We prefer the Penman (1956, Eq. 8b) wind function for most studies. There are a range of techniques available to estimate monthly actual evaporation of a catchment, including Morton's procedure, the aridity-advection model of Brutsaert-Strickler, and the models of Szilagyi-Jozsa and Granger-Gray. The Budykolike equations may be used to estimate annual actual evaporation. However, analysts need to be aware that changes in land surface conditions due to vegetation and lateral inflow may occur; these are best modelled using remotely sensed data as inputs, an issue that is not explored here.

Turning to other practical topics, we observed that the Penman or Penman-Monteith models, incorporating a seasonal heat storage component and a water advection component, and the Morton CRLE model can be used to estimate evaporation from deep lakes and large voids. For shallow lakes or deep lakes, where only a mean annual evaporation estimate is required, the Morton model can be applied. Both the Penman and the Penman-Monteith equations modified to take into account heat storage effects are also acceptable procedures. For catchment water balance studies, in addition to the traditional simple water balance approach, the Morton model CRAE can be used. Our review of the literature suggests that any one of a number of the techniques can be used to estimate potential evaporation in rainfall-runoff modelling where the model parameters are calibrated. It has been customary in recent years to apply the FAO-56 reference crop evapotranspiration method to estimate crop water requirements. It is noted for semi-arid windy regions that a more suitable method is the Matt-Shuttleworth model. Other practical topics, that are considered, include evaporation from lakes covered by vegetation, bare soil evaporation and groundwater evaporation.

There are six additional issues addressed. We noted that care needs to be exercised in using hard-wired evaporation estimates from commercially available automatic weather stations. Where wind data are not available we observed that Morton's procedure can be used and Valiantzas (2006) developed an empirical equation to simulate Penman without wind data. Where at-site meteorological data or Class-A pan data are not available at or nearby the target site, outputs from spatial interpolation and spatial modelling offer an approach. The paradox of increasing annual temperature but decreasing evaporative power observed in many parts of the world is briefly addressed. We observe that in the context of a changing climate the four key variables for estimating evaporative demand (radiation, air temperature, relative humidity and wind) should be taken into account. We note that, except for several exceptions recorded in the paper and Supplement sections, standard meteorological data averaged (or estimated as an average) over a $24 \mathrm{~h}$ day rather than during daylight hours should be used in analysis. The last issue to be addressed is uncertainty in evaporation estimates; our focus was a literature review in which measures of uncertainty were collated, allowing the relative accuracies of most potential, reference crop and actual evaporation procedures to be assessed.

\section{Supplementary material related to this article is available online at: http://www.hydrol-earth-syst-sci.net/ 17/1331/2013/hess-17-1331-2013-supplement.pdf.}

Acknowledgements. This research was partially funded by the Australian Research Council project ARC LP100100756, Melbourne Water and the Australian Bureau of Meteorology. The authors are grateful to their colleagues especially Randall Donohue, Biju George, Hector Malano, Tim Peterson, Q.-J. Wang and Andrew Western for their support of the project through discussion of many practical issues, to Francis Chiew, Mike Hobbins, Roger Jones and Lu Zhang for access to a range of computer programs and manuals dealing with Morton's models, and to Fiona Johnson for providing detailed computations of PenPan which allowed us to independently check our own computations. Clarification of past research by Wilfried Brutsaert, Joe Landsberg, David McJannet, Mike Raupach, Jozsef Szilagyi and Jim Wallace is gratefully acknowledged. Lake temperature data were provided by Kim Seong Tan of Melbourne Water Corporation. The AWS climate data were provided by the Australian Bureau of Meteorology, National Climate Centre. We thank S. J. Schymanski, J. Szilagyi, J. Dracup and an anonymous referee for comments that helped us improve our paper.

Edited by: W. Buytaert

\section{References}

Abbott, M. B., Bathurst, C., Cunge, J. A., O’Connell, P. E., and Rasmussen, J.: An introduction to the European Hydrological System - Systeme Hydrologique Europeen, SHE. 1. History and philosophy of a physically-based, distributed modelling system, J. Hydrol., 87, 45-59, 1986a.

Abbott, M. B., Bathurst, C., Cunge, J. A., O'Connell, P. E., and Rasmussen, J.: An introduction to the European Hydrological System - Systeme Hydrologique Europeen, SHE. 2. Structure of a physically-based, distributed modelling system, J. Hydrol., 87, 61-77, 1986b.

Abtew, W.: Evaporation estimation for Lake Okeechobee in South Florida, J. Irrig. Drain. E. ASCE, 127, 140-177, 2001.

Abtew, W. and Obeysekera, J.: Lysimeter study of evapotranspiration of Cattails and comparison of three methods, T. ASAE, 38, 121-129, 1995. 
Abulohom, M. S., Shah, S. M. S., and Ghumman, A. R.: Development of a rainfall-runoff model, its calibration and validation, Water Resour. Manag., 15, 149-163, 2001.

Alexandris, S., Stricevic, R., and Petkovic, S.: Comparative analysis of reference evapotranspiration from the surface of rainfed grass in central Serbia, calculated by six empirical methods against the Penman-Monteith formula, European Water, 21/22, 17-28, 2008.

Ali, S., Ghosh, N. C., and Singh, R.: Evaluating best evaporation estimate model for water surface evaporation in semi-arid India, Hydrol. Process., 22, 1093-1106, 2008.

Allen, R. G. and Pruitt, W. O.: Rational use of the FAO BlaneyCriddle Formula, J. Irrig. Drain. E. ASCE, 112, 139-155, 1986.

Allen, R. G., Pereira, L. S., Raes, D., and Smith, M.: Crop evapotranspiration Guidelines for computing crop water requirements, FAO Irrigation and Drainage Paper 56, Food and Agriculture Organization of the United Nations, 1998.

Allen, R. G., Pereira, L. S., Howell, T. A., and Jensen, M. E.: Evapotranspiration information reporting: I. Factors governing measurement accuracy, Agr. Water Manage., 98, 899-920, 2011.

Amatya, D. M., Skaggs, R. G., and Gregory, J. D.: Comparison of methods for estimating REF-ET, J. Irrig. Drain. E. ASCE, 121, 427-435, 1995.

ASCE Standardization of Reference Evapotranspiration Task Committee: The ASCE standardized reference evapotranspiration equation, Task Committee on Standardized Reference Evapotranspiration, January 2005, EWRI-American Society Civil Engineers, 59 pp., 2000.

ASCE: The ASCE Standardized Reference Evapotranspiration Equation, edited by: Allen, R. G., Walter, I. A., Elliott, R., Howell, T., Itenfisu, D., and Jensen, M., American Society of Civil Engineers, 2005.

Baumgartner, W. C. and Reichel, E.: The world water balance. Mean annual global, continental and marine precipitation, Elsevier, Amsterdam, 1975.

Beven, K.: A sensitivity analysis of the Penman-Monteith actual evapotranspiration estimates, J. Hydrol., 44, 169-190, 1979.

Boesten, J. J. T. I. and Stroosnijder, L.: Simple model for daily evaporation from fallow tilled soil under spring conditions in a temperate climate, Neth. J. Agr. Sci., 34, 75-90, 1986.

Bouchet, R. J.: Evapotranspiration reelle et potentielle, signification climatique, International Association of Hydrological Sciences Publ., 62, 134-142, 1963.

Boughton, W.: The Australian water balance model, Environ. Modell. Softw., 19, 943-956, 2004.

Brutsaert, W.: Evaporation into the Atmosphere, Theory, History, and Applications, Kluwer Academic Publishers, London, 1982.

Brutsaert, W. and Parlange, M. B.: Hydrologic cycle explains the evaporation paradox, Nature, 396, p. 30, 1998.

Brutsaert, W. and Strickler, H.: An advection-aridity approach to estimate actual regional evapotranspiration, Water Resour. Res., 15, 443-449, 1979.

Burnash, R. J. C., Ferral, R. L., and McGuire, R. A.: A generalized streamflow simulation system - conceptual modelling for digital computers, US Department of Commerce, National Weather Service and State of California, Department of Water Resources, 1973.

Budyko, M. I.: Climate and Life, translated from Russian by Miller, D. H., Academic Press, San Diego, Calif., 1974.
Castellvi, F., Stockle, C. O., Perez, P. J., and Ibanez, M.: Comparison of methods for applying the Priestley-Taylor equation at a regional scale, Hydrol. Process., 15, 1609-1620, 2001.

Chattopadhyay, N. and Hulme, M.: Evaporation and potential evapotranspiration in India under conditions of recent and future climate change, Agr. Forest Meteorol., 87, 55-73, 1997.

Chen, D., Gao, G., Xu, C. Y., Guo, J., and Ren, G.: Comparison of the Thornthwaite method and pan data with the standard Penman-Monteith estimates of reference evapotranspiration in China, Clim. Res., 28, 123-132, 2005.

Chiew, F. H. S. and Leahy, C. P.: Comparison of evapotranspiration variables in evapotranspiration maps for Australia with commonly used evapotranspiration variables, Australian Journal of Water Resources, 7, 1-11, 2003.

Chiew, F. H. S. and McMahon, T. A.: Estimating groundwater recharge using surface watershed modelling approach, J. Hydrol., 114, 285-304, 1990.

Chiew, F. H. S., Stewardson, M. J., and McMahon, T. A.: Comparison of six rainfall-runoff modelling approaches, J. Hydrol., 147, 1-36, 1993.

Chiew, F. H. S., Kamaladasa, N. N., Malano, H. M., and McMahon, T. A.: Penman-Monteith, FAO-24 reference crop evapotranspiration and class-A pan data in Australia, Agr. Water Manage., 28, 9-21, 1995.

Chiew, F. H. S., Peel, M. C., and Western, A. W.: Application and testing of the simple rainfall-runoff model SIMHYD, in: Mathematical Models of Small Watershed Hydrology and Applications, edited by: Singh, V. P. and Frevert, D. K., Water Resources Publications, Colorado, 335-367, 2002.

Cohen, S., Ianetz, A., and Stanhill, G.: Evaporative climate changes at Bet Dagan, Israel, 1964-1998, Agr. Forest Meteorol., 111, 8391, 2002.

Cong, Z. T., Yang, D. W., and Ni, G. H.: Does evaporation paradox exist in China?, Hydrol. Earth Syst. Sci., 13, 357-366, doi:10.5194/hess-13-357-2009, 2009.

Crosbie, R. S., Jolly, I. D., Leaney, F. W., and Petheram, C.: Can the dataset of field based recharge estimates in Australia be used to predict recharge in data-poor areas?, Hydrol. Earth Syst. Sci., 14, 2023-2038, doi:10.5194/hess-14-2023-2010, 2010.

Daaman, C. C. and Simmonds, L. P.: Measurement of evaporation from bare soil and its estimation using surface resistance, Water Resour. Res., 32, 1393-1402, 1996.

Dawson, T. E., Burgess, S. S. O., Tu, K. P., Oliveira, R. S., Santiago, L. S., Fisher, J. B., Simonin, K. A., and Ambrose, A. R.: Nighttime transpiration in woody plants from contrasting ecosystems, Tree Physiol., 27, 561-575, 2007.

de Bruin, H. A. R.: The determination of (reference crop) evapotranspiration from routine weather data, Proceedings of Technical Meeting 38, Committee for Hydrological Research TNO, Evaporation in relation to hydrology, Proceedings and Informations, 28, 25-37, 1981.

de Bruin, H. A. R.: Temperature and energy balance of a water reservoir determined from standard weather data of a land station, J. Hydrol., 59, 261-274, 1982.

de Bruin, H. A. R.: From Penman to Makkink, In Evaporation and Weather, Proceedings and Informations 39, 5-31, Committee for Hydrological Research TNO, The Hague, The Netherlands, 1987. 
Dingman, S. L.: Physical Hydrology, Prentice Hall, Upper Savage, New Jersey, 1992.

Donohue, R. J., Roderick, M. L., and McVicar, T. R.: On the importance of including vegetation dynamics in Budyko's hydrological model, Hydrol. Earth Syst. Sci., 11, 983-995, doi:10.5194/hess11-983-2007, 2007.

Donohue, R. J., McVicar, T. R., and Roderick, M. L.: Assessing the ability of potential evaporation formulations to capture the dynamics in evaporative demand within a changing climate, J. Hydrol., 386, 186-197, 2010a.

Donohue, R. J., Roderick, M. L., and McVicar, T. R.: Can dynamic vegetation information improve the accuracy of Budyko's hydrological model?, J. Hydrol., 390, 23-34, 2010b.

Donohue, R. J., Roderick, M. L., and McVicar, T. R.: Assessing the differences in sensitivities of runoff to changes in climatic conditions across a large basin, J. Hydrol., 406, 234-244, 2011.

Donohue, R. J., Roderick, M. L., and McVicar, T. R.: Roots, storms and soil pores: incorporating key ecohydrological processes into Budyko's hydroclimatic framework, J. Hydrol., 436-437, 35-50, 2012.

dos Reis, R. J. and Dias, N. L.: Multi-season lake evaporation: energy budget estimates and CRLE model assessment with limited meteorological observations, J. Hydrol., 208, 135-147, 1998.

Douglas, E. M., Jacobs, J. M., Sumner, D. M., and Ray, R. L.: A comparison of models for estimating potential evapotranspiration for Florida land cover types, J. Hydrol., 373, 366-376, 2009.

Doyle, P.: Modelling catchment evaporation: an objective comparison of the Penman and Morton approaches, J. Hydrol., 121, 257276, 1990.

Droogers, P. and Allen, R. G.: Estimating reference evapotranspiration under inaccurate data conditions, Irrig. Drain. Syst., 16, 33-45, 2002.

Edinger, J. E., Duttweiller, D. W., and Geyer, J. C.: The response of water temperature to meteorological conditions, Water Resour. Res., 4, 1137-1143, 1968.

Eichinger, W. E., Parlange, M. B., and Strickler, H.: On the concept of equilibrium evaporation and the value of the Priestley-Taylor coefficient, Water Resour. Res., 32, 161-164, 1996.

Elsawwaf, M., Willems, P., and Feyen, J.: Assessment of the sensitivity and prediction uncertainty of evaporation models applied to Nasser Lake, Egypt, J. Hydrol., 395, 10-22, 2010.

Federer, C. A., Vörösmarty, C., and Fekete, B.: Intercomparison of methods for calculating potential evaporation in regional global water balance models, Water Resour. Res., 32, 2315-2321, 1996.

Feng, X., Vico, G., and Porporato, A.: On the effects of seasonality on soil water balance and plant growth, Water Resour. Res., 48, W05543, doi:10.1029/2011WR011263, 2012.

Ficke, J. F.: Comparison of evaporation computation methods, Pretty Lake, La Grange County, Northeastern Indiana, United States Geological Survey Professional Papers, 686-A, 49 pp., 1972.

Ficke, J. F., Adams, D. B., and Danielson, T. W.: Evaporation from seven reservoirs in the Denver Water-Supply System, Central Colorado, United States Geological Survey Water-Resources Investigations, 76-114, 170 pp., 1977.

Finch, J. W.: A comparison between measured and modelled open water evaporation from a reservoir in south-east England, Hydrol. Process., 15, 2771-2778, 2001.
Finch, J. and Calver, A.: Methods for the quantification of evaporation from lakes, Prepared for the World Meteorological Organization Commission of Hydrology, CEH Wallingford, UK, 2008.

Finch, J. W. and Gash, J. H. C.: Application of a simple finite difference model for estimating evaporation from open water, J. Hydrol., 255, 253-259, 2002.

Fisher, J. B., Whittaker, R. J., and Malhi, Y.: ET come home: potential evapotranspiration in geographical ecology, Global Ecol. Biogeogr., 20, 1-18, 2011.

Fleming, P. M., Brown, J. A. H., and Aitken, A. P.: Evaporation in Botswana and Australia, the transference of equations and techniques between continents, Hydrology and Water Resources Symposium 1989, The Institution of Engineers Australia, National Conference Publication, 89, 58-65, 1989.

$\mathrm{Fu}, \mathrm{B}$. P.: On the calculation of the evaporation from land surface, Sci. Atmos. Sin., 5, 23-31, 1981 (in Chinese).

$\mathrm{Fu}, \mathrm{G}$., Charles, S. H., and Yu, J.: A critical overview of pan evaporation trends over the last 50 years, Climate Change, 97, 193214, 2009.

Gallego-Elvira, B., Baille, A., Martín-Górriz, B., and MartínezÁlvarez, V.: Energy balance and evaporation loss of an agricultural reservoir in a semi-arid climate (south-eastern Spain), Hydrol. Process., 24, 758-766, 2010.

Garcia, M., Raes, D., Allen, R., and Herbas, C.: Dynamics of reference evapotranspiration in the Bolivian highlands (Altiplano), Agr. Forest Meteorol., 125, 67-82, 2004.

Garrett, D. R. and Hoy, R. D.: A study of monthly lake to pan coefficients using a numerical lake model. Hydrology Symposium, 1978, The Institution of Engineers Australia, National Conference Publication, 78, 145-149, 1978.

Gash, J. H. C.: An analytical model of rainfall interception by forests, Q. J. Roy. Meteor. Soc., 105, 43-55, 1979.

Glenn, E. P., Nagler, P. L., and Huete, A. R.: Vegetation index methods for estimating evapotranspiration by remote sensing, Surv. Geophys., 31, 531-55, 2010.

Granger, R. J.: An examination of the concept of potential evaporation, J. Hydrol., 111, 9-19, 1989a.

Granger, R. J.: A complementary relationship approach for evaporation from nonsaturated surfaces, J. Hydrol., 111, 31-38, 1989b.

Granger, R. J. and Gray, D. M.: Evaporation from natural nonsaturated surfaces, J. Hydrol., 111, 21-29, 1989.

Gunston, H. and Batchelor, C. H.: A comparison of the PriestleyTaylor and Penman methods for estimating reference crop evapotranspiration in tropical countries, Agr. Water Manage., 6, 65-77, 1982.

Ham, J. M. and DeSutter, T. M.: Seepage losses and nitrogen export from swine waste lagoons: a water balance study, J. Environ. Qual., 28, 1090-1099, 1999.

Han, S., Hu, H., Yang, D., and Tiam, F.: A complementary relationship evaporation model referring to the Granger model and the advection-aridity model, Hydrol. Process., 25, 2094-2101, 2011.

Hansen, J., Ruedy, R., Sato., M., and Lo, K.: Global surface temperature change, Rev. Geophys., 48, RG4004, doi:10.1029/2010RG0000345, 2010.

Hargreaves, G. H. and Samani, Z. A.: Reference crop evapotranspiration from temperature, Appl. Eng. Agric., 1, 96-99, 1985.

Harmsen, E. W., Pérez, A. G., and Winter, A.: Estimating long-term average monthly evapotranspiration from pan evaporation data at seven locations in Puerto Rico, NOAA-CREST/NASA-EPSCoR 
Joint Symposium for Climate Studies, University of Puerto Rico - Mayaguez Campus, 7 pp., 2003.

Hobbins, M. T. and Ramírez, J. A.: Trends in pan evaporation and actual evapotranspiration across the conterminous U.S.: Paradoxical or complementary?, Geophys. Res. Lett., 31, L13503, doi:10.1029/2004GL019846, 2004.

Hobbins, M. T., Ramírez, J. A., Brown, T. C., and Claessens, L. H. J. M.: The complementary relationship in estimation of regional evapotranspiration: The Complementary Relationship Areal Evapotranspiration and Advection-Aridity models, Water Resour. Res., 37, 1367-1387, 2001a.

Hobbins, M. T., Ramírez, J. A., and Brown, T. C.: Complementary relationship in the estimation of regional evapotranspiration: An enhanced Advection-Aridity model, Water Resour. Res., 37, 1389-1403, 2001b.

Hounam, C. E.: Comparison between pan and lake evaporation, World Meteorological Organisation Technical Note 126, 52 pp., 1973.

Hoy, R. D. and Stephens, S. K.: Field study of evaporation - Analysis of data from Eucumbene, Cataract, Manton and Mundaring, Australian Water Resources Council Technical Paper 21, 195 pp., 1977.

Hoy, R. D. and Stephens, S. K.: Field study of lake evaporation analysis of data from phase 2 storages and summary of phase 1 and phase 2, Australian Water Resources Council Technical Report Paper No. 41, 1979.

Irmak, S., Odhiambo, L. O., and Mutiibwa, D.: Evaluating the impact of daily net radiation models on grass and alfalfa-reference evapotranspiration using the Penman-Monteith equation in a subhumid and semiarid climate, J. Irrig. Drain. E. ASCE, 137, 5972, 2011.

Istanbulluoglu, E., Wang, T., Wright, O. M., and Lenters, J. D.: Interpretation of hydrologic trends from a water balance perspective: the role of groundwater storage in the Budyko hypothesis, Water Resour. Res., 48, W00H16, doi:10.1029/2010WR010100, 2012.

Jayasuriya, L. N. N., O’Neill, I. C., McMahon, T. A., and Nathan, R. J.: Parameter uncertainty in rainfall-runoff modelling, Conference on Agricultural Engineering, Hawkesbury Agricultural College, NSW, 1988.

Jayasuriya, L. N. N., Dunin, F. X., McMahon, T. A., and O’Neill, I. C.: The complementary method and its use in modelling evapotranspiration for forested and grass catchments, Hydrology and Water Resources Symposium, Christchurch, NZ, 1989.

Jensen, M. E., Burman, R. D., and Allen, R. G. (Eds): Evapotranspiration and irrigation water requirements, ASCE Manuals and Reports on Engineering Practice, 70, 1990.

Johnson, F. and Sharma, A.: A comparison of Australian open water body evaporation trends for current and future climates estimated from Class A evaporation pan and general circulation models, J. Hydrometeorol., 11, 105-121, 2010.

Jones, R. N., Bowler, J. M., and McMahon, T. A.: Modelling water budgets of closed lakes, western Victoria, Quaternary Australasia Papers, 11, 50-60, 1993.

Jones, R. N., McMahon, T. A., and Bowler, J. M.: Modelling historical lake levels and recent climate change at three closed lakes, Western Victoria, Australia (c. 1840-1990), J. Hydrol., 246, 159180, 2001.
Jovanovic, B., Jones, D., and Collins, D.: A high-quality monthly pan evaporation dataset for Australia, Climatic Change, 87, 517535, 2008.

Jung, M., Reichstein, M., Ciais, P., Seneviratne, S. I., Sheffield, J., Goulden, M. L., Bonan, G., Cescatti, A., Chen, J., de Jeu, R., Dolman, A. J., Eugster, W., Gerten, D., Gianelle, D., Gobron, N., Heike, J., Kimball, J., Law, B. E., Montagnani, L., Mu, Q., Mueller, B., Oleson, K., Papale, D., Richardson, A.D., Roupsard, O., Running, S., Tomelleri, E., Viovy, N., Weber, U., Williams, C., Wood, E., Zaekle, S., and Zhang, K.: Recent decline in the global land evapotranspiration trend due to limited moisture supply, Nature, 467, 951-954, 2010.

Kahler, D. M. and Brutsaert, W.: Complementary relationship between daily evaporation in the environment and pan evaporation, Water Resour. Res., 42, W05413, doi:10.1029/2005WR004541, 2006.

Kalma, J. D., McVicar, T. R., and McCabe, M. F.: Estimating land surface evaporation: A review of methods using remotely sensed surface temperature data, Surv. Geophys., 29, 421-469, 2008.

Katerji, N. and Perrier, A.: A model of actual evapotranspiration for a field of lucerne - the role of a crop coefficient, Agronomie, 3, 513-521, 1983.

Katerji, N. and Rana, G.: Crop reference evapotranspiration: a discussion of the concept, analysis of the process and validation, Water Resour. Manag., 25, 1581-1600, 2011.

Katul, G. G. and Parlange, M. B.: Estimation of bare soil evaporation using skin temperature measurements, J. Hydrol., 132, 91106, 1992.

Kay, A. L. and Davies, H. N.: Calculating potential evaporation from climate model data: A source of uncertainty for hydrological climate change impacts, J. Hydrol., 358, 221-239, 2008.

Keijman, J. Q.: The estimation of the energy balance of a lake from simple weather data. Bound.-Lay. Meteorol., 7, 399-407, 1974.

Keijman, J. Q.: Theoretical background of some methods for determining of evaporation, In Evaporation in Relation to Hydrology, Proceedings and Informations 28, 12-24, Committee for Hydrological Research TNO, The Hague, 1981.

Keijman, J. Q. and Koopmans, R. W. R.: A comparison of several methods of estimating the evaporation of Lake Flevo, International Association of Hydrological Sciences Publ., 109, 225232, 1973.

Kirono, D. G. C. and Jones, R. N.: A bivariate test for detecting inhomogeneities in pan evaporation time series, Aust. Meteorol. Mag., 56, 93-103, 2007.

Kirono, D. G. C., Jones, R. N., and Cleugh, H. A.: Pan-evaporation measurements and Morton-point potential evaporation estimates in Australia: are their trends the same?, Int. J. Climatol., 29, 711 718, 2009.

Kohler, M. A.: Lake and pan evaporation, in: Water-Loss Investigations: Lake Hefner Studies, Technical Report, United States Geological Survey Professional Paper, 269, 127-149, 1954.

Kohler, M. A. and Parmele, L. H.: Generalized estimates of freewater evaporation, Water Resour. Res., 3, 997-1005, 1967.

Kohler M. A., Nordenson, T. J., and Fox, W. E.: Evaporation from pans and lakes, Weather Bureau Research Paper 38, US Department of Commerce, Washington, 1955.

Kondo, J. and Saigusa, N.: A model and experimental study of evaporation from bare-soil surfaces, J. Appl. Meteorol., 31, 304-312, 1992. 
Konukcu, F.: Modification of the Penman method for computing bare soil evaporation, Hydrol. Process., 21, 3627-3634, 2007.

Lhomme, J.-P.: A theoretical basis for the Priestley-Taylor coefficient, Bound.-Lay. Meteorol., 82, 179-191, 1997.

Lhomme, J. P. and Guilioni, L.: Comments on some articles about the complementary relationship, J. Hydrol., 323, 1-3, 2006

Lidén, R. and Harlin, J.: Analysis of conceptual rainfall-runoff modelling performance in different climates, J. Hydrol., 238, 231247, 2000.

Linacre, E. T.: Data-sparse estimation of lake evaporation, using a simplified Penman equation, Agr. Forest Meteorol., 64, 237-256, 1993.

Linacre, E. T.: Estimating U.S. Class-A pan evaporation from few climate data, Water Int., 19, 5-14, 1994.

Liu, B., Xu, M., Henderson, M., and Gong, W.: A spatial analysis of pan evaporation trends in China, 1955-2000, J. Geophys. Res., 109, D15102, doi:10.1029/2004JD004511, 2004.

Lowe, L. D., Webb, J. A., Nathan, R. J., Etchells, T., and Malano, H. M.: Evaporation from water supply reservoirs: An assessment of uncertainty, J. Hydrol., 376, 261-274, 2009.

Lu, J., Sun, G. McNulty, S. G., and Amatya, D. M.: A comparison of six potential evapotranspiration methods for regional use in the Southeastern United States, J. Am. Water Resour. As., 41, 621-633, 2005.

Luo, Y. F., Peng, S. Z., Klan, S., Cui, Y. L., Wang, Y., and Feng, Y. H.: A comparative study of groundwater evapotranspiration functions, 18th IMACS World Congress MODSIM09 Proceedings, 3095-3101, 2009.

Maidment, D. R.: Handbook of Hydrology, McGraw-Hill Inc., New York, 1992.

Masoner, J. R., Stannard, D. I., and Christenson, S. C.: Differences in evaporation between a floating pan and Class-A pan on land, J. Am. Water Resour. As., 44, 552-561, 2008.

McJannet, D. L., Webster, I. T., Stenson, M. P., and Sherman, B. S.: Estimating open water evaporation for the Murray-Darling Basin. A report to the Australian Government from the CSIRO Murray-Darling Basin Sustainable Yields Project, CSIRO, Australia, 50 pp., 2008.

McJannet, D. L., Webster, I. T., and Cook, F. J.: An area-dependent wind function for estimating open water evaporation using landbased meteorological data, Environ. Modell. Softw., 31, 76-83, doi:10.1016/j.envsoft.2011.11.017, 2012.

McKenney, M. S. and Rosenberg, N. J.: Sensitivity of some potential evapotranspiration estimation methods to climate change, Agr. Forest Meteorol., 64, 81-110, 1993.

McMahon, T. A. and Adeloye, A. J.: Water Resources Yield, Water Resources Publications, LLC, Colorado, 220 pp., 2005.

McNaughton, K. G.: Evaporation and advection I: evaporation from extensive homogeneous surfaces, Q. J. Roy. Meteor. Soc., 102, 181-191, 1976.

McVicar, T. R., Li, L. T., Van Niel, T. G., Hutchinson, M. F., Mu, X.-M., and Liu, Z.-H.: Spatially distributing 21 years of monthly hydrometeorological data in China: Spatio-temporal analysis of FAO-56 crop reference evapotranspiration and pan evaporation in the context of climate change, CSIRO Land and Water Technical Report 8/05, Canberra, Australia, available at: http://www.clw. csiro.au/publications/technical2005/tr8-05.pdf, 2005.

McVicar, T. R., Li, L. T., Van Niel, T. G., Zhang, L., Li, R., Yang, Q. K., Zhang, X. P., Mu, X. M., Wen, Z. M., Liu, W. Z., Zhao, Y. A.,
Liu, Z. H., and Gao, P.: Developing a decision support tool for China's re-vegetation program: Simulating regional impacts of afforestation on average annual streamflow in the Loess Plateau, Forest Ecol. Manag., 251, 65-81, 2007a.

McVicar, T. R., Van Niel, T. G., Li, L. T., Hutchinson, M. F., Mu, X. M., and Liu, Z. H.: Spatially distributing monthly reference evapotranspiration and pan evaporation considering topographical influences, J. Hydrol., 338, 196-220, 2007b.

McVicar, T. R., Van Niel, T. G., Li, L. T., Roderick, M. L., Rayner, D. P. Ricciardulli, L., and Donohue, R. J.: Wind speed climatology and trends for Australia, 1975-2006: Capturing the stilling phenomenon and comparison with nearsurface reanalysis output, Geophys. Res. Lett., 35, L20403, doi:10.1029/2008GL035627, 2008.

McVicar, T. R., Roderick, M. L., Donohue, R. J., Li, L. T., Van Niel, T. G., Thomas, A., Grieser, J., Jhajharia, D., Himri, Y., Mahowald, N. M., Mescherskaya, A. V., Kruger, A. C., Rehman, S., and Dinpashoh, Y.: Global review and synthesis of trends in observed terrestrial near-surface wind speeds: Implications for evaporation, J. Hydrol., 416-417, 182-205, 2012a.

McVicar, T. R., Roderick, M. L., Donohue, R. J., and Van Niel, T. G.: Less bluster ahead? Overlooked ecohydrological implications of global trends of terrestrial near-surface wind speeds, Ecohydrology, 5, 381-388, 2012b.

Milly, P. C. D. and Dunne, K. A.: Macroscale water fluxes 2. Water and energy supply control of their interannual variability, Water Resour. Res., 38, 1206, doi:10.1029/2001/WR000760, 2002.

Mohamed, Y. A., Bastiaanssen, W. G. M., Savenije, H. H. G., van den Hurk, B. J. J. M., and Finlayson, C. M.: Evaporation from wetland versus open water: a theoretical explanation and an application with satellite data over the Sudd wetland, Royal Netherlands Met. Institute, available at: http://www.knmi. nl/publications/fulltexts/sudd_wetland.pdf, 2008.

Monteith, J. L.: Evaporation and environment, in: The state and movement of water in living organisms, Symposium Society Experimental Biology, edited by: Fogg, G. E., 19, 205-234, Cambridge University Press, London, 1965.

Monteith, J. L.: Evaporation and surface temperature, Q. J. Roy. Meteor. Soc., 107, 1-27, 1981.

Monteith, J. L.: Weather and water in the Sudano-Sahelian zone. Soil Water Balance in the Sudano-Sahelian Zone, Proceedings of the Niamey Workshop, February 1991, International Association of Hydrological Sciences Publication, 199, 11-28, 1991.

Morton, F. I.: Climatological estimates of lake evaporation, Water Resour. Res., 15, 64-76, 1979.

Morton, F. I.: Operational estimates of areal evapotranspiration and their significance to the science and practice of hydrology, J. Hydrol., 66, 1-76, 1983a.

Morton, F. I.: Operational estimates of lake evaporation, J. Hydrol., 66, 77-100, 1983b.

Morton, F. I.: Practical estimates of lake evaporation, J. Clim. Appl. Meteorol., 25, 371-387, 1986.

Morton, F. I., Richard, F., and Fogarasi, S.: Operational estimates of areal evapotranspiration and lake evaporation - Program WREVAP, NHRI Paper 24, Inland Waters Directorate, Environment Canada, Ottawa, 1985.

Mutziger, A. J., Burt, C. M., Howes, D. J., and Allen, R. G.: Comparison of measured and FAO-56 modeled evaporation from bare soil, J. Irrig. Drain. E. ASCE, 13, 59-72, 2005. 
Muzylo, A., Llorens, P., Valente, F., Keize, J. J., Domingo, F., and Gash, J. H. C.: A review of rainfall interception modelling, J. Hydrol., 370, 191-206, 2009.

Nandagiri, L. and Kovoor, G. M.: Performance evaluation of Reference Evapotranspiration equations across a range of Indian climates, J. Irrig. Drain. E. ASCE, 132, 238-249, 2006.

Nash, J. E.: Potential evaporation and "the complementary relationship", J. Hydrol., 111, 1-7, 1989.

Nichols, J., Eichinger, W., Cooper, D. I., Prueger, J. H., Hipps, L. E., Neale, C. M. U., and Bawazir, A. S.: Comparison of evaporation estimation methods for a riparian area, IIHR Technical Report No 436, Hydroscience and Engineering, University of Iowa, 2004.

Ol'dekop, E. M.: On evaporation from the surface of river basins, Transactions on Meteorological Observations, 4, University of Tartu, 1911 (in Russian).

Oudin, L., Hervieu, F., Michel, C., Perrin, C., Andréassian, V., Anctil, F., and Loumagne, C.: Which potential evapotranspiration input for a lumped rainfall-runoff model? Part 2 - Towards a simple and efficient potential evapotranspiration model for rainfallrunoff modelling, J. Hydrol., 303, 290-306, 2005.

Ozdogan, M., Salvucci, G. D., and Anderson, B. T.: Examination of the Bouchet-Morton complementary relationship using a mesoscale climate model and observations under a progressive irrigation scenario, J. Hydrometeorol., 7, 235-251, 2006.

Penman, H. L.: Natural evaporation from open water, bare soil and grass, Proc. R. Soc. Lond. A, 193, 120-145, 1948.

Penman, H. L.: Evaporation: An introductory survey, Neth. J. Agr. Sci., 4, 9-29, 1956.

Pereira, A. R.: The Priestley-Taylor parameter and the decoupling factor for estimating reference crop evapotranspiration, Agr. Forest Meteorol., 125, 305-313, 2004.

Perrier, A.: Étude physique de l'évapotranspiration dans le conditions naturelles. II. expressions et parameters donnant l'évapotranspiration réele d'une surface "mince", Ann. Agronomy, 26, 105-123, 1975.

Peterson, T. C., Golubev, V. S., and Groisman, P. Ya.: Evaporation losing its strength, Nature, 377, 687-688, 1995.

Petheram, C., Walker, G., Grayson, R., Thierfelder, T., and Zhang, L.: Towards a framework for predicting impacts of land-use on recharge: 1. A review of recharge studies in Australia, Aus. J. Soil Sci., 40, 397-417, 2002.

Pettijohn, J. C. and Salvucci, G. D.: A new two-dimensional physical basis for the Complementary Relationship between terrestrial and pan evaporation, J. Hydrometeorol., 10, 565-574, 2009.

Philip, J. R.: Evaporation and moisture and heat fields in the soil, J. Meteorol., 14, 354-366, 1957.

Pike, J. G.: The estimation of annual runoff from meteorological data in a tropical climate, J. Hydrol., 2, 116-123, 1964.

Potter, N. J. and Zhang, L.: Interannual variability of catchment water balance in Australia, J. Hydrol., 369, 120-129, 2009.

Priestley, C. H. B. and Taylor, R. J.: On the assessment of surface heat flux and evaporation using large scale parameters, Mon. Weather Rev., 100, 81-92, 1972.

Qiu, G. Y., Yano, T., and Momii, K.: An improved methodology to measure evaporation from bare soil based on comparison of surface temperature with a dry soil surface, J. Hydrol., 210, 93$105,1998$.
Ramírez, J. A., Hobbins, M. T., and Brown, T. C.: Observational evidence of the complementary relationship in regional evaporation lends strong support for Bouchet's hypothesis, Geophys. Res. Lett., 32, L15401, doi:10.1029/2005GL023549, 2005.

Raupach, M. R.: Combination theory and equilibrium evaporation, Q. J. Roy. Meteor. Soc., 127, 1149-1181, 2001.

Raupach, M. R., Kirby, J. M., Barrett, D. J., Briggs, P. R., Lu, H., and Zhang, H.: Balances of Water, Carbon, Nitrogen and Phosphorus in Australian Landscapes: (2) Model Formulation and Testing, CSIRO Land and Water Technical Report 41/01, Canberra, 2001.

Ritchie, J. T.: Model for predicting evaporation from row crop with incomplete cover, Water Resour. Res., 8, 1204-1213, 1972.

Roderick, M. L. and Farquhar, G. D.: Changes in Australian pan evaporation from 1970 to 2002, Int. J. Climatol., 24, 1077-1090, 2004.

Roderick, M. L., Rotstayn, L. D., Farquhar, G. D. and Hobbins, M. T.: On the attribution of changing pan evaporation, Geophys. Res. Lett., 34, L17403, doi:10.1029/2007GL031166, 2007.

Roderick, M. L., Hobbins, M. T., and Farquhar, G. D.: Pan evaporation trends and the terrestrial water balance. 1. Principles and observations, Geography Compass, 3, 746-760, 2009a.

Roderick, M. L., Hobbins, M. T., and Farquhar, G. D.: Pan evaporation trends and the terrestrial water balance. 2. Energy balance and interpretation, Geography Compass, 3, 761-780, $2009 \mathrm{~b}$.

Rosenberry, D. O., Sturrock, A. M., and Winter, T. C.: Evaluation of the energy budget method of determining evaporation at Williams Lake, Minnesota, using alternative instrumentation and study approaches, Water Resour. Res., 29, 2473-2483, 1993.

Rosenberry, D. O., Stannard, D. I., Winter, T. C., and Martinez , M. L.: Comparison of 13 equations for determining evapotranspiration from a prairie wetland, Cottonwood Lake Area, North Dakota, USA, Wetlands, 24, 483-497, 2004.

Rosenberry, D. O., Winter, T. C., Buso, D. C., and Likens, G. E.: Comparison of 15 evaporation methods applied to a small mountain lake in the northeastern USA, J. Hydrol., 340, 149-166, 2007.

Rotstayn, L. D., Roderick, M. L., and Farquhar, G. D.: A simple pan-evaporation model for analysis of climate simulation: Evaluation over Australia, Geophys. Res. Lett., 33, L17715, doi:10.1029/2006GL027114, 2006.

Rutter, A. J., Kershaw, K. A., Robins, P. C., and Morton, A. J.: A predictive model of rainfall interception in forests. I. Derivation of the model from observations in a plantation of Corsican pine, Agr. Meteorol., 9, 367-384, 1971.

Rutter, A. J., Morton, A. J., and Robins, P. C.: A predictive model of rainfall interception in forests. II. Generalization of the model and comparison with observations in some coniferous and hardwood stands, J. Appl. Ecol., 12, 367-380, 1975.

Sacks, L. A., Lee, T. M., and Radell, M. J.: Comparison of energybudget evaporation losses from two morphometrically different Florida seepage lakes, J. Hydrol., 156, 311-334, 1994.

Salvucci, G. D.: Soil and moisture independent estimation of stagetwo evaporation from potential evaporation and albedo or surface temperature, Water Resour. Res., 33, 111-122, 1997.

Scanlon, B. R., Keese, K. E., Flint, A. L., Flint, L. E., Gaye, C. B., Edmunds, W. M., and Simmers, I.: Global synthesis of groundwater recharge in semiarid and arid regions. Hydrol. Process., 20, 3335-3370, 2006. 
Schneider, K., Ketzer, B., Breuer, L., Vaché, K. B., Bernhofer. C., and Frede, H.-G.: Evaluation of evapotranspiration methods for model validation in a semi-arid watershed in northern China, Adv. Geosci., 11, 37-42, 2007,

http://www.adv-geosci.net/11/37/2007/.

Schreiber, P.: Über die Beziehungen zwischen dem Niederschlag und der Wasserführung der Flü $\beta$ e in Mitteleuropa, Z. Meteorol., 21, 441-452, 1904.

Sheffield, J., Goteti, G., and Wood, E. F.: Development of a 50-year high-resolution global dataset of meteorological forcings for land surface modeling, J. Climate, 19, 3088-3111, 2006.

Shenbin, C., Yunfeng, L., and Thomas, A.: Climatic change on the Tibetan Plateau: potential evapotranspiration trends from 19612000, Climatic Change, 76, 291-319, 2006.

Shi, T., Guan, D., Wang, A., Wu, J., Jin, C., and Han, S.: Comparison of three models to estimate evapotranspiration for a temperate mixed forest, Hydrol. Process., 22, 3431-3443, 2008.

Shuttleworth, W. J.: Evaporation, Chapter 4, in: Handbook of Hydrology, edited by: Maidment, D. R., McGraw-Hill Inc., New York, 1992.

Shuttleworth, W. J.: Putting the "vap" into evaporation, Hydrol. Earth Syst. Sci., 11, 210-244, doi:10.5194/hess-11-210-2007, 2007.

Shuttleworth, W. J. and Wallace, J. S.: Calculating the water requirements of irrigated crops in Australia using the Matt-Shuttleworth approach, T. ASABE, 52, 1895-1906, 2009.

Shuttleworth, W. J., Serrat-Capdevila, A., Roderick, M. L., and Scott, R. L.: On the theory relating changes in area-average and pan evaporation, Q. J. Roy. Meteor. Soc., 135, 1230-1247, 2009.

Siriwardena, L., Finlayson, B. L., and McMahon, T. A.: The impact of land use change on catchment hydrology in large catchments: The Comet River, Central Queensland, Australia, J. Hydrol., 326, 199-214, 2006.

Slatyer, R. O. and McIlroy, I. C.: Evaporation and the principle of its measurement, in: Practical Meteorology, CSIRO (Australia) and UNESCO, Paris, 1961.

Snyder, R. L., Bali, K., Ventura, F., and Gomez-MacPherson, H.: Estimating evaporation from bare or nearly bare soil, J. Irrig. Drain. E. ASCE, 126, 399-403, 2000.

Souch, C., Grimmond, C. S. B., and Wolfe, C. P.: Evapotranspiration rates from wetlands with different disturbance histories: Indiana Dunes National Lakeshore, Wetlands, 18, 216-229, 1998.

Stannard, D. I.: Comparison of Penman-Monteith, ShuttleworthWallace, and modified Priestley-Taylor Evapotranspiration models for wildland vegetation in semiarid rangeland, Water Resour. Res., 29, 1379-1392, 1993.

Stewart, R. B. and Rouse, W. R.: A simple method for determining the evaporation from shallow lakes and ponds, Water Resour. Res., 12, 623-628, 1976.

Stigter, C. J.: Assessment of the quality of generalized wind functions in Penman's equations, J. Hydrol., 45, 321-331, 1980.

Sumner, D. M. and Jacobs, J. M.: Utility of Penman-Monteith, Priestley-Taylor, reference evapotranspiration, and pan evaporation methods to estimate pasture evapotranspiration, J. Hydrol., 308, 81-104, 2005.

Sweers, H. E.: A nomograph to estimate the heat-exchange coefficient at the air-water interface as a function of wind speed and temperature; a critical survey of some literature, J. Hydrol., 30, 375-401, 1976.
Szilagyi, J.: Modeled areal evaporation trends over the conterminous United States, J. Irrig. Drain. E. ASCE, 127, 196-200, 2001.

Szilagyi, J.: On the inherent asymmetric nature of the complementary relationship of evaporation, Geophys. Res. Lett., 34, L02405, doi:10.1029/2006GL028708, 2007.

Szilagyi, J. and Jozsa, J.: New findings about the complementary relationship-based evaporation estimation methods, J. Hydrol., 354, 171-186, 2008.

Szilagyi, J. and Jozsa, J.: Complementary relationship of evaporation and the mean annual water-energy balance, Water Resour. Res. 45, W09201, doi:10.1029/2009WR008129, 2009.

Thom, A. S., Thony, J.-L., and Vauclin, M,: On the proper employment of evaporation pans and atmometers in estimating potential transpiration, Q. J. Roy. Meteor. Soc., 107, 711-736, 1981.

Thomas, A.: Development and properties of 0.25-degree gridded evapotranspiration data fields of China for hydrological studies, J. Hydrol., 358, 145-158, 2008.

Thornthwaite, C. W.: An approach toward a rational classification of climate, Geogr. Rev., 38, 55-94, 1948.

Todorovic. M.: Single-layer evapotranspiration model with variable canopy resistance, J. Irrig. Drain. E. ASCE, 125, 235-245, 1999.

Trajkovic, S. and Kolakovic, S.: Evaluation of reference evapotranspiration equations under humid conditions, Water Resour. Manag., 23, 3057-3067, 2009.

Turc, L.: Water balance of soils; relationship between precipitation, evapotranspiration and runoff, Ann. Agronomy, 5, 491-595, 1954 (in French).

Turc, L.: Estimation of irrigation water requirements, potential evapotranspiration: A simple climatic formula evolved up to date, Ann. Agronomy, 12, 13-49, 1961 (in French).

Valiantzas, J. D.: Simplified versions for the Penman evaporation equation using routine weather data, J. Hydrol., 331, 690-702, 2006.

van Bavel, C. H. M.: Potential evaporation: The combination concept and its experimental verification, Water Resour. Res., 2, 455-467, 1966.

Van Niel, T. G., McVicar, T. R., Roderick, M. L., van Dijk, A. I. J. M, Renzullo, L. J., and van Gorsel, E.: Correcting for systematic error in satellite-derived latent heat flux due to assumptions in temporal scaling: Assessment from flux tower observations, J. Hydrol., 409, 140-148, 2011.

Vardavas, I. M. and Fountoulakis, A.: Estimation of lake evaporation from standard meteorological measurements: application to four Australian lakes in different climatic regions, Ecol. Model., 84, 139-150, 1996.

Vicente-Serrano, S. M., Lanjeri, S., and Lopez-Moreno, J.: Comparison of different procedures to map reference evapotranspiration using geographical information systems and regressionbased techniques, Int. J. Climatol., 27, 1103-1118, 2007.

Wang, D. B.: Evaluating interannual water storage changes at watersheds in Illinois based on long-term soil moisture and groundwater level data, Water Resour. Res., 48, W03502, doi:10.1029/2011WR010759, 2012.

Wang, Q. J., Chiew, F. H. S., McConachy, F. L. N., James, R., de Hoedt, G. C., and Wright, W. J.: Climatic Atlas of Australia Evapotranspiration, Bureau of Meteorology, Australia, 2001.

Watson, F. G. R., Vertessy, R. A., and Grayson, R. B.: Large scale modelling of forest hydrological processes and their long-term effect on water yield, Hydrol. Process., 13, 689-700, 1999. 
Weeks, W. D.: Evaporation: a case study using data from a lake in Eastern Queensland, Hydrology and Water resources Symposium, Melbourne, The Institution of Engineers, Australia, National Conference Publication 82/3, 189-193, 1982.

Weedon, G. P., Gomes, S., Viterbo, P., Shuttleworth, W. J., Blyth, E., Osterle, H., Adam, J. C., Bellouin, N., Boucher, O., and Best, M.: Creation of the WATCH forcing data and its use to assess global and regional Reference Crop Evaporation over land during the Twentieth Century, J. Hydrometeorol., 12, 823-848, 2011.

Weiß, M. and Menzel, L.: A global comparison of four potential evapotranspiration equations and their relevance to stream flow modelling in semi-arid environments, Adv. Geosci., 18, 15-23, 2008 , http://www.adv-geosci.net/18/15/2008/.

Welsh, W. D.: Water balance modelling in Bowen, Queensland, and the ten iterative steps in model development and evaluation, Environ. Modell. Softw., 23, 195-205, 2008.

Wessel, D. A. and Rouse, W. R.: Modelling evaporation from wetland tundra, Bound.-Lay. Meteorol., 68, 109-130, 1994.

Wiesner, C. J.: Climate, irrigation and agriculture, Angus and Robertson, Sydney, 1970.

Wilson, E. M.: Engineering Hydrology, Fourth Edition, Macmillan, London, 1990.

Winter, T. C.: Uncertainties in estimating the water balance of lakes, Water Resour. Bull., 17, 82-115, 1981.

World Meteorological Organization (WMO): Guide to meteorological instruments and methods of observation, Seventh Edition, WMO, 2006.

$\mathrm{Xu}, \mathrm{C}$.-Y. and Chen, D.: Comparison of seven models for estimation of evapotranspiration and groundwater recharge using lysimeter measurement data in Germany, Hydrol. Process., 19, 3717-3734, 2005.

$\mathrm{Xu}, \mathrm{C}-\mathrm{Y}$. and Singh, V. P.: Evaluation and generalisation of radiation-based methods for calculating evaporation, Hydrol. Process., 14, 339-349, 2000.

$\mathrm{Xu}$, C.-Y. and Singh, V. P.: Evaluation and generalisation of temperature-based methods for calculating evaporation, Hydrol. Process., 15, 305-319, 2001.

$\mathrm{Xu}$, C.-Y. and Singh, V. P.: Cross comparison of empirical equations for calculating potential evapotranspiration with data from Switzerland, Water Resour. Manag., 16, 197-219, 2002.
Yang, D., Sun, F., Liu, Z., Cong, Z., and Lei, Z.: Interpreting the complementary relationship in non-humid environments based on the Budyko and Penman hypotheses, Geophys. Res. Lett., 33, L18402, doi:10.1029/2006GL02657, 2006.

Yang, H., Yang, D., Lei, Z., and Sun, F.: New analytical derivation of the mean annual water-energy balance equation, Water Resour. Res., 44, W03410, doi:10.1029/2007WR006135, 2008.

Yao, H.: Long-term study of lake evaporation and evaluation of seven estimation methods: Results from Dickie Lake, Southcentral Ontario, Canada, Journal of Water Resource and Protection, 2, 59-77, 2009.

Yu, J. J., Zhang, Y. Q., and Liu, C. M.: Validity of the Bouchet's complementary relationship at 102 observatories across China, Science in China Series D: Earth Sciences, 52, 708-713, 2009.

Yunusa, I. A. M., Sedgley, R. H., and Tennant, D.: Evaporation from bare soil in south-western Australia: a test of two models using lysimetry, Aust. J. Soil Res., 32, 437-446, 1994.

Zhao, R.-N.: The Xinanjiang model applied in China, J. Hydrol., 135, 371-381, 1992.

Zhang, L., Dawes, W. R., and Walker, G. R.: Response of mean annual evapotranspiration to vegetation changes at catchment scale, Water Resour. Res., 37, 701-708, 2001.

Zhang, L., Hickel, K., Dawes, W. R., Chiew, F. H. S., Western, A. W., and Briggs, P. R.: A rational function approach for estimating mean annual evapotranspiration, Water Resour. Res., 40, W02502, doi:10.1029/2003WR002710, 2004.

Zhang, L., Potter, N., Hickel, K., Zhang, Y. Q., and Shao, Q. X.: Water balance modeling over variable time scales based on the Budyko framework-model development and testing, J. Hydrol. 360, 117-131, 2008.

Zhang, X. P., Zhang, L., McVicar, T. R., Van Niel, T. G., Li, L. T., Li, R., Yang, Q. K., and Liang, W.: Modeling the impact of afforestation on mean annual streamflow in the Loess Plateau, China, Hydrol. Process., 22, 1996-2004, 2008.

Zhang, Y. Q. and Chiew, F. H. S.: Estimation of mean annual runoff across southeast Australia by incorporating vegetation types into Budyko-framework, Australian Journal of Water Resources, 15, 109-120, 2011. 